\title{
Research progress, models and simulation of electrospinning technology: a review
}

\author{
Yajin Guo ${ }^{1,2,3}$, Xinyu Wang ${ }^{1,2,3,4, *} \mathbb{0}$, Ying Shen ${ }^{1,2,3}$, Kuo Dong ${ }^{1,3}$, Linyi Shen ${ }^{1,3}$, and \\ Asmaa Ahmed Abdullah Alzalab ${ }^{1,3}$ \\ ${ }^{1}$ State Key Laboratory of Advanced Technology for Materials Synthesis and Processing, Wuhan University of Technology, \\ Wuhan 430070, People's Republic of China \\ ${ }^{2}$ International School of Materials Science and Engineering, Wuhan University of Technology, Wuhan 430070, People's Republic of \\ China \\ ${ }^{3}$ Biomedical Materials and Engineering Research Center of Hubei Province, Wuhan University of Technology, Wuhan 430070, \\ People's Republic of China \\ ${ }^{4}$ Foshan Xianhu Laboratory of the Advanced Energy Science and Technology Guangdong Laboratory, Xianhu Hydrogen Valley, \\ Foshan 528200, People's Republic of China
}

Received: 21 April 2021

Accepted: 29 September 2021 Published online:

13 October 2021

(C) The Author(s), under exclusive licence to Springer Science+Business Media, LLC, part of Springer Nature 2021

\begin{abstract}
In recent years, nanomaterials have aroused extensive research interest in the world's material science community. Electrospinning has the advantages of wide range of available raw materials, simple process, small fiber diameter and high porosity. Electrospinning as a nanomaterial preparation technology with obvious advantages has been studied, such as its influencing parameters, physical models and computer simulation. In this review, the influencing parameters, simulation and models of electrospinning technology are summarized. In addition, the progresses in applications of the technology in biomedicine, energy and catalysis are reported. This technology has many applications in many fields, such as electrospun polymers in various aspects of biomedical engineering. The latest achievements in recent years are summarized, and the existing problems and development trends are analyzed and discussed.
\end{abstract}

\section{Introduction}

Nanowires, nanowhiskers, nanofibers, nanotubes and other one-dimensional nanostructured materials have excellent performance in improving the optical, electrical, thermal and mechanical properties of functional materials and composites. Dielectric and semiconductor nanomaterials made of these one-dimensional materials are widely used in the fields of photocatalysis, sensors, drug delivery, bifunctional materials and so on [1-10].

Many nanofiber fabrication techniques have been developed [11], such as splitting of bicomponent

Handling Editor: Chris Cornelius.

Address correspondence to E-mail: wangxinyu@whut.edu.cn 
fibers [12], melt blowing [13], physical drawing [14], dry-wet spinning [15], phase separation [16], selfassembling [17], centrifugal spinning [18] and electrospinning [19].

Electrospinning is one of the most versatile, simplest and effective technologies compared with template polymerization and melt spraying [20-23]. It is also the only method for large-scale production of continuous nanofibers in industry $[24,25]$

Electrospinning also has the advantages of wide range of available raw materials, simple process, small fiber diameter and high porosity. Although electrospinning technology originated in the early twentieth century, it was not widely used until around 2000. There are quite a few research results on the instrument development and the influence of process parameters.

\section{History}

Electrospinning technology can be traced back to 1897. Rayleigh et al. [26-29] studied the phenomenon of charged liquid changing from cylinder to bead. In 1900, Cooley [30] applied for the world's first patent for electrospinning and invented four types of indirectly charged spinning heads-a conventional head, a coaxial head, an air assisted model and a spinneret featuring a rotating distributor. It generally believes that this is the beginning of electrospinning industrialization. However, Morton's 1902 patent on electrospinning lacks some key details [31]. Then, Zeleny [32-37] mathematically simulated the behavior of a fluid under static electricity. Anton [38-44] applied for many patents in the USA, France and other countries between 1931 and 1944, contributing to the electrospinning technology. In 1936, Norton [45] applied for the patent of melt electrospinning. Cellulose acetate nanofibers were prepared by electrospinning with dichloroethane and ethanol as solvents in 1938 by N.D. Rozenblum and I.V. Petryanov Sokolov in 1938. The cellulose acetate nanofibers were applied to filter materials to enhance the toughness and durability of the materials. The materials were produced in a large quantity by Tver antivirus surface ware factory in 1939 [46]. From 1964 to 1966, Taylor [47-49] established the "leaky dielectric model" for electrospinning technology, which laid a theoretical foundation for the "Taylor cone." In 1966, Simons [50] invented a process for printing nonwoven fabrics using electrospinning technology.
In 1971, Baumgarten [51] prepared acrylic fibers with DMF as solvent by electrospinning. In 1978, Annis et al. [52] published work examining electrospun polyurethane mats for use as vascular pros thesis. In 1981, Larrondo and St. John Manley [53-55] carried out electrospinning of polyethylene and polypropylene fibers from the melt. In 1985, Fisher et al. [56] studied electrospinning applications in arterial repair materials. In 1996, Reneker and Chun [57] successfully prepared more than 20 kinds of polymer nanofibers by electrospinning technology. In 2009, Jirsak et al. [58] invented a needleless electrospinning technology, and then, the Czech company Elmarco produced the world's first industrial electrospinning machine, Nanospider.

In the next decade or so, electrospinning technology was not only widely used in the biomedical field [59-61], but also widely used in energy [62-64], catalysis [65-67] and other fields because of its simple process and wide applicability. In addition, electrospinning can also be used to prepare self-assembled nanocomposites [68-72]. The number of publications and cited frequency of electrospinning increased year by year, as shown in Fig. 1. Figure 2 shows the number of publications on electrospinning in various countries. It can be seen that China published the most, followed by the USA and South Korea.

\section{Process}

The basic principle of electrospinning is that solution, suspension or melt is sprayed in a strong electric field to form continuous fibers. The basic electrospinning device consists of three parts (a) a high voltage power supply (b) a spinneret (c) a collector. Figure 3 shows the basic device of electrospinning. In the case of solution electrospinning, first, because of the surface tension of the solution, droplets are formed on the spinneret with induced charge on the surface [73]. When the electrostatic force is equivalent to the surface tension of the solution, the droplet changes from hemispheric shape to cone shape, which is called Taylor cone [49]. When the electrostatic force is greater than the surface tension, the solution can overcome the surface tension and form jets. In the process of reaching the collection device, the electrostatic force makes the jets stretched and the solvent evaporated, leaving only solid fibers. The collection device can collect the solid fibers with complex 


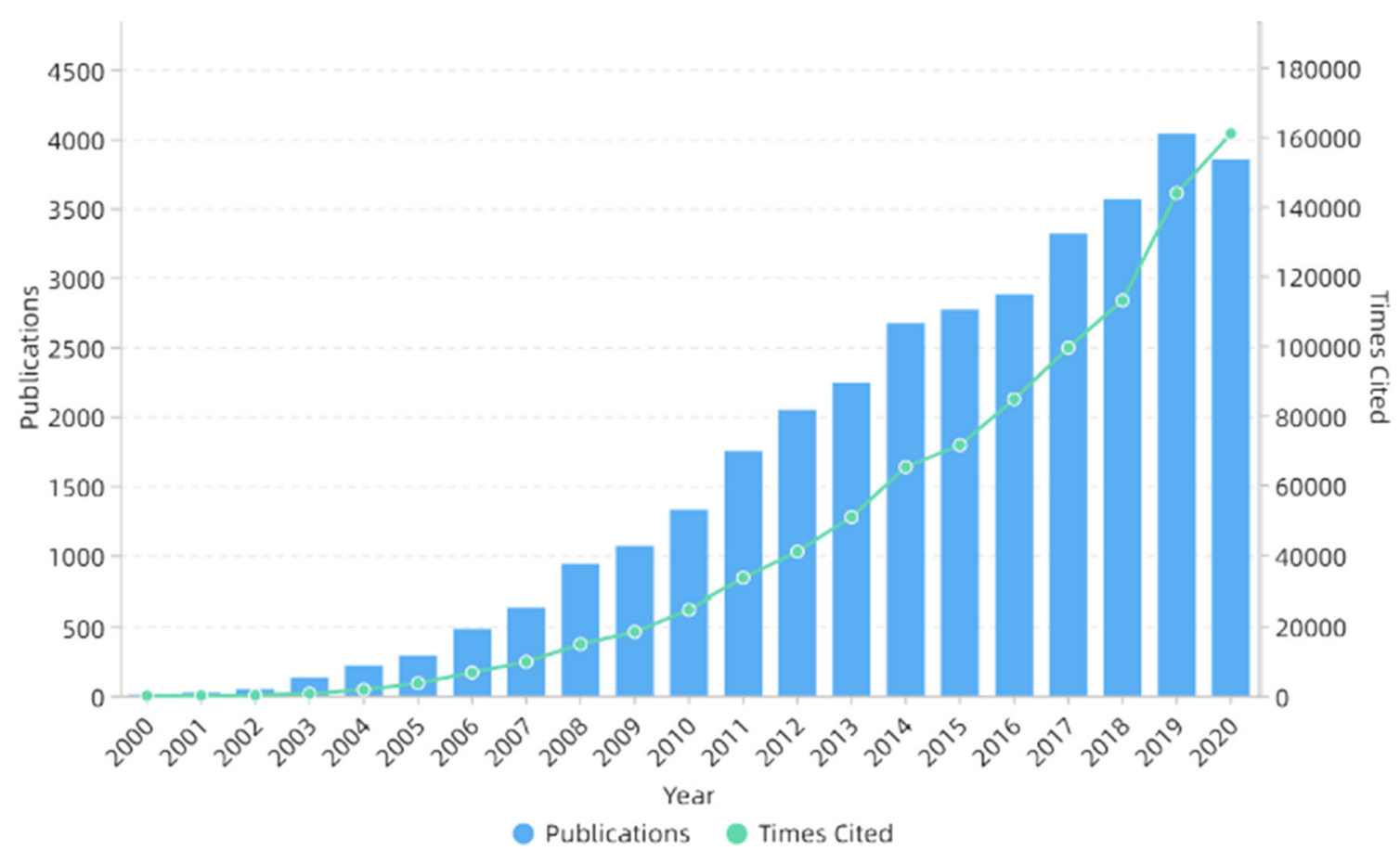

Figure 1 Number of publications and times cited on electrospinning. All the data used are from Web of Science. The functions we used are analyze results and create citation report.

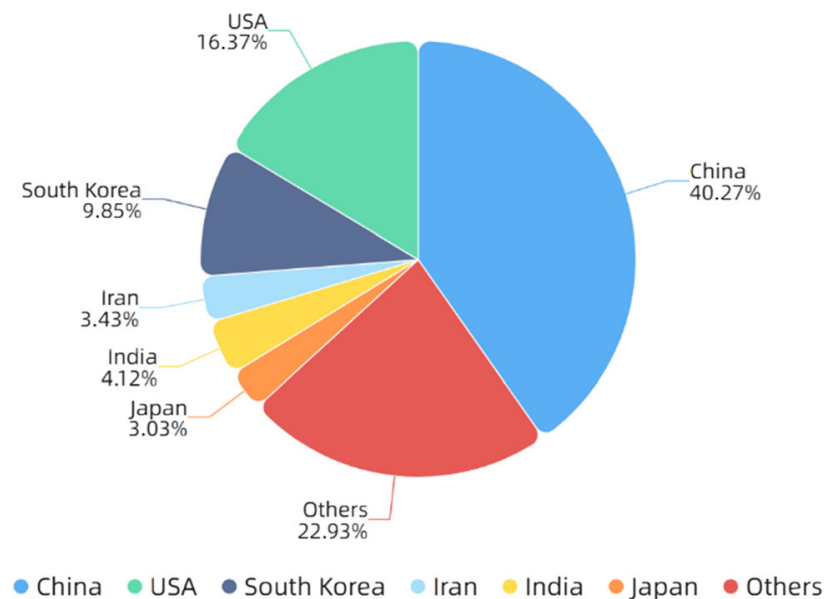

Figure 2 Number of publications on electrospinning in various countries. All the data used are from Web of Science. The functions we used are analyze results and create citation report.

network structure [74]. The same is true for melt and suspension electrospinning.

There are many types of electrospinning equipment on the market, most of which is innovative only in the jet device and collection device [75]. The traditional instrument uses electrode material as spinneret. In recent years, the needleless nozzle has been developed, which can be divided into two types: the rotary nozzle and the static nozzle. It can address the

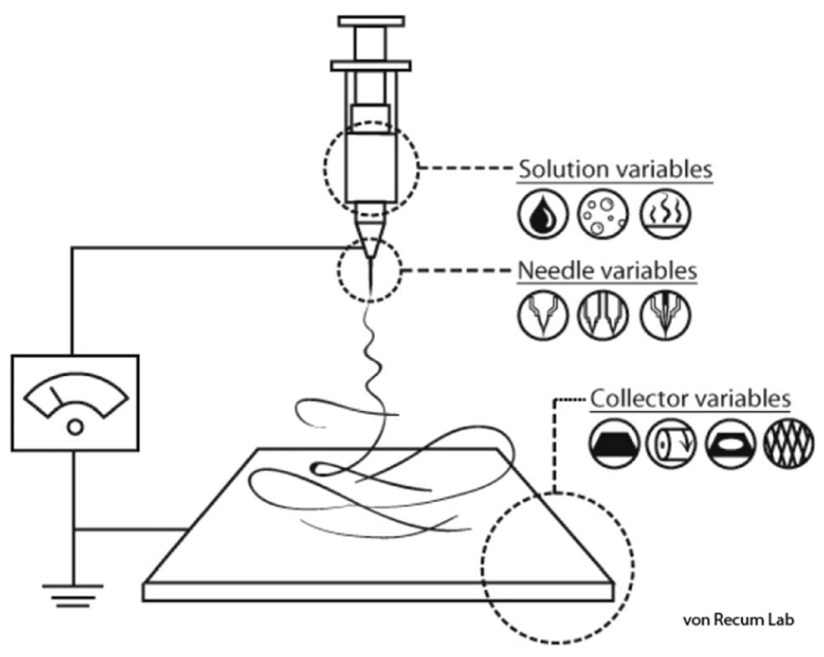

Figure 3 The basic equipment of electrospinning. https://en.wik ipedia.org/wiki/Electrospinning. Accessed 3 August 2021.

problems of needle clogging and low yield. It can be used in industrial production, but it is difficult to control the morphology and distribution of nanofibers [76]. The collection device is generally divided into vertical arrangement and horizontal arrangement $[77,78]$. The difference between the two is the droplet formation power is different. When the spinneret and collecting plate are arranged horizontally, droplets are generated by electrostatic force, 
and gravity is also involved in the horizontal arrangement $[79,80]$.

Up to now, more than 100 kinds of nanofibers of polymers and blends have been successfully prepared by electrospinning, with diameters ranging from several nanometers to hundreds of microns [81]. Besides, if the same polymer is dissolved in different solvents, the morphology of nanofibers prepared will be different $[82,83]$.

Electrospun nanofibers can be classified into many types according to different classification methods [11]. According to the chemical composition, they can be divided into inorganic nanofibers [84], organic nanofibers [85, 86], carbonaceous nanofibers [87, 88] and inorganic-organic hybrid nanofibers [89]. According to the morphology of nanofibers, as shown in Fig. 4, they can be divided into columnar nanofibers [90], beaded nanofibers [91], porous nanofibers [92], grooved nanofibers [93], nanograin nanofibers [94], nanobelt nanofibers [95] and so on. As shown in Fig. 5, according to the fiber orientation, it can be divided into random-distributed nanofibers [96], aligned nanofibers [96], crimped nanofibers [97] and so on.

\section{Parameters}

Besides the advantages of simple process and wide range of raw materials, electrospinning can control the morphology, orientation and pore size of nanofibers by adjusting the parameters [98, 99]. There are many parameters affecting electrospinning, some of which are uncontrollable. The controllable parameters can be divided into solution parameters, processing parameters and ambient parameters [100]. The solution parameters include concentration, viscosity, molecular weight, conductivity, surface tension and solvent type. The process parameters include applied voltage, flow rate and distance from jet device to collection device. The ambient parameters include temperature and humidity. However, if the parameters are adjusted appropriately, uniform and bead-free nanofibers with suitable diameter can be prepared. Although the National Science Foundation defines fibers with diameter less than $100 \mathrm{~nm}$ as nanofibers, in fact, submicron fibers are more widely used in many fields such as tissue engineering [101].
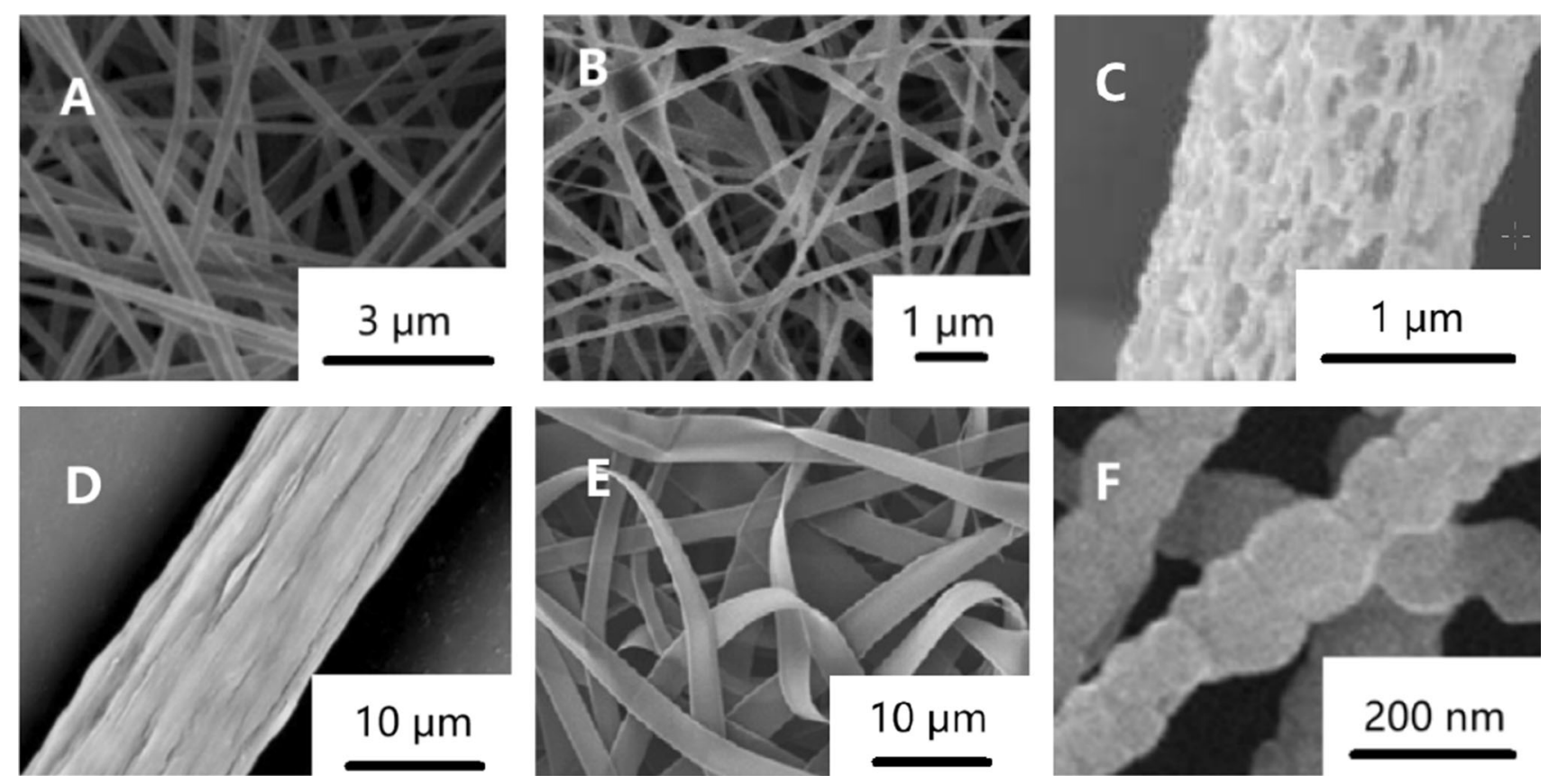

Figure 4 Morphology of electrospun nanofibers a columnar nanofibers [90] b beaded nanofibers [91] c porous nanofibers [92] d grooved nanofibers [93] e nanobelt nanofibers [95] f nanograin nanofibers [94]. Reproduced with permission from reference [90]. Copyright 2019, Elsevier B.V. Reproduced with permission from reference [91]. Copyright 2012, Elsevier B.V. Reproduced with permission from reference [92]. Copyright 2015, Elsevier Ltd. Reproduced with permission from reference [93]. Copyright 2016, Elsevier B.V. Reproduced with permission from reference [94]. Copyright 2013, Elsevier B.V. Reproduced with permission from reference [95]. Copyright 2011, Elsevier Ltd. 


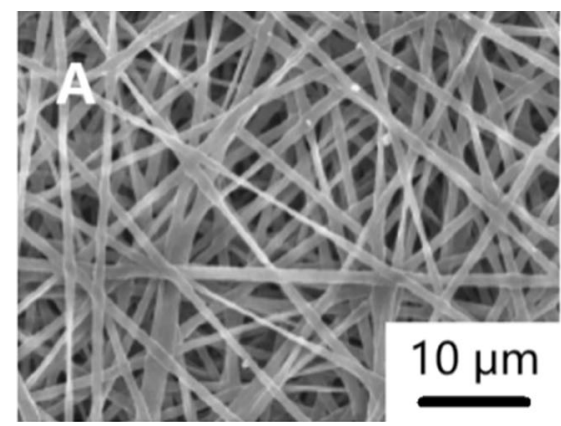

Figure 5 Orientation of electrospun nanofibers a randomdistributed arrangement [96] b aligned nanofibers [96] c crimped nanofibers [97]. Reproduced with permission from reference [96].

\section{Solution parameters}

\section{Concentration}

The concentration of the solution plays a decisive role in forming nanofibers. There is a minimum spinnability concentration. When the solution concentration is lower than this value, because of the low concentration and high surface tension, the interaction between the electric field force and surface tension will cause the entangled polymer to be disentangled before reaching the collection device $[102,103]$. This produces many beads rather than fibers [104-106]. With the increase in the concentration and viscosity, the entanglement concentration of polymer increases and the surface tension decreases, resulting in more and more fibers, and finally, uniform and smooth nanofibers without beads are formed [107]. At this time, the concentration is the best. When the solution concentration is higher than the optimal concentration, the solution is easy to block the spinneret, resulting in coarse and uneven ribbon fiber $[103,108]$. The optimal concentration is a range. As shown in Fig. 6, the nanofibers become coarser with the increase in the concentration in this range [105, 106, 109-111]. Some studies have also shown the solution viscosity can be improved by adding cosolvents at a certain polymer concentration. Increasing the concentration can usually improve the morphology of nanofibers or make it easier to electrospin polymers that are difficult. For example, sodium alginate can be electrospun into uniform and smooth nanofibers by adding glycerol or PEO $[112,113]$. It has been found that if there are many kinds of polymers in the solution, even if the viscosity is the same, different polymer concentration ratio will
Copyright 2015, Elsevier B.V. Reproduced with permission from reference [97]. Copyright 2014, American Chemical Society.

change the diameter of nanofibers, which is caused by the interaction between polymers [113]. Some researchers have also changed the solution concentration and prepared microspheres instead of nanofibers by electrospinning, which provides a new idea [114].

\section{Viscosity}

The viscosity of the solution is closely related to the concentration and molecular weight, which is one of the main parameters affecting the diameter and morphology of nanofibers [115]. If the viscosity is too low or too high, the bead structure will be formed [75]. If the viscosity is too low, it means the polymer entanglement is low and the surface tension is dominant, the droplets cannot connect into fibers and form spray [116]. With the increase in the viscosity, the stress relaxation time of the polymer becomes longer, which is conducive to forming nanofibers with larger and uniform diameter, as shown in Fig. 7 [117]. However, when the viscosity is too high, it is difficult for jets to form fiber [118]. Therefore, there is a best range of viscosity suitable for electrospinning nanofibers [102]. Some studies have shown the solution with viscosity of 1-20 $\mathrm{P}$ and surface tension of $35-55 \mathrm{dyn} / \mathrm{cm}^{2}$ is suitable for electrospinning nanofibers [119]. When the solution viscosity is too high to carry out electrospinning, some researchers propose using vibration technology to solve this problem [120]. For example, ultrasonic vibration can decrease the van der Waals force between polymer chains to achieve the purpose of temporarily reducing the viscosity of the solution, as shown in Fig. 8. At the same time, attention should be paid to avoid the rapid evaporation of the solvent during the vibration 
Figure 6 SEM images of electrospun polyimide nanofibers with different concentrations a $10 \%$, b $15 \%$ c $20 \%$ d $25 \%$ [105].

Reproduced with permission from reference [105]. Copyright 2017, De Gruyter.
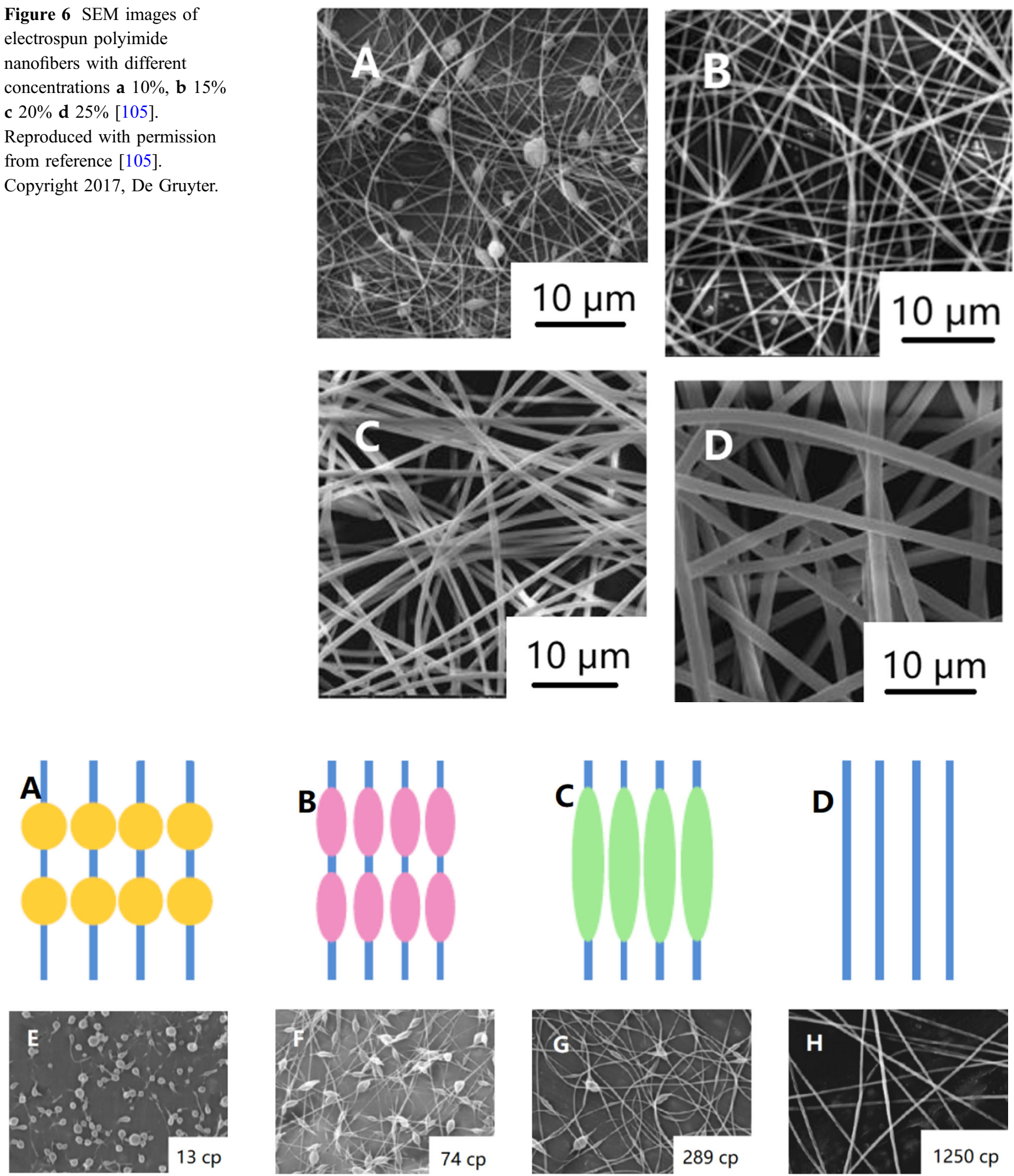

Figure 7 Morphology of nanofibers with increasing viscosity ad schematic diagram [123] and e-h SEM images of electrospun PEO nanofibers [104]. Reproduced with permission from

reference [104]. Copyright 1999, Elsevier B.V. Reproduced with permission from reference [123]. Copyright 2013, MDPI (Basel, Switzerland). 
process [121]. The viscosity of the solution can be controlled by adjusting the polymer concentration. The viscosity of the solution can be increased with the increase in the solubility when the conductivity is high, but the change of the diameter of the nanofiber can be ignored, because the conductivity will also increase with the increase in the concentration. The increase in the conductivity will cause the diameter of the nanofiber to become smaller [110]. The solution concentration can also be increased by adding nanoparticles to the solution. Although the diameter of the nanofibers increases with the increase in the content of nanoparticles, the nanofibers will be rougher and more uneven because of the increase in the friction and viscosity between particles [122].

\section{Molecular weight}

The molecular weight of the polymer can affect the rheological and electrical properties of the solution such as viscosity, surface tension and conductivity [124]. When the molecular weight is large, the intermolecular force is large, and the polymer may also generate more hydrogen bonds between the solvents, making the polymer expand, thus increasing the viscosity value $[125,126]$. Because of the inhomogeneity of polymer conductive system, the interchain conductivity is much lower than intrachain, and the larger the molecular weight, the smaller the degree of (a)

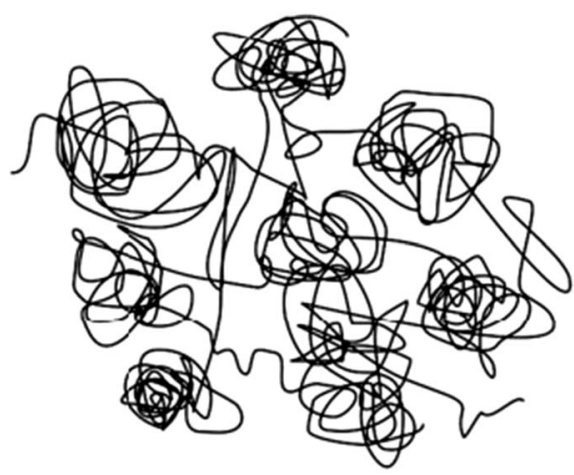

(b)

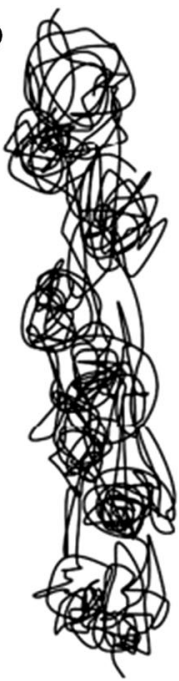

Figure 8 Influence of ultrasonic vibration on polymer molecular chain. a Entangled molecular chains in polymer solution without sonic vibration treatment, $\mathbf{b}$ entangled molecular chains in electrospun fiber without sonic vibration treatment, c molecular interchain discontinuity, the larger the interchain conductivity, and the larger the macroscopic conductivity [127-129]. However, some experiments have found the molecular weight has little relationship with the conductivity [130]. Similar to the effect of viscosity and concentration, the polymer with low molecular weight has insufficient entanglement degree, short chain length, small molecular friction force, difficult to resist unstable whipping, interrupted jet and difficult to form fibers [131]. In general, the diameter of nanofibers will also increase with the increase in the molecular weight. However, excessive molecular weight will produce ribbon fibers [132, 133]. Researchers have also found that intermolecular forces can be used to counter surface tension when the molecular weight is low [98].

\section{Conductivity}

The charged particles of polymer have great influence on jet formation. When the conductivity of the solution is too low, there will be beads and it is difficult to form uniform nanofibers. However, high conductivity may lead to bending whiplash and uneven diameter or formation of ribbon fibers [134]. The diameter of nanofibers decreases with the increase in the conductivity [113, 135]. Some researchers also found the conductivity has negligible effect on the fiber diameter [126]. It has been found

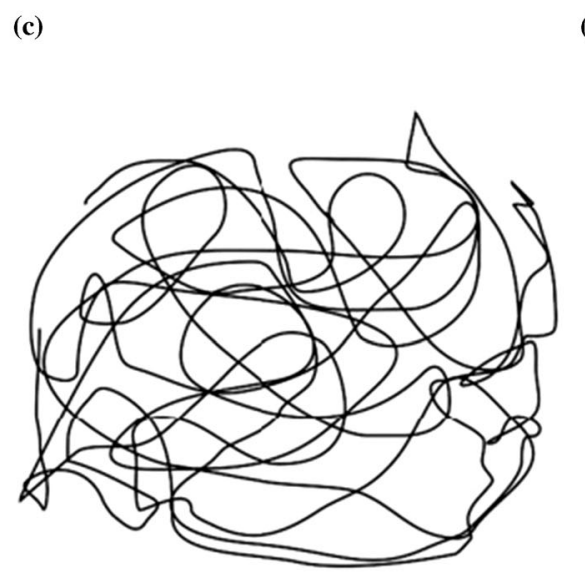

(d)

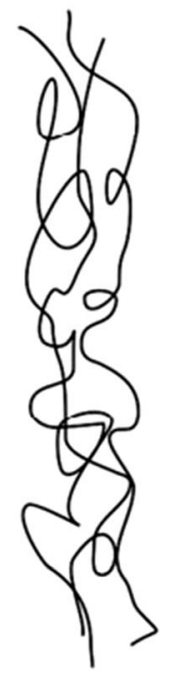

chains in polymer solution disentangled after sonic vibration treatment and $\mathbf{d}$ disentangled molecular chains in electrospun fiber with sonic vibration treatment [121]. Reproduced with permission from reference [121]. Copyright 2019, SAGE Publications Ltd. 
that theoretically the jet radius is inversely proportional to the cube root of the solution conductivity [51]:

$r_{0}=\sqrt[3]{\frac{4 \varepsilon Q}{k \pi \sigma \rho}}$

where $r_{0}$ is jet or filament radius, $Q$ is the mass flow rate, $\varepsilon$ is the permittivity, $\sigma$ is the electric conductivity, $\rho$ is the density. The conductivity of the solution can be improved by adding some inorganic salts such as sodium chloride, lithium chloride, magnesium chloride and copper chloride to the solution. This helps forming beadless fibers with smaller diameters and increases uniformity [136]. Some researchers discovered the opposite [137]. Some organic compounds are also feasible, such as pyridinium formate [138], benzyl trialkylammonium chloride [139], dodecyltrimethyl ammonium bromide (DTAB) [140], tetrabutylammonium chloride (TBAC) [140], triethylbenzyl ammonium chloride (TEBAC) [141] and tetraethylammonium bromide (TEAB). However, their conclusions are not compatible. $\mathrm{PH}$ also affects the conductivity of the solution [106]. The electrospinning properties of polystyrene solutions with 18 kinds of common organic solvents were measured [142]. It was found that only 1,2-dichloroethane, DMF, ethylacetate, MEK and THF could meet the needs of electrospinning.

\section{Surface tension}

Surface tension is affected by many factors, including molecular weight, solution concentration, solvent type and temperature [126]. However, adding surfactant can also effectively decrease the surface tension, which only has to be removed in the subsequent process. When the surface tension is low, the beads are fewer and the nanofibers are finer and smoother $[143,144]$. Some researchers believe the surface tension has little effect on the fiber diameter [145]. However, if the surface tension is too low, the jet will be unstable, the diameter distribution of nanofibers will be uneven [146] or even beads will be formed $[147,148]$. In general, the surface tension of water is higher than that of ethanol. Ethanol can be added to the solution to decrease the surface tension [104]. A little surfactant can decrease the surface tension of the solution, such as sodium dodecyl benzene sulfonate (SDBS) [149], dodecyltrimethylammonium bromide (DTAB) [140], tetrabutylammonium chloride (TBAC) [140] and Tween 80 [110]. However, some surfactants, such as Triton X-405 [140], have little effect, and even more Triton X-100 (TX100) may increase the fiber diameter [150].

\section{Solvent}

There is no doubt the choice of solvent is important. The properties of the solvent, including surface tension, dielectric constant, boiling point, density, as well as the interaction between solvent and solute, as shown in Fig. 9, will affect electrospinning [145]. For example, the volatility of the solvent is directly related to whether it can volatilize before reaching the collection device, and has a great impact on whether beads will appear or not [151]. The polarity and dielectric constant of the solvent will affect the conductivity of the solution [151]. Because of the toxicity of many organic solvents, if they cannot be completely removed, they would not be used in biological and food fields [152]. The influence of solvent types on electrospinning is complex. There is no clear theory to judge whether electrospinning can be carried out with a certain solvent [153-155]. According to Hansen solubility parameters, a ternary solubility diagram has been made by some researchers, as shown in Fig. 10. The three edges represent the dispersion component $\left(\delta_{\mathrm{d}}\right)$, polar component $\left(\delta_{\mathrm{p}}\right)$ and hydrogen bonding component $\left(\delta_{\mathrm{h}}\right)$, respectively, which can be used for in-depth study of solvent solubility [156-160]. The solvents in the green region is expected to dissolve the polymer. For example, when $\mathrm{MeOH}$ and $\mathrm{PrOH}$ are mixed, a good solvent such as $\mathrm{EtOH}$ can be found near their connecting line. The volume ratio of the two solvents can be calculated by the length ratio from the closest point to $\mathrm{EtOH}$ to both ends. The effects of solubility of polycaprolactone [161], polyethylene terephthalate (PET) [162] and polymethylsilsesquioxane (PMSQ) [159] in different solvents on electrospinning have been studied. When the solubility is low, it is easy to form nanofibers, and high dielectric constant will make the diameter of nanofibers smaller [159]. Kohse et al. [105] found the electrospinning of polyimide in $\mathrm{N}, \mathrm{N}$-dimethylformamide (DMF) produced smooth and round shaped nanofibers, but only ribbon shaped fibers were formed in 1,1,1,3,3,3-jexafluoro-2propanol (HFIP) and smooth but stucked fibers in dimethylsulfoxide (DMSO). 
Figure 9 SEM of electrospun polyimide nanofibers in different solvents [105]. a DMF, b HFIP, $\mathbf{c}$ and d DMSO. Reproduced with permission from reference [105]. Copyright 2017, De Gruyter.
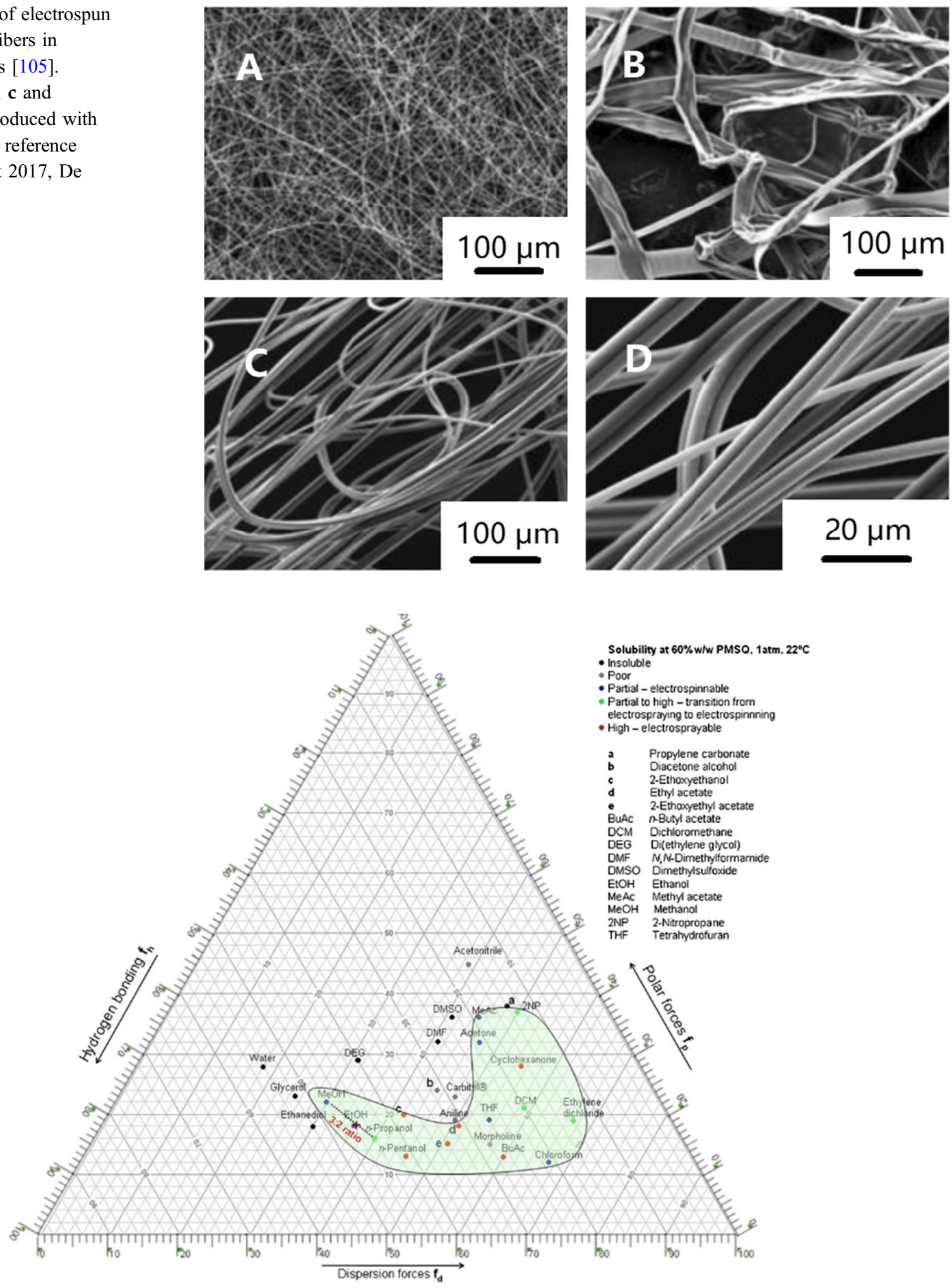

Figure 10 Ternary solubility diagram of polymethylsilsesquioxane in different solvents. The solvent with good solubility is in the green region [159]. Reproduced with permission from reference [159]. Copyright 2010, Elsevier B.V. 


\section{Processing parameters}

Applied voltage

The applied voltage is also a key parameter in the electrospinning process. Only when the critical voltage is reached can the droplet be ejected and finally reach the collection device. The applied voltage also affects the morphology and diameter of nanofibers. If the applied voltage is too high or too low, it will lead to forming beads [163]. The diameter of nanofibers decreases with the increase in the applied voltage; because the electrostatic force is large, the droplets are stretched longer [164-169]. But in fact, according to previous studies, there is no consensus on the effect of applied voltage on nanofibers. Some researchers believe the diameter of nanofibers will increase with the increase in the voltage because of the increase in the jet velocity [170-172]. Kim et al. [173] also found the nanofibers first decreased and then increased with the increase in the applied voltage, and made some mechanical analysis. In addition, some researchers found that with the increase in the voltage, the diameter distribution of nanofibers is more uneven [168, 171]. The effect of applied voltage on the diameter of nanofibers may vary with the polymer solution concentration and the distance from jet device to collection device [174-176]. More research is needed on the effect of applied voltage on the diameter of nanofibers.

\section{Flow rate}

The flow rate also affects the diameter and morphology of nanofibers. The diameter of nanofibers increases with the increase in the flow rate $[146,168,176,177]$. If the flow rate is too high, the solvent cannot completely evaporate before reaching the collection device, which will lead to forming beads [178] or ribbons [177]. Therefore, when the flow rate is moderate, the Taylor cone is more stable, and it is easier to generate smooth and uniform nanofibers [179]. Some researchers believe there is an ideal flow rate, and deviation from the optimal value will lead to the coarsening of nanofibers [180]. When the solution viscosity is low, the flow rate has little effect on the diameter of nanofibers $[175,176]$. When the applied voltage is higher, the effect of flow rate is more significant.

\section{Distance from jet device to collection device}

The distance from jet device to collection device can also be used to control the diameter and morphology of electrospun nanofibers [181]. The distance from jet device to collection device needs to be large enough to allow the solvent to evaporate. If the distance is too small, there will be beads [177]. However, the distance should not be too large. If the distance is too large, the jet will not be stable enough, and there will be beads. In fact, the distance from jet device to collection device has less effect on the diameter of nanofibers than other parameters [170, 176, 182]. However, some researchers believe the distance has a great influence on the fiber diameter [183]. Generally speaking, the larger the distance, the greater the bending instability, resulting in the overlap of some nanofibers, resulting in larger fiber diameter $[173,184]$. However, if the distance is small, the solvent evaporation time is not enough, and coarse nanofibers will be formed [116, 178, 185, 186].

\section{Ambient parameters}

\section{Temperature}

Generally speaking, the higher the temperature, the lower the viscosity and surface tension, the higher the solubility [147, 187, 188]. The increase in the temperature will lead to the decrease in the diameter of nanofibers and smoother surface [147, 187-189]. Yang et al. [189] studied the relationship between temperature and evaporation rate of PVP anhydrous ethanol solution using Knudsen layer theory. They found there was an inflection point in the relationship between temperature and nanofiber diameter, which was related to many properties of solution affected by temperature. However, De Vrieze et al. [147] also used the absolute ethanol solution of PVP and drew the opposite conclusion for the same temperature range.

\section{Humidity}

The influence of environmental humidity on electrospinning is also complex. When the humidity is low, the evaporation rate of solvent is faster, which will make the diameter of nanofibers larger [147, 190-193]. However, because of the different hydrophilicity of solvents, some organic solvents 
such as ethanol will absorb the moisture in the air, which makes the solvent more difficult to evaporate, and the electrostatic force is decreased, which makes the nanofibers thinner [147, 194]. Therefore, this should depend on the type and solubility of solvents [195]. Some researchers have also found there is no obvious relationship between ambient humidity and the thickness of nanofiber mats [106, 196, 197]. When the humidity is too high, the diameter distribution of nanofibers is more uneven, the surface is more rough, and the pores or fibers are less [106, 191, 197, 198]. Ding et al. [199] found that under the condition of high voltage and low humidity, the rapid separation of polymer and solvent can produce nanowebs with overlapping layers, uniform pore size and fine fiber.

\section{Models and simulation}

It is of great significance to simulate electrospinning by computer. Because the phenomena observed in many experiments are sometimes difficult to explain, we need to use theoretical models and computer simulation to help us better understand various problems. Although electrospinning technology has been widely concerned, there are few studies on simulation. In fact, because of the complex parameters affecting electrospinning, many researchers have put forward some empirical relationships. For example, Wang et al. [200, 201] obtained some empirical scaling laws of parameters and diameter through experiments, and Yousefi et al. [202] did some similar experiments. However, because of the lack of systematization and characterization, the applicability of the empirical model is limited [203]. By establishing a perfect mathematical and physical model for electrospinning simulation, the morphology and properties of nanofibers can be well predicted, which could improve the work efficiency of researchers and expand the electrospinning technology application.

\section{Physical models}

\section{Models of electric field}

Taylor [49] first studied the initial stage of the jet. In principle, when the electric field force and surface tension are equal, the viscous droplet will form a cone with the half vertex angle of $49.3^{\circ}$ and the state is called the Rayleigh stability limit [28].

Taylor [48] gave the critical voltage of viscous fluid jet:

$\boldsymbol{V}_{\boldsymbol{k}}^{2}=\frac{4 \boldsymbol{H}^{2}}{\boldsymbol{L}^{2}}\left(\boldsymbol{l n} \frac{2 \boldsymbol{L}}{\boldsymbol{R}}-\frac{3}{2}\right)(1.30 \pi \boldsymbol{R} \boldsymbol{T})(0.09)$

where $\mathrm{V}_{\mathrm{k}}$ is the potential at breakdown, $\mathrm{H}$ is the distance between jet device and collection device, $\mathrm{L}$ is the injector length, $\mathrm{R}$ is the injector radius and $\mathrm{T}$ is the surface tension of the liquid.

Besides, they introduced the leaky dielectric model to explain the behavior of droplets deformed by a steady field, which laid the foundation for the later theoretical research.

Hendricks et al. [204] gave an empirical formula for the critical voltage of hemispheric suspension droplets:

$\boldsymbol{V}=300 \sqrt{20 \pi \gamma \boldsymbol{a}}$

where $\mathrm{V}$ is the critical voltage, $\gamma$ is the surface tension, and $\mathrm{a}$ is the capillary radius.

Of course, Taylor's and Hendricks' studies assumed the droplet is in a stable state at the capillary port, and the model only applies to weakly conductive liquids, without considering the effects of liquid conductivity and viscosity.

Interestingly, Yarin et al. [205] confirmed theoretically and experimentally the half angle of Taylor cone should be $33.5^{\circ}$ instead of $49.3^{\circ}$. This may be because of the existence of non-self-similar solutions for hyperboloid shape in equilibrium with its own electric field under the surface tension action.

\section{Models of jet}

When the applied voltage is higher than the critical voltage and the electric field force is greater than the surface tension, the jet will first go through the stable stage and then enter the unstable stage.

Stable stage In the stable stage, the polymer jet does uniaxial stretching, and the jet shape does not change with time. In this process, the jet radius is the focus of research, because it directly affects the diameter of nanofibers.

Baumgarten [51] derived the jet radius from the relationship between transfer current and conduction current: 
$r_{0}=\sqrt[3]{\frac{4 \varepsilon Q}{k \pi \sigma \rho}}$

where $r_{0}$ is jet or filament radius, $Q$ is the mass flow rate, $\varepsilon$ is the permittivity, $\sigma$ is the electric conductivity and $\rho$ is the density.

However, the axial voltage gradient in jet in units still needs to be obtained.

According to the equations of mass balance, electric charge balance and momentum balance, Spivak et al. [206, 207] established a simple one-dimensional model of nonlinear power-law fluid:

$\frac{d}{d \tilde{z}}\left[\tilde{R}^{-4}+\left(N_{W}{ }_{\boldsymbol{R}}\right)^{-1}-\boldsymbol{N}_{\boldsymbol{E}}^{-1} \tilde{\boldsymbol{R}}^{-2}-\boldsymbol{N}_{\boldsymbol{R}}^{-1}\left(\frac{{ }^{\tilde{\boldsymbol{R}}^{-2}}}{d_{\tilde{z}}^{\tilde{z}}}\right)^{\boldsymbol{m}}\right]$
$\quad=1$

where $\mathrm{z}$ is the axial coordinate, $\mathrm{R}$ is the dimensionless jet radius, $\mathrm{N}_{\mathrm{W}}$ is the dimensionless Weber number, $\mathrm{N}_{\mathrm{E}}$ is the dimensionless parameter, $\mathrm{N}_{\mathrm{R}}$ is the effective Reynolds number and $\mathrm{m}$ is the flow index.

However, the one-dimensional linear symmetrical model is too simple, which is different from the actual.

Later, according to the leaky dielectric model and the slender body theory, Hohman et al. [208, 209] introduced the free charge and obtained the approximate model of jet dynamics:

$$
\left\{\begin{array}{l}
\partial_{t}\left(\boldsymbol{h}^{2}\right)+\left(\boldsymbol{h}^{2} \boldsymbol{v}\right)^{\prime}=0 \\
\partial_{t}(\boldsymbol{\sigma h})+\left(\boldsymbol{\sigma} \boldsymbol{h} \boldsymbol{v}+\frac{\boldsymbol{K}^{*}}{2} \boldsymbol{h}^{2} \boldsymbol{E}\right)^{\prime}=0 \\
\partial_{t} \boldsymbol{v}+\boldsymbol{v} \boldsymbol{v}^{\prime}=-\left(\frac{1}{\boldsymbol{h}}-\boldsymbol{h}^{\prime \prime}-\frac{\boldsymbol{E}^{2}}{8 \pi}-2 \pi \boldsymbol{\sigma}^{2}\right)^{\prime}+\frac{2 \boldsymbol{\sigma} \boldsymbol{E}}{\sqrt{\boldsymbol{\beta}} \boldsymbol{h}}+\boldsymbol{g}^{*}+\frac{3 \boldsymbol{v}^{*}}{\boldsymbol{h}^{2}}\left(\boldsymbol{h}^{2} \boldsymbol{v}^{\prime}\right)^{\prime} \\
\boldsymbol{E}-\boldsymbol{l n} \frac{1}{\chi}\left[\frac{\boldsymbol{\beta}}{2}\left(\boldsymbol{h}^{2} \boldsymbol{E}\right)^{\prime \prime}-4 \pi \sqrt{\boldsymbol{\beta}}(\boldsymbol{h} \boldsymbol{\sigma})^{\prime}\right]=\boldsymbol{\Omega}_{0}
\end{array}\right.
$$

where $\mathrm{h}$ is the radius of jet, $\mathrm{v}$ is the fluid velocity parallel to axis of jet, $\sigma$ is the surface charge density, $\mathrm{K}^{*}$ is the dimensionless conductivity, $\mathrm{E}$ is the electric field parallel to axis of jet, $\beta=\frac{\epsilon}{\bar{\epsilon}}-1, v^{*}$ is the dimensionless viscosity, $\mathrm{X}$ is the aspect ratio and $\Omega_{0}$ is the dimensionless external field strength.

However, this model is not suitable for non-Newtonian fluid. After that, Feng [210] improved it and considered the non-Newtonian fluid:

$$
\left\{\begin{array}{l}
\boldsymbol{R}^{2} \boldsymbol{v}=1 \\
\boldsymbol{E} \boldsymbol{R}^{2}+\boldsymbol{P} \boldsymbol{R} \boldsymbol{R} \boldsymbol{\sigma}=1 \\
\boldsymbol{v} \boldsymbol{v}^{\prime}=\frac{1}{\boldsymbol{F} \boldsymbol{r}}+\frac{3}{\boldsymbol{R} \boldsymbol{e}} \frac{1}{\boldsymbol{R}^{2}} \frac{d\left(\boldsymbol{\eta} \boldsymbol{R}^{2} \boldsymbol{v}^{\prime}\right)}{d z}+\frac{1}{\boldsymbol{W e}} \frac{\boldsymbol{R}^{\prime}}{\boldsymbol{R}^{2}}+\boldsymbol{\varepsilon}\left(\boldsymbol{\sigma} \boldsymbol{\sigma}^{\prime}+\boldsymbol{\beta} \boldsymbol{E} \boldsymbol{E}^{\prime}+\frac{2 \boldsymbol{E} \boldsymbol{\sigma}}{\boldsymbol{R}}\right) \\
\boldsymbol{E}(z)=\boldsymbol{E}_{\infty}(z)-\ln \boldsymbol{\chi}\left(\frac{d(\boldsymbol{\sigma} \boldsymbol{R})}{d z}-\frac{\boldsymbol{\beta}}{2} \frac{d^{2}\left(\boldsymbol{E} \boldsymbol{R}^{2}\right)}{d z^{2}}\right)
\end{array}\right.
$$

where $\mathrm{v}$ is the axial velocity, Pe is the Electric Peclet number, Fr is the Froude number, Re is the Reynolds number, $\eta$ is the viscosity, $E$ is the axial field, $z$ is the axial position, We is the Weber number, $\varepsilon=\frac{\epsilon_{0}^{2}}{\rho v_{0}^{2}}, \bar{\epsilon}$ is the dielectric constant of the ambient air, $\beta=\frac{\epsilon}{\bar{\epsilon}}-1, X$ is the aspect ratio and $E_{\infty}$ is the external field.

Unstable Stage The unstable stage is much more complicated than the stable stage, and researchers have made great efforts. The instability is caused by the charge repulsion in the jet. There are three kinds of instability in the unstable stage of electrospinning [211]: the classical Rayleigh mode (axisymmetric) instability, electric field-induced axisymmetric conducting mode (bending) instability and whipping conducting mode instabilities. These instabilities change with the applied voltage, the distance from jet device to collection device and the solution parameters, which affect the morphology and distribution of nanofibers [212].

Strutt and Rayleigh [26] first proposed and found the axisymmetric instability, and derived the relationship between the instability deviation distance and the potential and other factors. Unfortunately, there is no effective experimental support.

Huebner and Chu [213] analyzed the influence of surface tension and electrodynamic effect on jet radius on the basis of empirical formula, but also lacked experimental support.

Reneker et al. [214] established a three-point-like charges model and analyzed the cause of the bending instability:

$\boldsymbol{m} \frac{d^{2} \boldsymbol{\delta}}{d \boldsymbol{t}^{2}}=\frac{2 \boldsymbol{e}^{2}}{\boldsymbol{l}_{1}^{3}} \boldsymbol{\delta}$

where $\mathrm{m}$ is the mass, $\delta$ is the distance, $l$ is the length and e is the charge.

They also proposed a viscoelastic model of a rectilinear electrified liquid jet. The linear Maxwell equations were used to describe the jet flow. The spinning process was simplified as a system of 


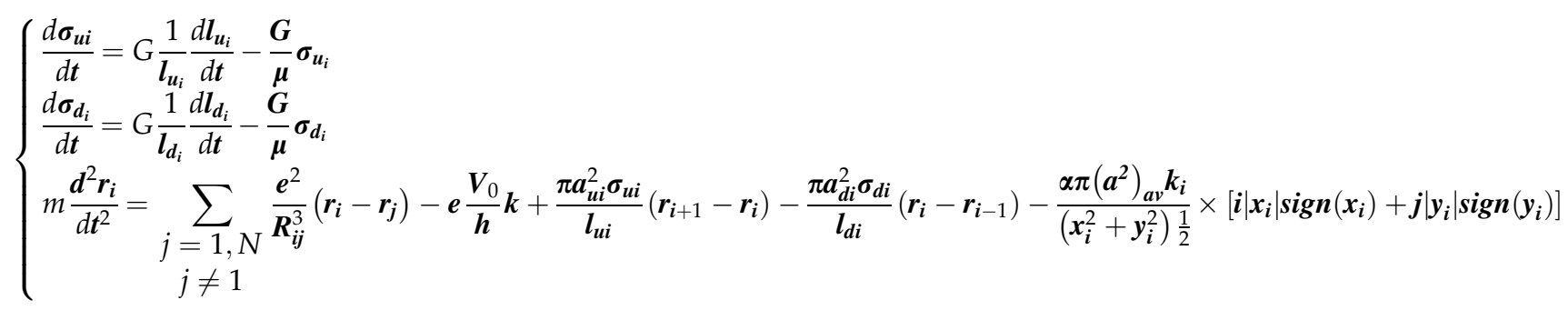

beads:where $\sigma$ is the stress, $t$ is the time, 1 is the length, $G$ is the elastic modulus, $\mu$ is the viscosity, $r_{i}=i_{x_{i}}+j_{x_{i}}+k_{x_{i}}, m$ is the mass, $e$ is the charge, $\mathrm{R}_{\mathrm{ij}}=\left[\left(\mathrm{x}_{\mathrm{i}}-\mathrm{x}_{\mathrm{j}}\right)^{2}+\left(\mathrm{y}_{\mathrm{i}}-\mathrm{y}_{\mathrm{i}}\right)^{2}+\left(\mathrm{z}_{\mathrm{i}}-\mathrm{z}_{\mathrm{j}}\right)^{2}\right]^{\frac{1}{2}}, \mathrm{~V}_{0}$ is the voltage, $h$ is the distance from pendent drop to grounded collector, $a$ is the radius and $k_{i}$ is the jet curvature.

$\left\{\begin{array}{cc}\operatorname{sign}(\mathrm{x})=1, \text { if } x & g t ; 0 \\ \operatorname{sign}(\mathrm{x})=-1, \text { if } x & l t ; 0 \\ \operatorname{sign}(\mathrm{x})=0, \text { if } x=0 & \end{array}\right.$

According to Yarin et al. [215], the main cause of instability is the electric bending force, and the wave number $\mathrm{X}^{*}$ and the growth rate $\gamma$ of the fastest growing bending perturbation are derived:

$\chi^{*}=\left(\frac{8}{9} \frac{\boldsymbol{\rho} \mathbf{a}_{0}^{2}}{\boldsymbol{\mu}^{2}}\left[\frac{\mathbf{e}_{0}^{2} \ln \left(\frac{\mathbf{L}}{\mathbf{a}_{0}}\right)}{\pi \mathbf{a}_{0}^{2}}-\frac{\boldsymbol{\sigma}}{\mathbf{a}_{0}}\right]\right)^{\frac{1}{6}}$

$\gamma^{*}=\frac{\left[\frac{\mathbf{e}_{0}^{2} \ln \left(\frac{\mathrm{L}}{\mathbf{a}_{0}}\right)}{\pi \mathbf{a}_{0}}-\boldsymbol{\sigma}\right]^{\frac{2}{3}}}{\left(3 \mu \rho \mathbf{a}_{0}^{4}\right)^{\frac{1}{3}}}$

where $\rho$ is the density, $a_{0}$ is the jet cross-sectional radius which does not change for small perturbations, $\mu$ is the viscosity, $L$ is the cutoff length, $a$ is the cross-sectional radius of the jet element and $\sigma$ is the surface tension.

Hohman et al. [208, 209] developed the slender body theory and established a jet dynamic model to clarify the influence of the surrounding electric field on the jet charge:

$$
\begin{aligned}
\ddot{\boldsymbol{X}}(s)= & \partial_{s s}\left[-\frac{3}{4} \boldsymbol{v}^{*} \dot{\boldsymbol{\kappa}}_{j e t}-\frac{\overline{\boldsymbol{\epsilon}}(\boldsymbol{\beta}+1)}{16 \pi \sqrt{\boldsymbol{\beta}}} \boldsymbol{\Omega}_{0 t} \boldsymbol{P}^{\prime}\right] \\
& +\boldsymbol{\beta}^{-\frac{1}{2}} \partial_{s}\left[\frac{\boldsymbol{\Omega}_{0 t} \boldsymbol{\sigma}_{0}}{\boldsymbol{R}}+\overline{\boldsymbol{\epsilon}} \boldsymbol{\sigma}_{0} \boldsymbol{P}^{\prime}-\boldsymbol{\Omega}_{0 t} \boldsymbol{\sigma}_{\boldsymbol{D}}\right]-\frac{\bar{\epsilon} \sqrt{\boldsymbol{\beta}} \boldsymbol{\Omega}_{0 t}}{4 \pi} \boldsymbol{P}^{\prime} \\
& +\frac{1}{\boldsymbol{R}}-\frac{4 \pi \boldsymbol{\sigma}_{0}^{2}}{\boldsymbol{R}} \boldsymbol{l n}\left(\frac{1}{\chi}\right)+2 \boldsymbol{\beta}^{-\frac{1}{2}} \boldsymbol{\sigma}_{0} \boldsymbol{\Omega}_{0 \xi}
\end{aligned}
$$

where $\mathrm{X}$ is the oscillation of the centerline, $\mathrm{s}$ is the arc length, $v^{*}$ is the dimensionless viscosity, $\bar{\epsilon}$ is the air dielectric constant, $\beta=\frac{\epsilon}{\bar{\epsilon}}-1, \Omega_{0}$ is the dimensionless external field strength, $\mathrm{P}$ is the dipole density, $\sigma_{0}$ is the dimensionless background free charge density, $\mathrm{R}$ is the radius, $\sigma_{\mathrm{D}}$ is the dipolar component of free charge density, $X$ is the aspect ratio and $\xi$ is the coordinate in the principal normal direction.

Shin et al. [216] also proposed the whipping instability model and gave the amplification factor for a perturbation convected a distance downstream:

$\Gamma\left(E_{\infty}, Q\right)=\ln \left[\frac{A(d)}{A(0)}\right]=\int_{0}^{d} \frac{\omega(\boldsymbol{h}, E, \sigma) \pi h^{2}}{Q}$

where $\Gamma$ is the amplification factor, $\mathrm{E}_{\infty}$ is the applied electric field, $\mathrm{Q}$ is the flow rate, $\mathrm{A}$ is the amplitude of a perturbation, $\mathrm{d}$ is the distance, $\omega$ is the growth rates, $E$ is the local electric field, $h$ is the radius of the jet and $\sigma$ is the surface charge distribution.

After that, Fridrikh et al. [217] established a mathematical model of the influence of parameters and obtained the equation of motion of the jet:

$$
\begin{aligned}
\boldsymbol{\rho} \pi \boldsymbol{h}^{2} \ddot{\boldsymbol{x}}= & 2 \pi \boldsymbol{h} \boldsymbol{\sigma}_{0} \boldsymbol{E}_{\infty} \cdot \widehat{\boldsymbol{\xi}} \\
& +\left(\pi \gamma+\frac{\boldsymbol{h} \overline{\boldsymbol{\varepsilon}}}{2} \boldsymbol{\beta}\left(\boldsymbol{E}_{\infty} \cdot \widehat{\boldsymbol{t}}\right)^{2}+\frac{2 \pi^{2} \boldsymbol{h} \boldsymbol{\sigma}_{0}^{2}}{\overline{\boldsymbol{\varepsilon}}}(3-2 \ln \boldsymbol{\chi})\right) \frac{\boldsymbol{h}}{\boldsymbol{R}}
\end{aligned}
$$

where $\rho$ is the density, $h$ is the jet diameter, $x$ is the motion for normal displacements of the centerline of the jet, $\mathrm{E}_{\infty}$ is the applied electric field, $\widehat{\xi}$ is the unit 
vectors normal to the centerline of the jet, $\gamma$ is the surface tension, $\overline{\boldsymbol{\varepsilon}}$ is the dielectric constant, $\widehat{t}$ is the unit vectors tangential to the centerline of the jet, $\mathrm{X}$ is the dimensionless wavelength of the instability responsible for the normal displacements and $R$ is the radius of curvature.

Theron et al. [218] studied the parameters of electrospinning with the help of empirical formulas.

Carroll et al. [219] calculated the expected growth rate of the axisymmetric beads, as well as the expected bead wave number, and analyzed the instability mechanism from the perspective of energy. They found that electrical forces mainly drive the unstable axisymmetric mode for electrically driven, highly conducting jets:

$$
\begin{aligned}
& \left(f_{1} \omega+F_{1}\right)\left(f_{2} \omega+F_{2}\right)\left(f_{3} \omega+F_{3}\right)\left[-\omega-v_{s} i k-\frac{3 B}{R e} k^{2}\right] \\
& \quad+\frac{i k}{\operatorname{Re}}\left(f_{1} \omega+F_{1}\right)\left(f_{3} \omega+F_{3}\right)\left[X_{e}-X_{f}\right]+\left(f_{2} \omega+F_{2}\right) \\
& \quad \times\left(f_{3} \omega+F_{3}\right) X_{a}\left[\frac{i k}{\operatorname{Re}} \frac{2\left(\tau_{p z z s}-\tau_{p r r s}\right)}{R_{s}}+\frac{i k}{W e}\left(\frac{1}{R_{s}^{2}}-k^{2}\right)-\frac{2 \varepsilon_{E} E_{s} \sigma_{s}}{R_{s}^{2}}\right] \\
& \quad+\varepsilon_{E}\left(f_{1} \omega+F_{1}\right)\left(f_{2} \omega+F_{2}\right)\left[\sigma_{s} i k X_{d}+\beta E_{s} i k X_{c}+\frac{2}{R_{s}}\left(\sigma_{S} X_{c}+E_{s} X_{d}\right)\right]=0
\end{aligned}
$$

where $f_{1}=2 R_{s}, F_{1}=2 i k R_{s} v_{s}, f_{2}=D e, F_{2}=1+v_{s} i k D e$, $\mathrm{f}_{3}=-\frac{\mathrm{Pe}}{\mathrm{R}_{\mathrm{s}} \mathrm{ik}^{\prime}}, \quad \mathrm{F}_{3}=-\frac{\mathrm{Pev}_{\mathrm{s}}}{\mathrm{R}_{\mathrm{s}}}+\frac{\ln (\chi) \mathrm{R}_{\mathrm{s}} \mathrm{k}}{1+\ln (\chi) \frac{\beta_{2}}{2} \mathrm{R}_{\mathrm{s}}^{2} \mathrm{k}^{2}}, \quad \mathrm{~B}=\frac{\eta_{\mathrm{s}}}{\eta_{\mathrm{p}},} \quad \mathrm{X}_{\mathrm{e}}=$ $2(1-B) i k+2 \operatorname{De} \tau_{\text {pzzs }} \mathrm{ik}, \quad \mathrm{X}_{\mathrm{f}}=-(1-\mathrm{B}) \mathrm{ik}-\operatorname{De} \tau_{\mathrm{prrs}} \mathrm{ik}$, $\mathrm{X}_{\mathrm{a}}=-\mathrm{ikR}_{\mathrm{s}}^{2}, \quad \mathrm{X}_{\mathrm{d}}=\mathrm{X}_{1}-\mathrm{X}_{2}, \quad \mathrm{X}_{1}=$ $\frac{-\ln (\chi)\left(\frac{\mathrm{X}_{\mathrm{a}}}{\mathrm{f}_{1} \omega+\mathrm{F}_{1}}\right)\left[\sigma_{\mathrm{s}} \mathrm{ik}+\beta \mathrm{R}_{\mathrm{s}} \mathrm{E}_{\mathrm{s}} \mathrm{k}^{2}\right]}{1+\ln (\chi)\left[{ }_{2} \mathrm{R}_{\mathrm{s}}^{2} \mathrm{~s}^{2}\right]}, \quad \mathrm{X}_{2}=-\left(\frac{\mathrm{Pe}}{\mathrm{R}_{\mathrm{s}}^{2} \mathrm{ik}}\right)\left[\left(\frac{\mathrm{X}_{\mathrm{a}}}{\mathrm{f}_{1} \omega+\mathrm{F}_{1}}\right)\left(\sigma_{\mathrm{s}} \omega+\right.\right.$ $\left.\left.\sigma_{s} v_{s} i k+\frac{2 R_{s} E_{s} i k}{P e}\right)+R_{s} \sigma_{s} i k\right]$

$\mathrm{X}_{\mathrm{c}}=\mathrm{X}_{1}\left(\mathrm{f}_{3} \omega+\mathrm{F}_{3}\right)+\mathrm{X}_{3}\left(\mathrm{X}_{1}-\right) \mathrm{X}_{2}, \mathrm{X}_{3}=-\frac{\ln (\chi) \mathrm{R}_{\mathrm{s}} \mathrm{ik}}{1+\ln (\chi) \frac{\beta_{2}}{2} \mathrm{~s}_{\mathrm{s}}^{2}{ }^{2}}$.

Using JETSPIN software package, Carroll and Joo [219] studied the effect of gas flow on electrospinning by using nonlinear Langevin-like approach and made experimental comparison:

$$
\left\{\begin{array}{l}
\frac{d \sigma_{i}}{d t}=\frac{G}{l_{i}} \frac{d l_{i}}{d t}-\frac{G}{\mu} \sigma_{i} \\
m_{i} \frac{d v_{i}}{d t}=f_{e l, i}+f_{c, i}+f_{v e, i}+f_{s t, i}+f_{g, i}+f_{d i s s, i}+f_{r a n d} \\
\frac{\mathrm{d} r_{i}}{\mathrm{~d} t}=v_{i}
\end{array}\right.
$$

where $\sigma \mathrm{i}$ is the stress on the ith dumbbell which connects the bead $i$ with the bead $i+1$, li is the length of the element, $G$ is the elastic modulus, $\mu$ is the viscosity of the fluid jet, $t$ is the time, $v_{i}$ is the velocity of the ith bead, $f_{e l, i}$ is the electric force, $f_{c, i}$ is the net coulomb force, $\mathrm{f}_{\mathrm{ve}, \mathrm{i}}$ is the viscoelastic force, $\mathrm{f}_{\mathrm{st}, \mathrm{i}}$ is the force due to the surface tension, $f_{g, i}$ is the force due to the gravity, $f_{\text {diss }, i}$ is the dissipative force, $f_{\text {rand }}$ is the random force and $r_{i}$ is the position vector of the ith bead.

Yousefi et al. [220] used a physics-based computational model, mass-springdamper (MSD) approach to incorporate the mechanical properties of the fibers in predicting the formation and morphology of the electrospun fibers:

$\frac{d}{d t}\left[\begin{array}{l}v_{i} \\ r_{i}\end{array}\right]=\left[\begin{array}{c}f_{i}^{\sum} / m_{i} \\ v_{i}\end{array}\right]$

where $r_{i}$ is the position vector of bead $i, m_{i}$ is the mass of bead $\mathrm{i}, \mathrm{f}_{\mathrm{i}}^{\Sigma}=f_{i}^{v e}+f_{i}^{s t}+f_{i}^{e l}+f_{i}^{C}, f_{i}^{v e}, f_{i}^{v e}$ is the viscoelastic forces acting on bead $i, f_{i}^{s t}$ is the surface tension force, $f_{i}^{e l}$ is the electric attraction force and $f_{i}^{C}$ is the Columbic force.

\section{Molecular simulation}

Molecular simulation technology includes Monte Carlo method and molecular dynamics method [83, 221]. Monte Carlo method is based on statistics and is suitable for equilibrium system. Molecular dynamics method is a deterministic method based on classical mechanics, which can solve the equations of motion of all particles in the system, and is suitable for studying time-dependent phenomena. In electrospinning, molecular dynamics method is commonly used to study the interaction of composite materials and the adsorption or surface interaction of nanofiber products with drugs or proteins. Jirsák et al. [222] used Monte Carlo method and molecular dynamics method to simulate the initial stage of the jet, as shown in Fig. 11. The results obtained by the two methods are qualitatively consistent with the experimental results and found the balance of ion concentration and field strength affects forming beads in nanofibers. Danwanichakul et al. [223] used Monte Carlo method to simulate the deposition stage of nanofibers, obtained the positive correlation between the concentration and the pore size of the fibers, and tested the filtration performance of polystyrene particles, which was consistent with the experimental results. Sarmadi et al. [224] simulated the protein adsorption capacity of electrospun PCL/ PVA nanofibers by molecular dynamics method, 

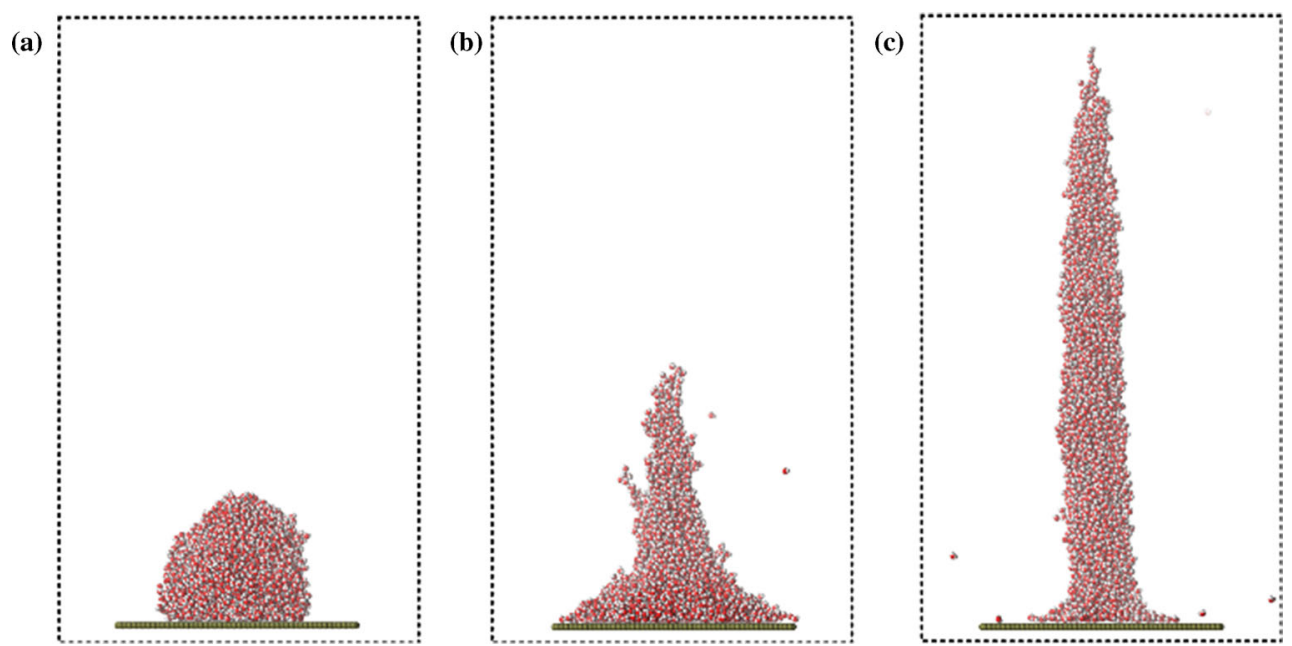

Figure 11 Sequence of snapshots showing the transformation of a droplet on the wall modeling the apex of the Taylor cone to a jet. a System before the field was applied, $\mathbf{b}$ the instant soon after the field was applied, and $\mathbf{c}$ a later instant when the droplet is

which was consistent with the experimental results. In addition, Vao-soongnern [225] analyzed the effect of molecular weight and chain conformation of polymers on the structure and properties of electrospun nanofibers using Monte Carlo method. Steffens et al. [226] simulated the interaction between PVA nanofibers and drug-loaded dacarbazine using quantum mechanics calculations, molecular modeling techniques and molecular dynamics simulation, thus explaining the principle of controlled drug release.

\section{Others}

As well as the above models and simulation methods, there are some other interesting methods. For example, lattice Boltzmann method, which is an advanced computational fluid dynamics method, has the characteristics of mesoscopic model between micromolecular dynamics model and macro-continuous model. Karra [227] modified the discrete bead model and proposed a hybrid numerical scheme that couples lattice Boltzmann method with the finite difference method to solve Oldroyd-B viscoelastic problem. Finite element model is equally a commonly used model in physics. Yin et al. [228] used representative volume element to analyze the relationship between the nanofiber membrane performance and single nanofiber performance, and verified the correctness of the conclusion through transformed to the jet. Colored spheres represent atoms and ions as follows: red-oxygen, white-hydrogen, blue-sodium cation and cyan-chloride anion [222]. Reproduced with permission from reference [222]. Copyright 2014, American chemical society.

experiments. Neural network is a hot machine learning algorithm recently, but its application in electrospinning is still less. Sarkar et al. [229] used neural network algorithm, taking concentration, conductivity, flow rate and electric field strength as input variables, can well predict the change of fiber diameter, but only consider the influence of four variables, which is not suitable for complex electrospinning process.

\section{Applications}

\section{Biomedicine}

\section{Tissue engineering}

Tissue engineering is a major branch of biomedical engineering, whose main purpose is the repair and regeneration of organs or tissues [230-233]. Tissue engineering consists of three parts: scaffold materials, growth factors and cells. The nanofibers prepared by electrospinning have the characteristics of high porosity and large specific surface area, which are similar to the structure of extracellular matrix (ECM). They can provide sites for cell adhesion and facilitate the transport of nutrients and wastes [234-236]. Besides, the electrospinning parameters are mostly controllable, which can prepare nanofibers with ideal diameters and shapes, as well as nanoparticles or nanotubes and other structures, and have a wide 


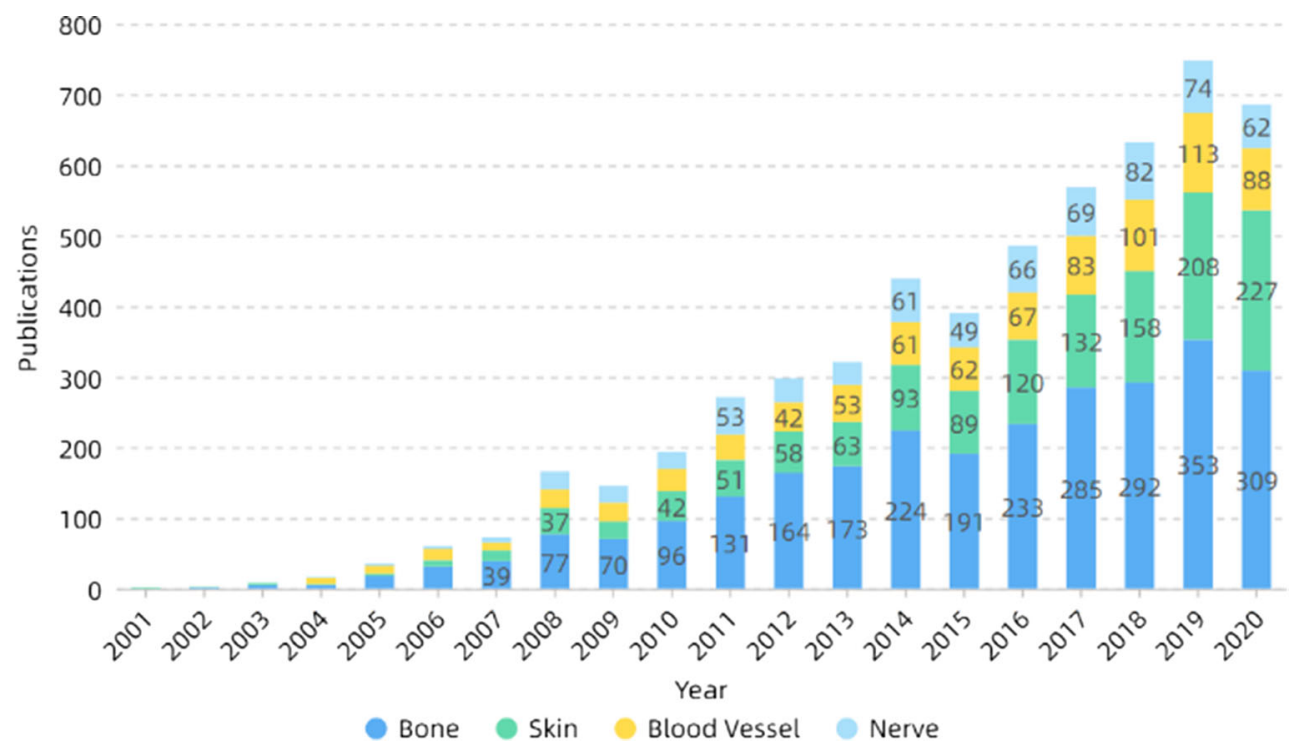

Figure 12 Number of publications on electrospinning in different directions of tissue engineering. All the data used are from Web of Science. The functions we used are analyze results and create citation report.

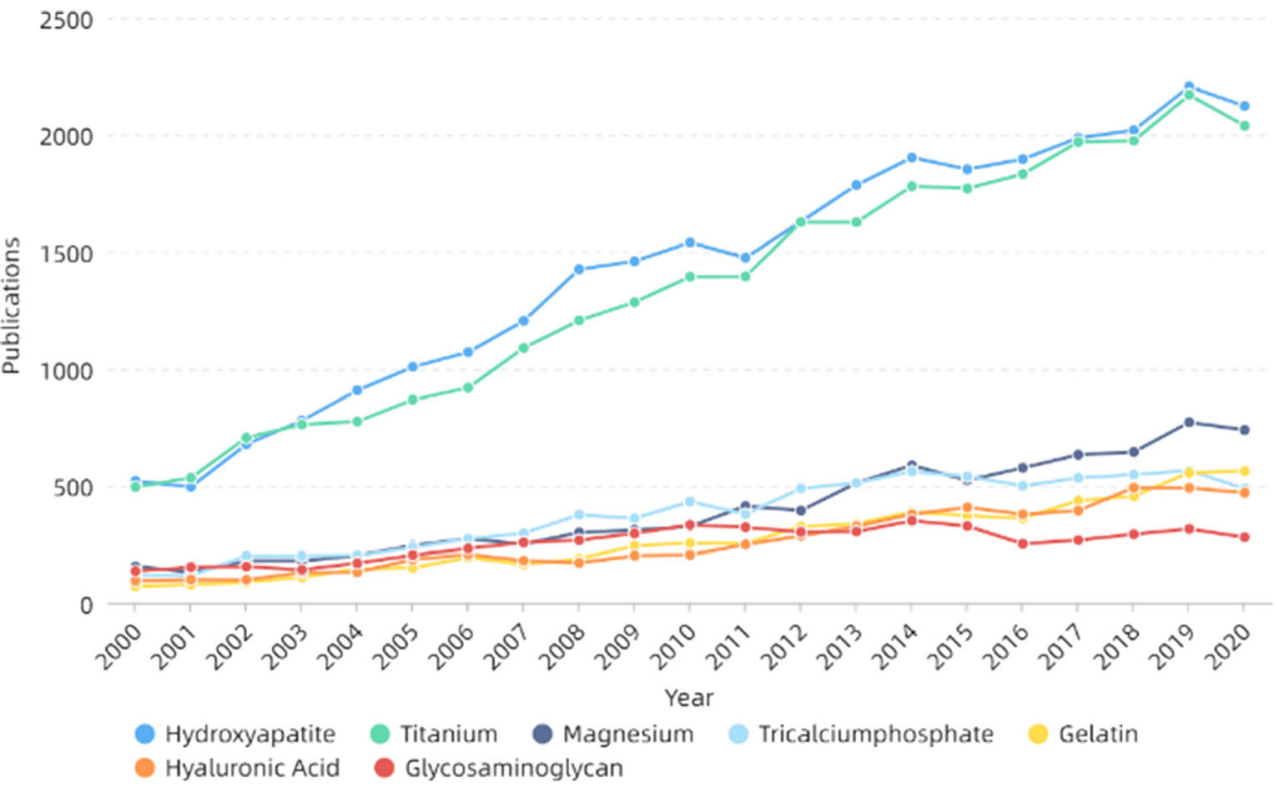

Figure 13 Number of publications of some bone repair materials in recent years. All the data used are from web of science. The functions we used are analyze results and create citation report.

application prospect in tissue engineering [214, 237, 238]. Figure 12 shows the number of publications on electrospinning in different directions of tissue engineering. It can be seen that researchers mainly focus on bones and skin, and less on blood vessels and nerves.

Bones Bone is a complex nanocomposite comprising about 70\% hydroxyapatite (HAP) and about 30\% collagen fibers [239, 240]. When human bones are damaged by disease or accident, tissue engineering techniques can be utilized to repair or regenerate them. Electrospinning technology has great potential in bone repair [241, 242]. Bone repair materials can fall into three categories: metal, polymer and ceramic. Figure 13 and Table 1 both show that hydroxyapatite and titanium-related materials are widely used in bone repair, which are the two most important bone 
Table 1 Some progress of electrospinning in bones in recent years

\begin{tabular}{|c|c|c|c|c|c|c|}
\hline Material & Solvent & $\begin{array}{l}\text { Flow rate } \\
(\mathrm{mL} / \mathrm{h})\end{array}$ & $\begin{array}{l}\text { Distance } \\
(\mathrm{cm})\end{array}$ & $\begin{array}{l}\text { Voltage } \\
(\mathrm{kV})\end{array}$ & Cells & Reference \\
\hline Chitosan/PEO/halloysites & Water & 1.2 & 15 & $19-26$ & NHOst & {$[255]$} \\
\hline $\mathrm{PHB} /$ keratin & Chloroform/DMF & 0.96 & 25 & 13 & MG-63 & {$[256]$} \\
\hline PLGA/ $\beta$-TCP particles & $\mathrm{DCE} / \mathrm{DMF}$ & 1 & 25 & 18 & MC3T3 & {$[257]$} \\
\hline Chitosan/PHB/alumina nanowires & TFA & 0.6 & 25 & 22 & MG-63 & {$[258]$} \\
\hline $\begin{array}{l}\text { PCL/nanomagnesium phosphate/nanohydroxyapatite/ } \\
\text { hyperbranched polyglycerol }\end{array}$ & $\mathrm{DMF} / \mathrm{CHCl} 3$ & 0.5 & 11 & $9-13$ & $\begin{array}{l}\text { MG-63/ } \\
\text { hMSCs }\end{array}$ & [259] \\
\hline Deacetylated cellulose acetate & Acetone/water & $2-4$ & $12-15$ & $20-22$ & MC3T3 & {$[260]$} \\
\hline Zein/trimethylolpropane triglycidyl ether (TMPGE) & Ethanol/water & 2.5 & 25 & $17-20$ & MC3T3 & [261] \\
\hline silk fibroin/PLCL/parathyroid hormone & HFIP & 1 & $12 / 15$ & $12 / 15$ & BMMSCs & [262] \\
\hline $\begin{array}{l}\text { PCL/amine-functionalized single-walled carbon } \\
\text { nanotube }\end{array}$ & $\mathrm{DCM} / \mathrm{DMF}$ & 2 & 23 & 17 & rMSCs & [263] \\
\hline PHB/PCL/levofloxacin/sol-gel derived silica & Chloroform/DMF & 4 & 15 & 15 & MG-63 & {$[264]$} \\
\hline PCL/chitosan or carboxymethyl chitosan & $\begin{array}{l}\text { Acetic acid/formic } \\
\text { acid }\end{array}$ & $0.1-0.7$ & $16-20$ & $18-30$ & MG-63 & [265] \\
\hline PCL/F18 bioactive glass & $\mathrm{DCM} / \mathrm{DMF}$ & 3 & 18 & 17 & MG-63 & [266] \\
\hline PLLA/synthetic glass-reinforced hydroxyapatite & $\mathrm{DMC} / \mathrm{DMF}$ & 0.5 & 20 & 25 & MG-63 & {$[267]$} \\
\hline PLLA/glass-reinforced hydroxyapatite microparticles & $\begin{array}{l}\text { DMF/ } \\
\text { dichloromethane/ } \\
\text { DCM }\end{array}$ & 0.5 & 20 & 25 & MG-63 & [268] \\
\hline PCL/gelatin & $\begin{array}{l}\text { TFE/acetic acid/ } \\
\text { ethanol }\end{array}$ & 3 & 18 & 20 & MC3T3 & [269] \\
\hline Cellulose/nanohydroxyapatite & $\mathrm{LiCl} / \mathrm{DMAc}$ & 0.24 & 10 & 20 & HDFCs & {$[270]$} \\
\hline $\begin{array}{l}\text { Poly(3-hydroxybutyrate-co-3-hydroxyvalerate)/silicate } \\
\text { containing hydroxyapatite nanoparticles }\end{array}$ & Chloroform & 2 & 5 & 7 & hMSCs & [271] \\
\hline Polyamide- $6,6 /$ chitosan & Acetic acid/HFIP & 0.5 & 17 & 20 & MC3T3 & [272] \\
\hline PHB/hydroxyapatite nanoparticles & Chloroform & 1 & 20 & 15 & MSCs & [273] \\
\hline Zein/calcium lactate/PCL & $\mathrm{DMF} / \mathrm{DCM}$ & 1 & 18 & 17 & MC3T3 & {$[274]$} \\
\hline
\end{tabular}

repair materials in metal and ceramics. Metal materials have excellent biocompatibility and mechanical properties, but they are generally non-biodegradable and have less effect on surrounding tissues. Polymers and ceramics have good biological activity, some with good mechanical properties are more suitable for bone tissue engineering [243]. Hydroxyapatite (HA), the main inorganic component of human bones, has good biocompatibility and is suitable for use as a bone repair material [244, 245]. Besides, HA can also promote growth and proliferation of osteoblasts and induce bone mineralization [246]. However, its mechanical properties are poor, brittle and easy to break, so it needs to be modified or compounded with other materials. In recent years, preparing hydroxyapatite-related materials by electrospinning has been widely studied. Many studies have shown that hydroxyapatite can be combined with gelatin [247], collagen [248], silk [249], PCL [250], chitosan [251] and so on, making it more suitable for bone repair. For example, Chen et al. [252] prepared gelatin-chitosan core-shell structure nanofibers using coaxial electrospinning technology. Hydroxyapatite was wet deposited on the surface of the fibers, which was conducive to the adhesion and proliferation of osteocytes, improved mineralization efficiency of hydroxyapatite, then cultured MG-63 cells for evaluation. It was noted the cell activity was significantly improved, indicating that its biocompatibility was good. Ko et al. [253] coated glycidoxypropyltrimethoxysilane (GPTMS) on the surface of hydroxyapatite to improve the dispersion in silk fibroin solution and added PEO to improve the stability of electrospinning. After electrospinning, polydopamine (PDA) and hydroxyapatite nanoparticles were coated on the surface, and a new 
Table 2 Some progress of electrospinning in skin in recent years

\begin{tabular}{|c|c|c|c|c|c|c|}
\hline Material & Solvent & $\begin{array}{l}\text { Flow } \\
\text { rate } \\
(\mathrm{mL} / \mathrm{h})\end{array}$ & $\begin{array}{l}\text { Distance } \\
(\mathrm{cm})\end{array}$ & $\begin{array}{l}\text { Voltage } \\
(\mathrm{kV})\end{array}$ & Cells & Reference \\
\hline Silk fibroin/PCL/PEO & $\begin{array}{l}\text { Formic acid/ } \\
\text { TFE }\end{array}$ & $1 / 2.3$ & $10-12$ & 28 & NHDF & {$[290]$} \\
\hline $\begin{array}{l}\mathrm{PCL} / \text { chitosan/PEO/aloe vera } \\
\text { extract/keratin }\end{array}$ & $\begin{array}{l}\text { Formic acid/ } \\
\text { acetic acid }\end{array}$ & 0.1 & $10-12$ & $15 / 16$ & L929 & [291] \\
\hline PCL/gelatin/MgO particles & HFIP & 2 & 22 & 24 & hEnSCs & [292] \\
\hline $\begin{array}{l}\text { Chitosan/PVA/glyoxal/halloysite } \\
\text { nanotubes }\end{array}$ & Acetic acid & 0.2 & 6 & 15 & Human normal fibroblast cells & [293] \\
\hline Silk fibroin/PCL/PEO & Formic acid & 0.3 & 12 & 17.5 & Human BJ fibroblast cells & [294] \\
\hline $\begin{array}{l}\text { PCL/Althea Officinalis Extract/ } \\
\text { gelatin }\end{array}$ & $\begin{array}{l}\text { Formic acid/ } \\
\text { acetic acid }\end{array}$ & 0.3 & 10 & $15-17$ & L929 & [295] \\
\hline $\begin{array}{l}\text { PCL/N-(2-hydroxy)-propyl-3- } \\
\text { trimethylammonium chitosan } \\
\text { chloride }\end{array}$ & $\begin{array}{l}\text { Formic acid/ } \\
\text { acetic acid }\end{array}$ & 0.9 & 15 & 25 & HDFn & [296] \\
\hline $\begin{array}{l}\text { PCL/chitosan/hyaluronic acid/ } \\
\text { PEO }\end{array}$ & Formic/acetone & $\begin{array}{c}1.2 / 1 / \\
0.1\end{array}$ & $15 / 18 / 10$ & $\begin{array}{l}16 / \\
18-20 / \\
11\end{array}$ & Vero cells & [297] \\
\hline PCL/zein/gum arabic & $\begin{array}{l}\text { Formic acid/ } \\
\text { acetic acid }\end{array}$ & 0.2 & 15 & 18 & L929 & [298] \\
\hline $\mathrm{PEO} /$ casein/silver nanoparticles & SDS & 0.3 & 15 & 20 & NIH-3T3 & {$[59]$} \\
\hline $\begin{array}{l}\text { Cellulose acetate/ } \\
\text { gelatin/nanohydroxyapatite }\end{array}$ & HFP & 0.8 & 13 & 18 & L929 & [299] \\
\hline $\begin{array}{l}\text { PCL/Maillard reaction products/ } \\
\text { glucose-arginine or } \\
\text { fructosearginine }\end{array}$ & TFE & 2.5 & 14 & 25 & NHDF & {$[300]$} \\
\hline PDLLA/PCL/ $\mathrm{Cu}_{2} \mathrm{~S}$ nanoparticles & DMF/THF & 0.9 & 15 & $8-12$ & $\begin{array}{l}\mathrm{HDFs} / \mathrm{HUVECs} / \text { murine B16F10 } \\
\text { melanoma cells/human A375 } \\
\text { melanoma }\end{array}$ & {$[301]$} \\
\hline $\begin{array}{l}\text { Chitosan/PEO/henna leaves } \\
\text { extract }\end{array}$ & Acetic acid & $0.1-1.5$ & $10-20$ & $5-25$ & $\mathrm{NHF}$ & {$[302]$} \\
\hline Gelatin/PVA/keratin & Formic acid & 0.1 & 10 & 20 & L929 & {$[284]$} \\
\hline $\begin{array}{l}\text { PLA/hyperbranched polyglycerol/ } \\
\text { curcumin }\end{array}$ & $\begin{array}{l}\text { Chloroform/ } \\
\text { methanol }\end{array}$ & 0.5 & 12 & $13-15$ & $3 \mathrm{~T} 3$ & {$[303]$} \\
\hline $\begin{array}{l}\text { Gelatin/sulfated } \\
\text { hyaluronan/chondroitin sulfate }\end{array}$ & TFE & 0.75 & 13 & 20 & $\mathrm{HaCaT} / \mathrm{Hs} 27 / \mathrm{hMSCs}$ & {$[304]$} \\
\hline PCL/chitosan & $\begin{array}{l}\text { Chloroform/ } \\
\text { methanol/ } \\
\text { acetic acid }\end{array}$ & 0.18 & 10 & 22 & Human fibroblast/keratinocyte & {$[305]$} \\
\hline $\begin{array}{l}\text { PCL/cellulose acetate/chitosan/ } \\
\text { PEO }\end{array}$ & $\begin{array}{l}\text { Chloroform/ } \\
\text { methanol/ } \\
\text { acetic acid }\end{array}$ & 2 & 15 & $20 / 25$ & L929 & {$[306]$} \\
\hline Gelatin/TEA/BDDGE & Acetic acid & 0.4 & 12 & 11 & $\mathrm{hDNF}$ & {$[307]$} \\
\hline $\mathrm{PCL} /$ chitosan/PEO/aloe vera & TFE & $2.5 / 4$ & $15 / 12$ & $25 / 28$ & NHDF & {$[308]$} \\
\hline PLGA & DMF/THF & 0.8 & 15 & 28 & $\mathrm{HDF} / \mathrm{HaCat}$ & {$[309]$} \\
\hline Silk fibroin/PEO/NaCl & Water & 1.2 & 15 & 22 & $\mathrm{HDF} / \mathrm{HaCAT}$ & {$[310]$} \\
\hline $\begin{array}{l}\text { Chitosan/bacterial cellulose/ } \\
\text { PEO/nanodiamond }\end{array}$ & Acetic acid & 0.3 & 10 & $20-22$ & L929 & [311] \\
\hline Cellulose acetate & Acetone $/ \mathrm{NaOH}$ & 5 & 20 & 15 & L929 & [312] \\
\hline PEUU/gelatin & HFIP & 1.5 & 15 & 12.5 & L929 & [313] \\
\hline PHB/gelatin & HFIP & 1.5 & 12 & 18 & NIH 3T3/HaCaT & {$[286]$} \\
\hline
\end{tabular}


Table 2 continued

\begin{tabular}{lllllll}
\hline Material & Solvent & $\begin{array}{l}\text { Flow } \\
\text { rate } \\
(\mathrm{mL} / \mathrm{h})\end{array}$ & $\begin{array}{l}\text { Distance } \\
(\mathrm{cm})\end{array}$ & $\begin{array}{l}\text { Voltage } \\
(\mathrm{kV})\end{array}$ & Cells & Reference \\
\hline $\begin{array}{l}\text { Silk fibroin/PEO/gold } \\
\text { nanoparticle }\end{array}$ & Water & $0.8-2$ & $13-23$ & $12-19$ & L929 & {$[314]$} \\
\begin{tabular}{l} 
PLGA/collagen \\
\hline
\end{tabular} & HFIP & 1 & 17 & 28 & HDF/HaCat & {$[315]$} \\
\hline
\end{tabular}

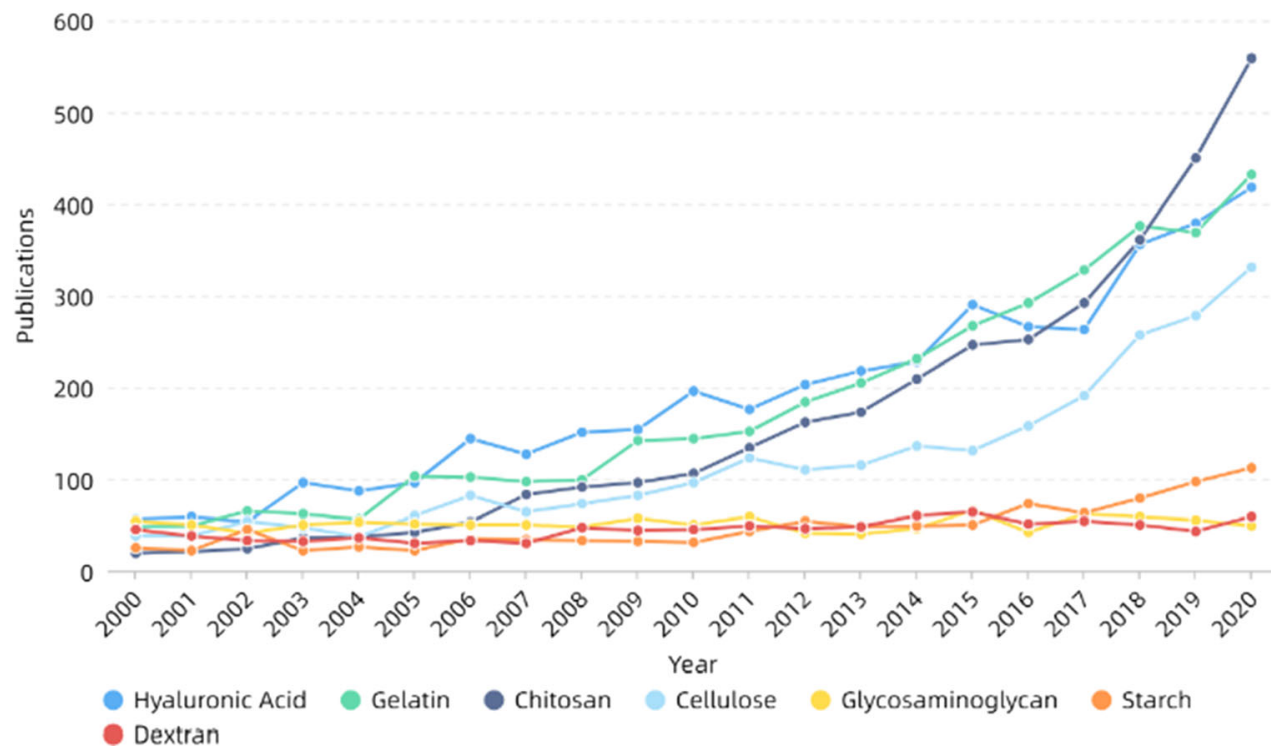

Figure 14 Number of publications of some skin repair materials. All the data used are from web of science. The functions we used are analyze results and create citation report.

nanofibrous scaffold material was obtained. Tests showed the coating improved the compressive resistance of the material. Then the human adiposederived mesenchymal stem cells (hADMSCs) activated by TAZ transcription regulator were cultured on the scaffold material, which further improved the osteoconductivity of the material, developed osteogenic ability of the cells and promoted the formation of bone. At the same time, it was found the concentration of hydroxyapatite had a great impact on the osteogenic ability, and its importance is self-evident. Using hydroxyapatite-TSF composite nanoparticles as the inner layer and pure tussah fibroin as the outer layer, Shao et al. [254] prepared nanofibers with different core-shell mass ratio using coaxial electrospinning technology, which was conducive to the proliferation and adhesion of MG-63 cells. Alkaline phosphatase, osteocalcin and matrix mineralization at different times were also measured, indicating the materials made bone development and maturation faster.

Skin Skin is the largest organ of the human body, the first defense line of the matrix from dehydration, injury and infection, and a barrier to prevent from invading external microorganisms. The main functions are protection, sensation, regulation of body temperature, absorption, secretion and excretion, respiration, metabolism and so on [275, 276]. Skin tissue engineering is one of the most important components in skin repair. Ideal skin repair materials should have good biocompatibility, degradability, mechanical properties and so on and need to ensure the transport of gases and nutrients and prevent bacterial infections as well as the loss of body fluids and proteins [276, 277]. Electrospinning can prepare nanofibers with similar structure to extracellular matrix, which have the advantages of controllable 
Table 3 Some progress of electrospinning in blood vessels in recent years

\begin{tabular}{|c|c|c|c|c|c|c|}
\hline Material & Solvent & $\begin{array}{l}\text { Flow rate } \\
(\mathrm{mL} / \mathrm{h})\end{array}$ & $\begin{array}{l}\text { Distance } \\
(\mathrm{cm})\end{array}$ & $\begin{array}{l}\text { Voltage } \\
(\mathrm{kV})\end{array}$ & Cells & Reference \\
\hline PVA/alginate or chitosan & $\begin{array}{l}\text { Acetic acid/ } \\
\text { DMSO }\end{array}$ & 4 & 8 & 8 & HMEC-1 & [329] \\
\hline PCL/Pluronic P123/cilostazol & $\begin{array}{l}\text { Chloroform/ } \\
\text { methanol }\end{array}$ & 2 & 15 & 10 & HUVECs/PASM & {$[330]$} \\
\hline PU/gelatin/single-walled carbon nanotube & HFIP & 0.3 & 12 & 18 & $\begin{array}{l}\text { myocardial } \\
\text { myoblast/ } \\
\text { endothelial cells }\end{array}$ & [331] \\
\hline PU/cedarwood oil/cobalt nitrate & $\mathrm{DMF}$ & 0.3 & 20 & 11 & $\mathrm{HDF}$ & {$[332]$} \\
\hline PCL/PLCL & $\begin{array}{l}\text { chloroform/ } \\
\text { ethanol/acetic } \\
\text { acid }\end{array}$ & 1.5 & 20 & 15 & $3 \mathrm{~T} 3$ & {$[333]$} \\
\hline $\begin{array}{l}\mathrm{PCL} / \text { gelatin/cysteine-terminated REDV } \\
\text { peptide }\end{array}$ & TFE/acetic acid & 0.4 & 15 & 10 & VEC/L929 & {$[334]$} \\
\hline $\begin{array}{l}\text { Acrylamide-terminated glycine-arginine- } \\
\text { glycine-aspartic peptides modified PEUU }\end{array}$ & HFIP & $0.5-1$ & 14 & $8.45-10$ & HUVECs & {$[335]$} \\
\hline $\begin{array}{l}\text { Zinc oxide nanoparticles/poly(vinylidene } \\
\text { fluoride-trifluoroethylene) }\end{array}$ & Acetone & 1.5 & 10 & 18 & hMSCs & [336] \\
\hline $\mathrm{PCU}$ & $\mathrm{DMF} / \mathrm{THF}$ & 1.5 & 13 & 16 & MEF & {$[337]$} \\
\hline PCL/PU & THF/DMF/MEK & 1.1 & 20 & 15 & EA.hy926 & [338] \\
\hline PCL/europium hydroxide nanorods & $\begin{array}{l}\text { chloroform/ } \\
\text { methanol }\end{array}$ & 1 & 15 & 18 & HUVECs/EA.hy926 & [339] \\
\hline PET & TFA/DCM & 1.5 & 15 & 18 & $3 \mathrm{~T} 3$ & {$[340]$} \\
\hline $\mathrm{PU} / \mathrm{PEG}$ or $\mathrm{PC}$ & THF/DMF & 0.01 & 15 & $22-23$ & HUVECs & [341] \\
\hline PCL/gelatin & TFE/acetic acid & 1 & 20 & 20 & hMSCs & [342] \\
\hline PU/PEG/cerium oxide nanoparticles/VEGF & THF/DMF & $0.8-1$ & $10-15$ & $8-10$ & EPCs & [343] \\
\hline
\end{tabular}

pore size, large specific surface area and good permeability. It is conducive to cell attachment, proliferation and differentiation and is suitable for skin repair [278-281]. Table 2 and Fig. 14 show that gelatin, hyaluronic acid and cellulose are of high concern in skin repair. Gelatin, derived from partial hydrolysis of collagen, is one of the commonly used natural polymers. Its low molecular weight can make electrospinning more stable and the nanofibers have smoother and uniform morphology. It also has many binding sites that are beneficial to cell adhesion, proliferation and differentiation [282, 283]. However, its poor mechanical properties limit its application in skin repair and even tissue engineering. In recent years, researchers have combined gelatin with keratin [284], PCL [285], PHB [286], PU [287] and so on to improve the mechanical properties of the materials, which has a wider application in skin repair. For example, Baghersad et al. [288] prepared gelatin/aloe vera/PCL composite scaffolds using double-nozzle electrospinning technology, studied the effect of parameters on the performance and morphology of nanofibers. They found the materials had high antibacterial activity against both Gram-positive and Gram-negative bacteria, while improving the cell activity of NIH $3 \mathrm{~T} 3$ fibroblast cells. In addition, Adeli-Sardou et al. [285] prepared nanofibers using coaxial electrospinning with PCL as shell polymer and gelatin-lawsone blend as core polymer, and found that they could significantly improve the biological activity of human gingiva fibroblast cells (HGF) and promote cell adhesion and proliferation. Then the in vitro gene expression of transforming growth factor $\beta$ (TGF-B1), collagen (COL1) and epidermal growth factor (EGF) was monitored using RTqPCR technique, and it was believed the material could effectively promote the regeneration of skin tissue. Shi et al. [289] prepared nanofiber membranes by mixing trimethoxysilylpropyl octadecyldimethyl ammonium chloride (QAS) with PCL/gelatin 


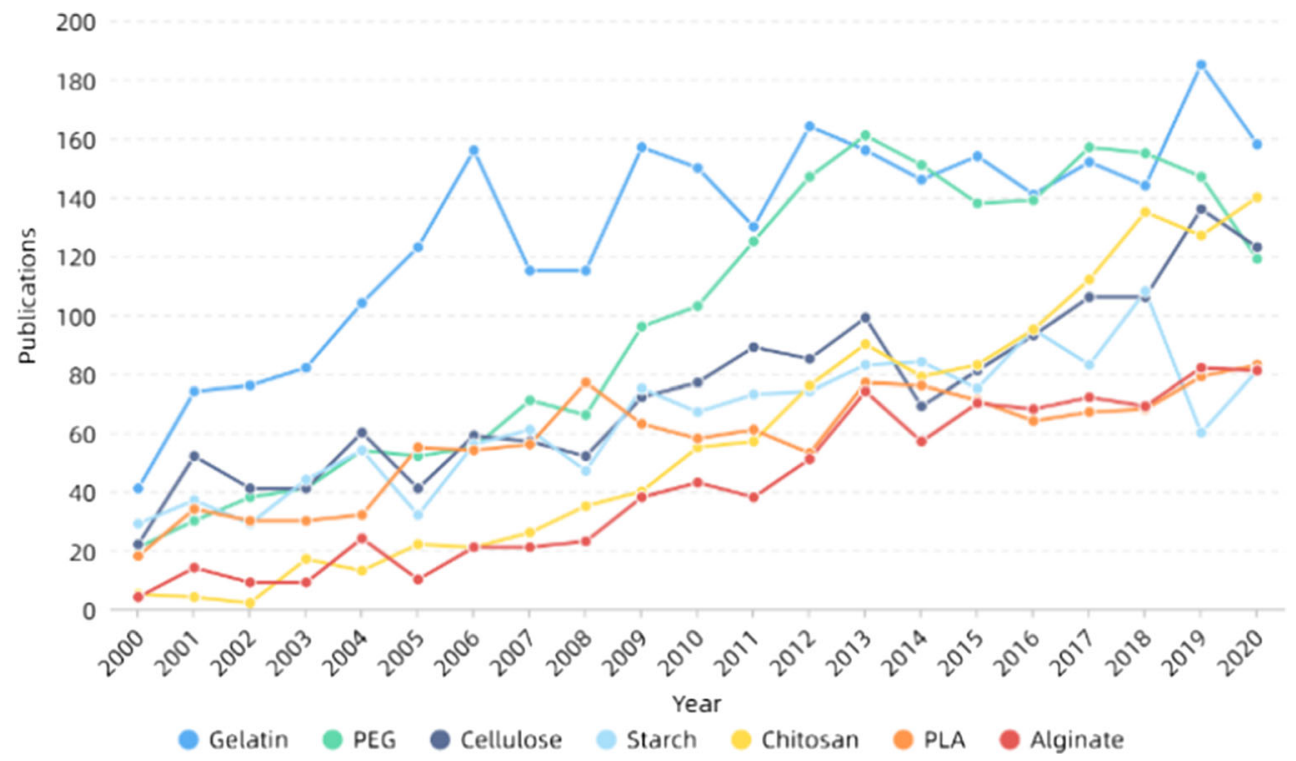

Figure 15 Number of publications of some blood vessel repair materials. All the data used are from web of science. The functions we used are analyze results and create citation report.

solution, and phase separation occurred. The nanofibers were mainly PCL inside and gelatin outside. The materials had broad-spectrum bactericidal effect and had no toxic side effects to L929 cells. They were suitable for use as skin antimicrobial materials.

Blood vessels In recent years, cardiovascular disease has been the leading cause of death among noncommunicable diseases. Atherosclerosis is one of the main causes of cardiovascular diseases [316]. The arteries are mainly composed of three layers: the tunica intima, the tunica media and the tunica adventitia. Among them, the tunica intima is the main part of vascular repair materials [317]. Electrospinning has been extensively used in vascular repair because of its controllable diameter and porosity of the prepared nanofibers [317-319]. Besides biocompatibility and mechanical properties, vascular repair materials also need to prevent thrombosis and vascular calcification [320, 321]. Some recent progress in electrospinning of blood vessels are listed in Table 3. It can be seen from Fig. 15 that the heat of gelatin in vascular repair has remained high, while PEG has been on the top in recent years and received extensive attention. PEG is a synthetic polymer with good biocompatibility. However, their biodegradability and mechanical strength are not ideal $[322,323]$. But relative to blood vessels, PEG has excellent hemocompatibility, can inhibit hemolysis and has a certain anticoagulant capacity, can inhibit thrombosis, so it is suitable for use as a vascular repair material [324-327]. Yin et al. [328] used PEGylated chitosan and PLCL mixed solution as the inner layer and PLCL/PEG as the outer layer, and prepared nanofiber materials by coaxial electrospinning technology. They found the mechanical properties were good, the strength was higher than that of human blood vessels, the compliance was close to human blood vessels, and the degradation rate was appropriate. The patency of the material was studied by femoral artery replacement model, and the positive endothelial cells and smooth muscle cells grew well, with high levels of related protein expression and good calcification, and are suitable for vascular repair.

Nerves Neural repair is an important component of tissue engineering, which is closely related to everyone's life [344-346]. The directionally aligned nanofibers prepared by electrospinning technology are conducive to the growth of nerve cells [347] and may have a good effect on cell synapses, which can be well applied in nerve tissue repair. Besides orientation, both morphology and surface coating of nanofibers affect nerve regeneration [348-350]. Some recent progress in electrospinning of nerves is listed in Table 4. Figure 16 shows that there are many kinds of nerve repair materials without obvious concentration, among which chitosan and cellulose have become the hot spots in recent years. Interestingly, these two materials are the two most abundant 
Table 4 Some progress of electrospinning in nerves in recent years

\begin{tabular}{|c|c|c|c|c|c|c|}
\hline Material & Solvent & $\begin{array}{l}\text { Flow rate } \\
(\mathrm{mL} / \mathrm{h})\end{array}$ & $\begin{array}{l}\text { Distance } \\
(\mathrm{cm})\end{array}$ & $\begin{array}{l}\text { Voltage } \\
(\mathrm{kV})\end{array}$ & Cells & Reference \\
\hline PLGA/Nimodipine & THF/DMF & $0.5-1$ & $10-15$ & $4.5-9$ & $\begin{array}{l}\text { SW10/RN33B/C8- } \\
\text { D1A }\end{array}$ & {$[359]$} \\
\hline PLLA & Chloroform & 2.08 & 5 & 15 & Dorsal root ganglia & {$[360]$} \\
\hline $\begin{array}{l}\text { PVA/poly(glycerol sebacate)/Kraft } \\
\text { lignin nanoparticle }\end{array}$ & Water/DMF & 0.5 & 30 & 19 & PC12 & {$[361]$} \\
\hline PDLLA $/ \beta-T C P /$ collagen & DCM/ethyl acetate & 0.8 & 15 & 3 & RSC96 & {$[362]$} \\
\hline PCL & Methanol/chloroform & 5 & 20 & 12 & $\begin{array}{l}\text { Schwann cells/dorsal } \\
\text { root ganglions }\end{array}$ & [363] \\
\hline PGS/PLLA & $\mathrm{DMF} / \mathrm{DCM}$ & 0.5 & 15 & 25 & A59 & {$[364]$} \\
\hline PLLA/NGF/VEGF & $\begin{array}{l}\text { Dichloromethane/span- } \\
\text { 80/methanol/water }\end{array}$ & 0.8 & 12 & 16 & iPSCs-NCSCs & {$[365]$} \\
\hline PLA/cellulose acetate & 1, 4-dioxane/acetone & 1 & 10 & 18 & Schwann cells & [366] \\
\hline PCU & $\mathrm{DMF} / \mathrm{THF}$ & 1 & 15 & 20 & DPSCs & [367] \\
\hline PCL/collagen/nano bioglass & Acetic acid & 1 & 8 & $15-18$ & hEnSCs & [368] \\
\hline PVDF/gold colloidal nanoparticles & DMAC/acetone & 0.5 & 18 & 15 & PC-12 & [369] \\
\hline Silk fibroin/PEO & Water & 1.2 & 14 & 12 & Schwann cells & {$[370]$} \\
\hline PLLA/gum tragacanth & HFP & 1 & 14 & 13 & $\mathrm{PC} 12$ & {$[371]$} \\
\hline $\begin{array}{l}\text { PGS-poly(ethylene glycol) methyl } \\
\text { ether methacrylate copolymers }\end{array}$ & HFP & 1 & 15 & 10 & $\mathrm{PC} 12$ & [372] \\
\hline PS & THF/DMF & 0.2 & $4-5$ & $5-14$ & U373 & [373] \\
\hline PELA-PPY & Trifluoroethanol & 1 & 15 & 20 & PC-12 & [374] \\
\hline
\end{tabular}

Figure 16 Number of publications of some nerve repair materials. All the data used are from web of science. The functions we used are analyze results and create citation report.

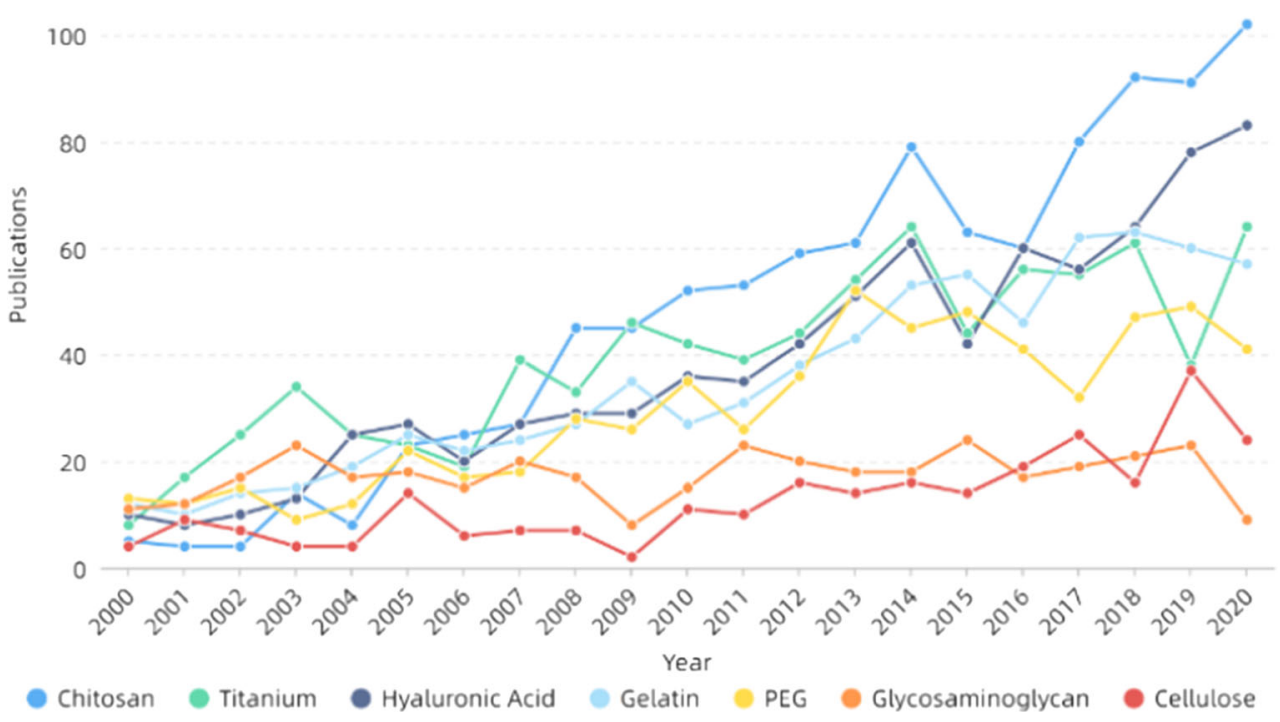

polymers in nature [351, 352]. Cellulose is a natural polymer produced by photosynthesis and is the most abundant polymer in nature. It can be converted into many derivatives, such as cellulose esters and cellulose ethers, which have good biocompatibility [353-355], and have better mechanical properties of other natural polymers [356], which are suitable for nerve conduit materials. Hou et al. [357] prepared PLGA outer conduit by electrospinning technology to bridge the sciatic nerve and then prepared oxidized bacterial cellulose-collagen sponge fillers by freezedrying technology to facilitate nerve regeneration 
Table 5 Some progress of electrospinning in drug delivery in recent years

\begin{tabular}{|c|c|c|c|c|c|c|c|}
\hline Material & Solvent & $\begin{array}{l}\text { Flow } \\
\text { rate } \\
(\mathrm{mL} / \mathrm{h})\end{array}$ & $\begin{array}{l}\text { Distance } \\
(\mathrm{cm})\end{array}$ & $\begin{array}{l}\text { Voltage } \\
(\mathrm{kV})\end{array}$ & Type & Drug & Reference \\
\hline Cellulose acetate/gliadin & HFIP/TFA & $0.1-0.5$ & 20 & 15 & Coaxial & Ferulic acid & [396] \\
\hline Hydroxypropyl-beta-cyclodextrin & Water & 0.5 & 15 & 15 & Blend & Ibuprofen & [397] \\
\hline PLA/PVP/multiwall carbon nanotubes & $\mathrm{DMF} / \mathrm{THF}$ & $0.3-1$ & 22.5 & 15 & Blend & $\begin{array}{l}\text { Tetracycline } \\
\text { hydrochloride }\end{array}$ & [398] \\
\hline PCL/PEO & $\mathrm{DCM} / \mathrm{DMF}$ & $0.1-0.6$ & $10-15$ & $12 / 15$ & Blend & Doxycycline & [399] \\
\hline poly(glycolide- $\varepsilon$-caprolactone)/PLGA & $\mathrm{DCM}$ & 2 & 15 & 20 & Blend & $\begin{array}{l}\text { papaverine } \\
\text { hydrochloride }\end{array}$ & [400] \\
\hline $\begin{array}{l}\text { Poly(N-isopropylacrylamide)/Eudragit } \\
\text { L100-55 }\end{array}$ & Ethanol & 1 & 20 & 16 & Blend & Ketoprofen & {$[401]$} \\
\hline $\begin{array}{l}\text { Carboxylated cellulose } \\
\text { nanocrystals/cellulose acetate }\end{array}$ & $\begin{array}{l}\text { acetone/ } \\
\text { DMAc }\end{array}$ & 1 & 15 & 25 & Blend & $\begin{array}{l}\text { Tetracycline } \\
\text { hydrochloride }\end{array}$ & {$[402]$} \\
\hline $\mathrm{PLA} / \mathrm{PCL}$ & DCM/DMF & 2 & 15 & $20 / 25$ & Blend & $\begin{array}{l}\text { Bovine serum } \\
\text { albumin }\end{array}$ & {$[403]$} \\
\hline PCL & $\begin{array}{l}\text { Chloroform/ } \\
\text { methanol }\end{array}$ & 2 & 15 & 10 & Blend & Cilostazol & [404] \\
\hline Silk fibroin/gelatin & Formic acid & 0.3 & 10 & 20 & Blend & $\begin{array}{l}\text { Thyme essential } \\
\text { oil/doxycycline } \\
\text { monohydrate }\end{array}$ & {$[405]$} \\
\hline $\begin{array}{l}\text { Sodium carboxymethyl cellulose/methyl } \\
\text { acrylate/PEO }\end{array}$ & $\begin{array}{l}\mathrm{DMF} / \\
\text { chloroform/ } \\
\text { methanol }\end{array}$ & 3 & 18 & 18 & Coaxial & $\begin{array}{l}\text { Tetracycline } \\
\text { hydrochloride }\end{array}$ & {$[406]$} \\
\hline PVA/chitosan/functionalized graphene oxide & Acetic acid & 0.6 & 14 & 22 & Blend & Curcumin & {$[407]$} \\
\hline $\begin{array}{l}\text { Ethyl hydroxy ethyl cellulose or } \\
\text { hydrophobically modified ethyl hydroxy } \\
\text { ethyl cellulose/PVA/citric acid }\end{array}$ & THF & 0.2 & 15 & 27 & Blend & $\begin{array}{l}\text { Chlorhexidine } \\
\text { Digluconate }\end{array}$ & {$[408]$} \\
\hline PLA/PVA & $\begin{array}{l}\mathrm{DMF} / \\
\text { chloroform }\end{array}$ & 1.5 & 9 & 15 & Blend & Dexamethasone & [409] \\
\hline $\begin{array}{l}\text { Sodium carboxymethyl cellulose/PEO/ } \\
\text { methyl acrylate }\end{array}$ & $\begin{array}{l}\text { DMF/ } \\
\text { chloroform/ } \\
\text { methanol }\end{array}$ & $3 / 0.4$ & 18 & 15 & $\begin{array}{c}\text { Coaxial/ } \\
\text { Blend }\end{array}$ & $\begin{array}{l}\text { Tetracycline } \\
\text { hydrochloride }\end{array}$ & {$[406]$} \\
\hline PCL-PEG-PCL & DCM/hexane & 6 & 12 & 18 & Blend & $\begin{array}{l}\text { Magnetic iron } \\
\text { oxide } \\
\text { nanoparticles }\end{array}$ & {$[410]$} \\
\hline $\begin{array}{l}\text { Poly }(3- \\
\text { hydroxybutyrate-co-3- } \\
\text { hydroxyvalerate)/cellulose nanocrystals }\end{array}$ & $\begin{array}{l}\mathrm{DMF} / \\
\text { chloroform/ } \\
\text { acetone }\end{array}$ & 1 & 18 & 15 & Blend & $\begin{array}{l}\text { Tetracycline } \\
\text { hydrochloride }\end{array}$ & [411] \\
\hline PVA/montmorillonite & Acetic acid & $1-10$ & $10-25$ & $10-25$ & Blend & $\begin{array}{l}\text { Bovine serum } \\
\text { albumin }\end{array}$ & [412] \\
\hline Zein & Ethanol & 0.12 & 12 & 24 & Blend & Progesterone & [413] \\
\hline Glutinous rice starch/PVA & Water & 0.3 & 15 & $18-20$ & Blend & $\begin{array}{l}\text { Chlorpheniramine } \\
\text { maleate }\end{array}$ & [414] \\
\hline PEG/PLGA/Au@Fe2O3 nanoparticles & DMF/DCM & 1 & 15 & 30 & Coaxial & Silibinin & {$[415]$} \\
\hline PLLA & HFIP & 0.6 & 12 & 15 & Blend & Lovastatin & {$[416]$} \\
\hline TPU & DMF & 1 & 20 & 13 & Blend & Naproxen & {$[417]$} \\
\hline PCL/gum tragacanth & Acetic acid & 1 & 15 & 15 & Blend & Curcumin & [418] \\
\hline Chitosan/phospholipids & TFA/DCM & 1.2 & 10 & 25 & Blend & $\begin{array}{l}\text { Vitamin B12/ } \\
\text { curcumin/ } \\
\text { diclofenac }\end{array}$ & [419] \\
\hline
\end{tabular}


Table 5 continued

\begin{tabular}{|c|c|c|c|c|c|c|c|}
\hline Material & Solvent & $\begin{array}{l}\text { Flow } \\
\text { rate } \\
(\mathrm{mL} / \mathrm{h})\end{array}$ & $\begin{array}{l}\text { Distance } \\
(\mathrm{cm})\end{array}$ & $\begin{array}{l}\text { Voltage } \\
(\mathrm{kV})\end{array}$ & Type & Drug & Reference \\
\hline PCL & $\begin{array}{c}\text { Chloroform/ } \\
\text { methanol }\end{array}$ & $0.5 / 0.6$ & 9 & 12 & Coaxial & Ampicillin & [420] \\
\hline PU/hydroxypropyl cellulose & DMF & 1 & 15 & 15 & Blend & Donepezil & [421] \\
\hline PVA/collagen & Acetic acid & 0.4 & 15 & 18 & Blend & Salicylic acid & [422] \\
\hline PVA/sodium alginate & Water & 0.3 & 10 & 14 & Blend & $\begin{array}{l}\text { Moxifloxacin } \\
\text { hydrochloride }\end{array}$ & [423] \\
\hline Gelatin & Acetic acid & 0.3 & 10 & 12 & Blend & Piperine & [424] \\
\hline
\end{tabular}

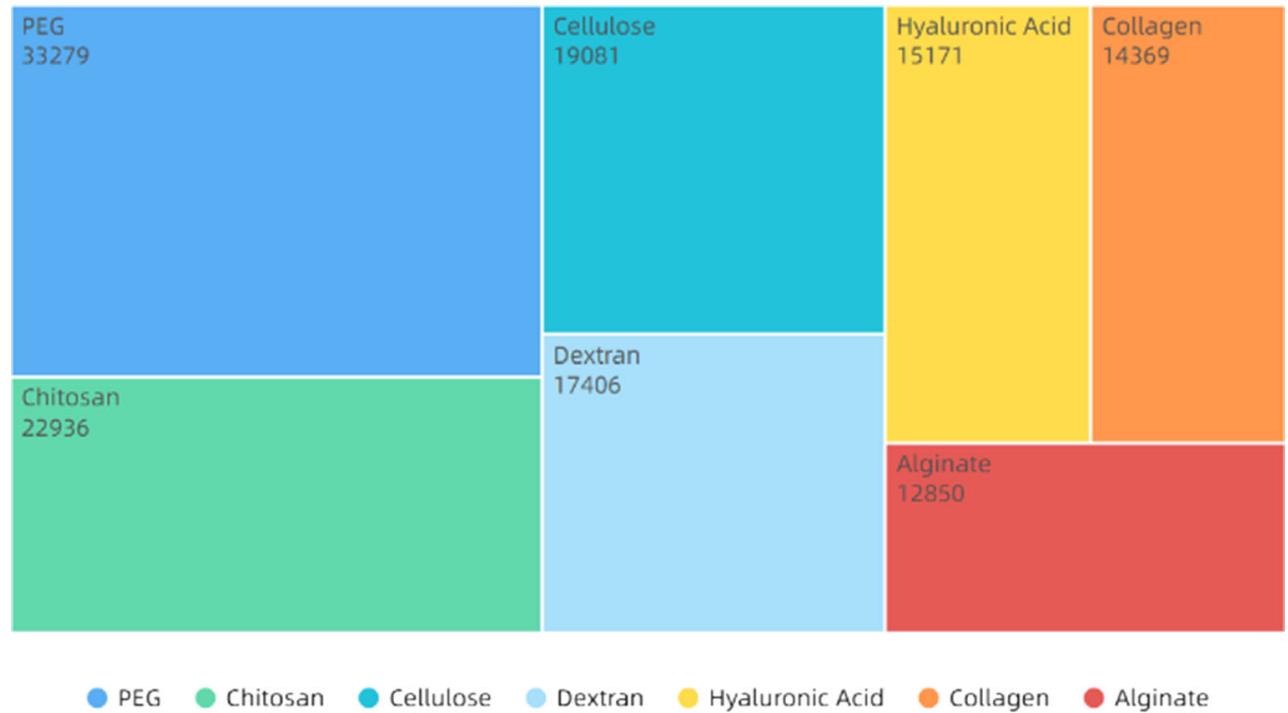

Figure 17 Publications of drug delivery materials. All the data used are from web of science. The functions we used are analyze results and create citation report.

across the injured nerve gap. When combined into nerve conduit, it can increase the efficiency of gap bridge rebuilding and effectively promote the functional restoration of gastrocnemius muscle. Farzamfar et al. [358] mixed gelatin and cellulose for electrospinning and added gabapentin, a drug that can promote nerve remyelination, and found that it can improve the activity of Schwann cells and promote their proliferation. The regeneration effect of sciatic nerve was indirectly evaluated using rat gastrocnemius muscles and found the material can improve the regeneration ability of the injured site. However, the porosity of this material does not meet the requirements of ideal scaffolds.

\section{Drug delivery}

Drug delivery refers to the use of carriers to transport drugs or biomolecules to certain areas, controllably release drugs and improve regional drug concentration [375-377]. Nanofibers have many advantages, such as large specific surface area, high drug loading, high porosity, high mechanical strength, easy surface modification and functionalization, and have been widely used to treat various diseases [378-380]. The diameter, porosity and drug binding mechanism of nanofibers all affect the drug release rate [102, 381-383]. There are two main methods, hybrid electrospinning and coaxial electrospinning, to combine drugs, as shown in Table 5 [384, 385]. As shown Fig. 17, PEG and chitosan are the main materials for 


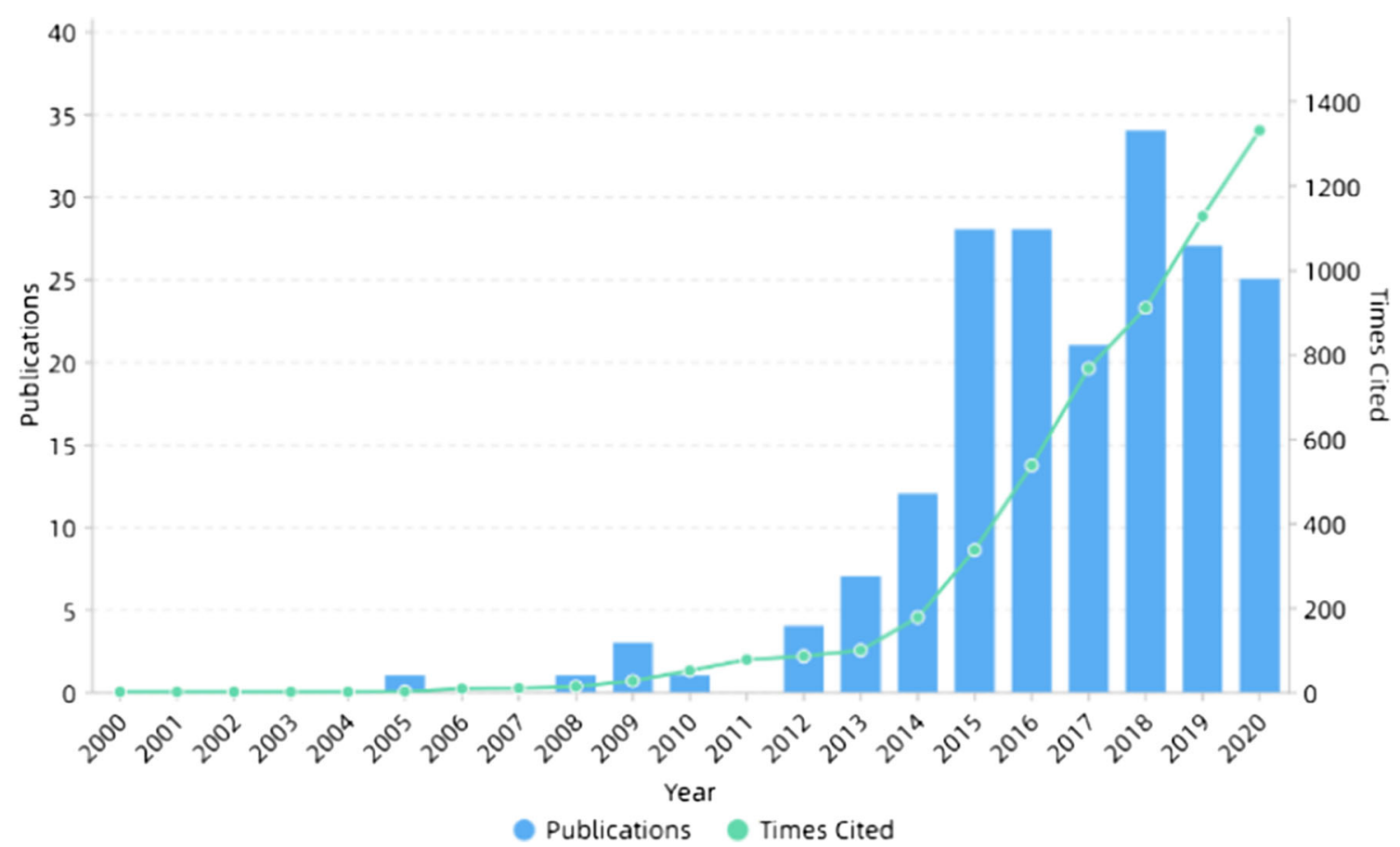

Figure 18 Number of publications and times cited on electrospinning in diagnosis. All the data used are from web of science. The functions we used are analyze results and create citation report.

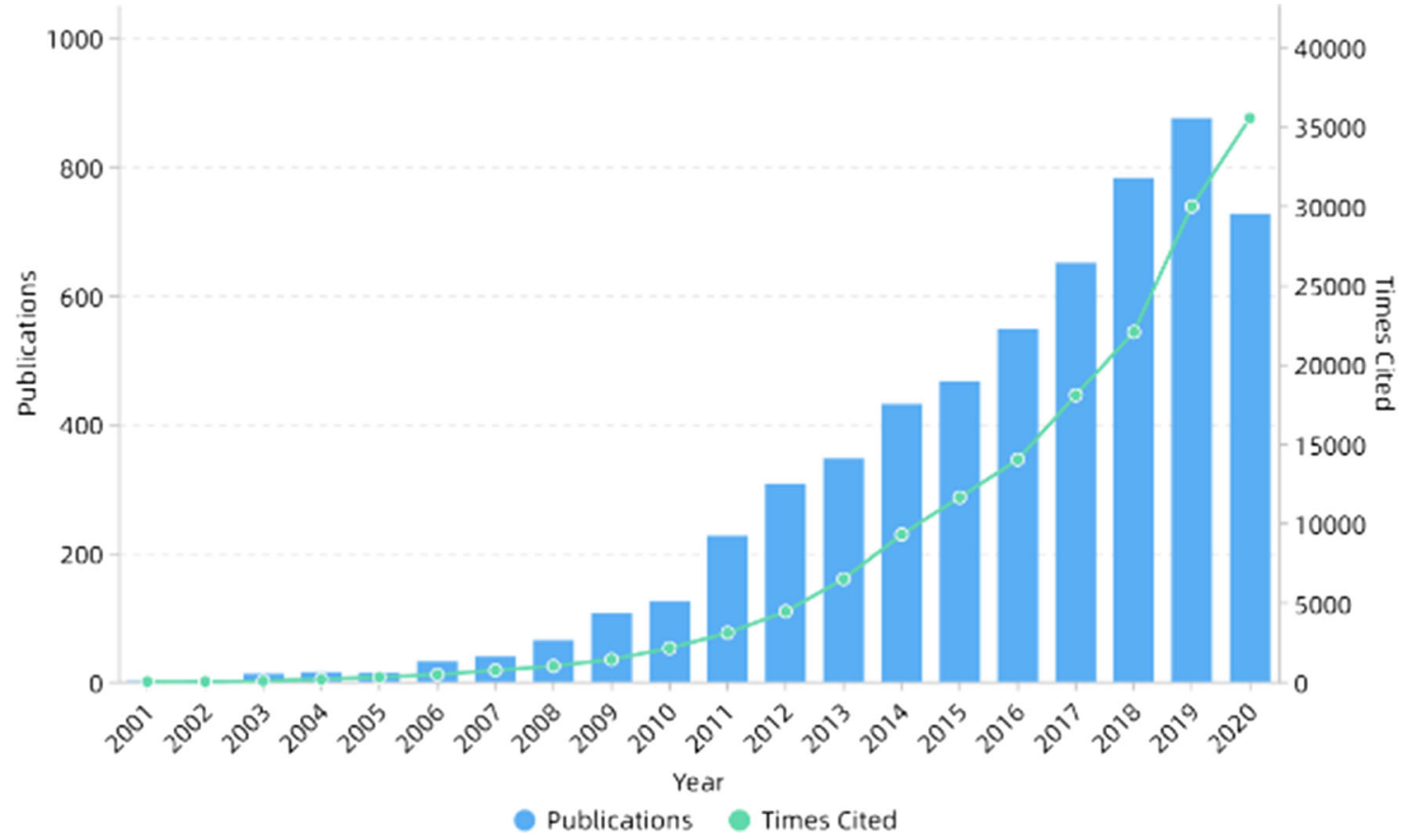

Figure 19 Number of publications and times cited on electrospinning in energy. All the data used are from web of science. The functions we used are analyze results and create citation report.

drug delivery. Chitosan, a polysaccharide made by deacetylation of chitin, has been used in drug delivery in various forms such as films [386], microspheres
[387], hydrogels [388] and nanofibers [389]. However, electrospinning of chitosan is difficult and needs to be compounded with other materials, such as PVA 


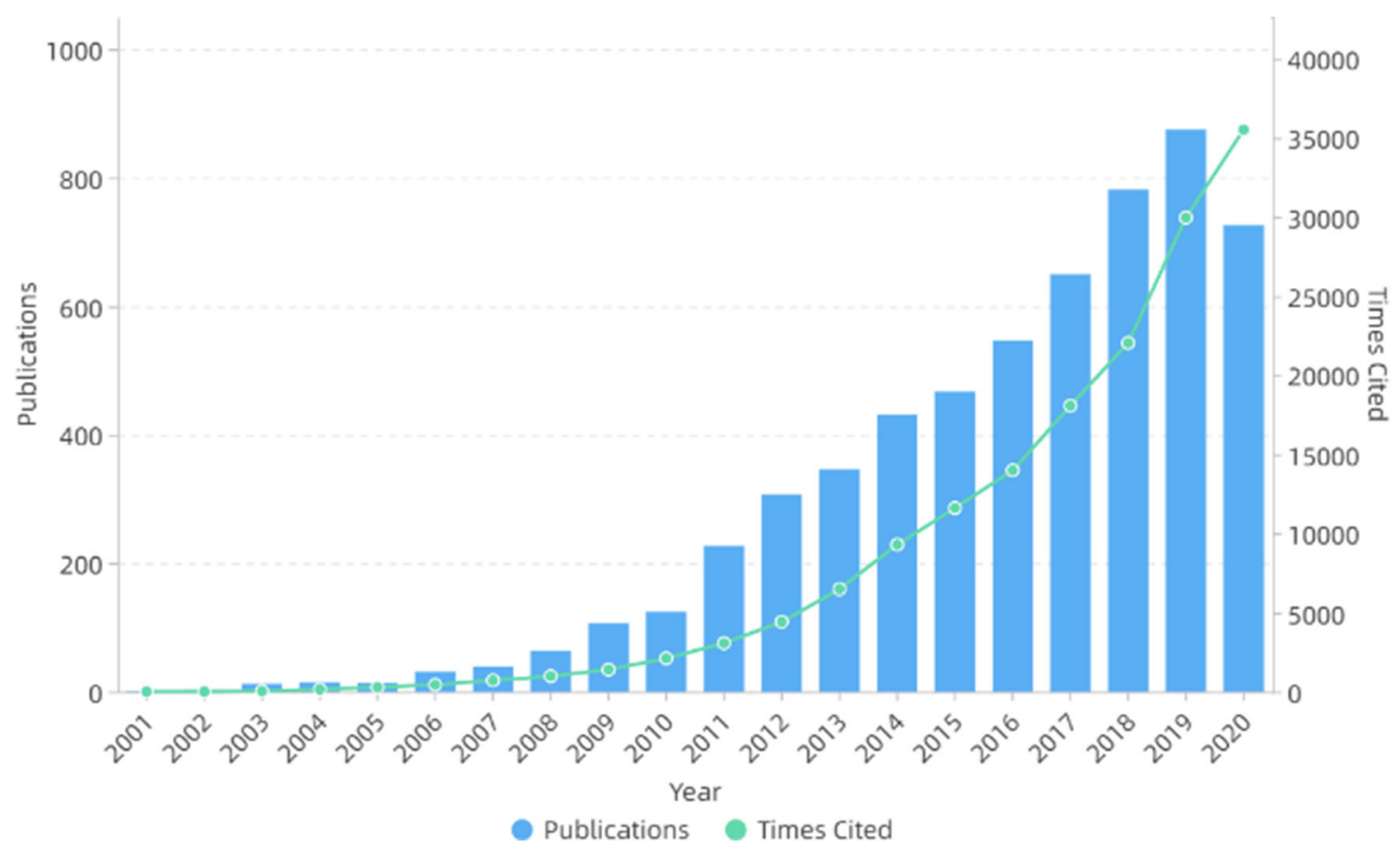

Figure 20 Number of publications and times cited on electrospinning in catalysis. All the data used are from web of science. The functions we used are analyze results and create citation report.

[390], pullulan [391] and xanthan gum [392]. Using electrospinning PVA/chitosan-loaded tetracycline hydrochloride (TCH), Alavarse et al. [393] found the drug could be evenly distributed and the material had good antibacterial property and cell compatibility. Balagangadharan et al. [394] developed a new approach by using ionic gelation technique to prepare sinapic acid/chitosan nanoparticles loaded on electrospun PCL nanofibers, which could promote the differentiation of osteoblasts, increase the expression levels of ALP, type Icollagen and osteocalcin. They further analyzed the effects of materials on the osteogenesis process and found that they actived various signaling pathways, such as TGF- $\beta$, BMP and FGF2. The calvarial bone defects in rats also showed the effect of materials to promote bone regeneration. In addition, Fazli et al. [395] mixed fumed silica nanoparticles with cefazolin and added them into chitosan-PEO solution for electrospinning to obtain nanofibrous mats. The results showed that drug molecules were coated by nanoparticles, and the nanofiber membranes had higher thermal stability, acid-base stability, tensile strength and better antimicrobial effect, and can promote skin healing.

\section{Diagnosis}

Medical diagnosis is of great importance in the early stage of disease. Medical diagnostic indicators are characterized by specificity and sensitivity. Biosensors are important in medical diagnosis. They have the advantages of low cost, fast detection speed, convenience and small side effects. The high specific surface area of nanofibers can improve the detection sensitivity. The biosensors prepared by electrospinning nanofibers mainly include electrochemical biosensors, organic gas sensors, fluorescent chemical sensors and immunosensors. As shown in Fig. 18, there are more researches on the application of electrospinning technology in medical diagnosis this year. Electrochemical sensors are mainly used for the molecular biological detection of glucose [425-427], proteins [428-430] and genes [431], which are generally composed of the working electrode, counter electrode and reference electrode [432]. Organic gas sensors mainly sense some specific volatile organic compounds, such as aromatic amines [433], acetaldehyde [434] and ammonia. They can be used for the diagnosis of lung cancer, kidney disease $[435,436]$ and so on. Cancer cells can also be diagnosed by detecting the oxygen concentration [437, 438]. Using tin dioxide and PEO as raw 
materials, Mehrabi et al. [439] developed a sensor for methanol and tetrahydrocannabinol (THC) by electrospinning, which can recognize smokers. Fluorescent chemical sensors are mainly used to detect amines in solution [440]. Immunosensors target antigens and antibodies [440]. In addition, Zhao et al. [441] developed a pulse measurement device that can be used to monitor heart rate using the piezoelectric characteristics of PLLA nanofibers along the fiber direction (d33). For cancer cells, targeting molecules include antibodies [442], DNA aptamers [443], E-selectins [444] and peptides, and modification methods include covalent coupling [445] and biotin-streptavidin-specific binding [446]. However, because targeting molecules mostly employed for only a single phenotype of cancer cells, the capture efficiency for multiple types of cancer cells is limited [446]. Pimentel et al. [447] developed a PLLA membranebased microfluidic substrate for colorimetric detection of glucose, which has many advantages over conventional paper-based substrates. Xu et al. [448] developed a hyaluronic acid and PLGA nanofibers microfluidic chip that can selectively capture CD44 + carcinoma of various origins, especially for HeLa cancer cells and its effectiveness, which can be separated for further analysis.

\section{Energy}

Nanomaterials are considered as good advanced materials in the energy field because of their good interfacial chemical reaction rate and easy conduction of charges because of nanosize effect [449-451]. In recent years, there have been many review articles on the application of electrospun nanofibers in energy, which have attracted much attention as shown in Fig. 19 [62, 452-456]. New devices in the energy field include solar cells, fuel cells, lithium-based batteries, sodium-ion batteries and supercapacitors. Lithiumion batteries, lithium-sulfur batteries and lithiumoxygen batteries, collectively known as lithium-based batteries, are one of the most important energy storage devices. The advantages of nanofibers, such as electrochemical activity, mechanical strength, specific surface area and porosity, indicate that they can improve many shortages of traditional energy storage devices. $\mathrm{Wu}$ et al. [457] constructed a core-shell structure of silicon/honeycomb-like carbon framework composite fibers using coaxial electrospinning technology, which showed stable cycle performance and high specific capacity, and was a good anode material. Darbar et al. [458] compared the differences between oxalate decomposition method and electrospinning method for preparing magnesium cobalt oxide negative electrode material, and found the negative electrode material prepared by electrospinning method had better cycling performance. Fuel cells include proton exchange membrane fuel cells, methanol fuel cells, alkaline fuel cells, phosphoric acid fuel cells, solid oxide fuel cells and molten carbonate fuel cells. Park et al. [459] prepared perfluorosulfonic acid (PFSA)/polyphenylsulfone (PPSU) composite nanofiber membranes with high ion conductivity, which are good electrode materials for fuel cells. Supercapacitors can be divided into electrical double-layer supercapacitors and pseudocapacitors (Faradaic supercapacitors) [460]. Kabir et al. [461] studied $\mathrm{Fe}-\mathrm{N}-\mathrm{C}$ platinum group metal-free nanofiber electrodes and found the electric double-layer capacitance increased, the electrode proton transport reduced, and the bulk electrode gas transport properties improved significantly. Pant et al. [462] also studied the electrode materials of supercapacitors. They used titanium dioxide nanoparticles embedded in carbon nanofibers, and their performance was improved. Li et al. [463] prepared ordered mesoporous carbons fiber webs using low molecular resin as carbon precursors, F127 as structure directed agent and PVP as fiber forming agent. They can be directly used as electrode materials of supercapacitor without binders or conductive additives and has high specific capacitance. In addition, the characteristics of electrospun nanofibers make them widely used in the field of oil-water separation. The oil-water separation permeability of electrospinning nanofiber membrane is high, the separation efficiency is high and the energy consumption is low [464]. Obaid et al. [465] incorporated $\mathrm{NaOH}$ nanoparticles into PSF nanofibers and a layer of polyamide film on the surface of PSF nanofiber mats by interfacial polymerization of MPD and TMC. The results show that the contact angle of the modified membrane is obviously reduced, and the membrane has good hydrophilicity and permeability, high water flux and can be reused. Li et al. [466] prepared two smart membranes through solution-casting method and electrospinning technology, respectively, based on temperature-responsive copolymer PMMA- $b$-PNIPAAm and found that the electrospinning membrane has obvious advantages. 


\section{Catalysis}

In recent years, there are more and more applications of electrospinning in catalysis, as shown in Fig. 20. Because the morphology, particle size and structure of the catalyst will affect its activity, the specific surface area, pore size, porosity and uniformity of electrospun nanofibers have great advantages. Some nanofibers can be directly used as catalysts after chemical treatment. In addition, catalyst immobilization on the surface of nanofibers is also widely used [467]. Nanofiber catalysts can be mainly divided into polymers, metals and oxides according to the materials. Nanofibers can immobilize enzymes [468], metals [469] and oxides [67, 470, 471]. Ternero-Hidalgo et al. [472] prepared $\mathrm{V}-\mathrm{Zr}-\mathrm{O}$ submicron fibers by electrospinning, which can be widely used in partial oxidation of alkanes. Lu et al. [473] prepared PAN/iron nitrate nanofibers and then converted them into carbon/iron nanofibers by one-pot carbonization process, which can be used as nanoadsorbents for $\mathrm{Cr}(\mathrm{VI})$. Xu et al. [474] prepared cellulose nanofibers and then deposited silver nanoparticles on the surface of the fibers, which was conducive to the reduction of $p$-nitrophenol. In addition, Hu et al. [475] used electrospun PVA/PEI nanofibers loaded with $\mathrm{Au} / \mathrm{Ag}$ bimetallic nanoparticles to reduce 4-nitrophenol. Ma et al. [470] prepared $\mathrm{PVP} /\left[\mathrm{PW}_{12-}\right.$ $\left.+\mathrm{Ti}\left(\mathrm{OC}_{4} \mathrm{H}_{9}\right)_{4}\right]$ composite nanofibers, which showed good desulfurization catalytic performance. $\mathrm{NiO}$ nanofibers were prepared by Hosseini et al. [476], which were effective for ethylene glycol oxidation after modification of carbon paste electrodes. Hosseini et al. [67] also prepared $\mathrm{PVA} / \mathrm{Cu}(\mathrm{OAc})_{2^{-}}$ $\mathrm{Ni}(\mathrm{OAc})_{2}$ composite nanofibers to improve the electrocatalytic activity of the modified electrode. Interestingly, Chen et al. [477] prepared a kind of Fe3O4 nanofibers as peroxidase mimics with good catalytic activity for the oxidation of 3,3',5,5'-tetramethylbenzidine (TMB) by hydrogen peroxide.

\section{Conclusion}

Over the past years, because of the rapid development of nanotechnology, electrospinning as a nanomaterial processing technology has been widely used in various fields, especially in tissue engineering. The outbreak of COVID-19 brings opportunities for electrospinning nanofibers. Researchers have found that the nanofibers as active layers in face mask can protect people from the coronavirus disease (COVID19)[478]. Some scholars summarized the advantages and prospects of the application of electrospun nanofibers in advanced face masks [479]. Electrospinning has the characteristics of wide source of raw materials, simple process, small fiber diameter, small pore size and high porosity, and can be used as the preferred method for researchers to prepare nanofibers. In addition, researchers can also control the morphology and diameter of nanofibers by adjusting parameters, including solution parameters, processing parameters and ambient parameters. However, the influence of some parameters on nanofibers is still controversial, such as the effect of applied voltage on fiber diameter. However, in general, electrospinning has made some progress and applications in biomedicine, energy and catalysis in recent years. Among these, researchers paid more attention to natural polymers, such as gelatin, chitosan and the composite of synthetic polymers, which can improve the biological and mechanical properties of materials at the same time. In addition, electrospinning has a set of physical theories to simulate the process of electrospinning and the influence of research parameters on nanofibers, not only in experiments, but also in theoretical research. With the development of computer technology, artificial intelligence and big data, it is believed the simulation method will be more applied in electrospinning technology to control and predict the morphology and performance for complex processes and parameters. However, although electrospinning has received more and more attention and research, this technology still has many shortcomings and development space, such as: (a) In principle, the influence of some parameters on electrospun nanofibers is not clear, such as the applied voltage, the optimal value of each parameter of each material is a complex but meaningful study. (b) As for equipment, the production speed of electrospinning is still a disadvantage to limit its large-scale production and application. Some researchers believed the productivity of nanofibers increases with the number of needles, but in fact, the space occupied by the nozzles will also increase, the cost will be higher, and there will be electric field interference between the nozzles. (c) The choice of solvent also made researchers distressed, because most of the organic solvents are biotoxic, although in the later process can be removed by various means, but there are still concerns for 
consumers. (d) Although electrospinning is widely used in many fields, it has not been applied to all aspects of life, such as magnetic properties of electrospun nanofibers, gradient scaffold materials and semiconductor-related applications. In this paper, the parameters, models, simulation and applications of electrospinning technology are discussed and summarized. It is hoped that these information can help researchers develop ideas and make progress in scientific research.

\section{Acknowledgements}

This work was supported by the National Key R\&D Program of China (No. 2017YFC1103800), the Major special projects of technological innovation of Hubei Province (No. 2017ACA168) and the Foshan Xianhu Laboratory of the Advanced EnergyScience and Technology Guangdong Laboratory (No. XHT2020010).

\section{Declarations}

Conflict of interest The authors have declared no conflicts of interest for this article.

\section{References}

[1] Law M, Goldberger J, Yang P (2004) Semiconductor nanowires and nanotubes. Annu Rev Mater Res 34:83-122

[2] Bae C, Yoo H, Kim S, Lee K, Kim J, Sung MM, Shin H (2008) Template-directed synthesis of oxide nanotubes: fabrication, characterization, and applications. Chem Mater 20:756-767

[3] Comini E, Baratto C, Faglia G, Ferroni M, Vomiero A, Sberveglieri G (2009) Quasi-one dimensional metal oxide semiconductors: preparation, characterization and application as chemical sensors. Prog Mater Sci 54:1-67

[4] Rao C, Deepak FL, Gundiah G, Govindaraj A (2003) Inorganic nanowires. Prog Solid State Chem 31:5-147

[5] Ge M, Cao C, Huang J, Li S, Chen Z, Zhang K-Q, AlDeyab S, Lai Y (2016) A review of one-dimensional TiO 2 nanostructured materials for environmental and energy applications. J Mater Chem A 4:6772-6801

[6] Ge M, Li Q, Cao C, Huang J, Li S, Zhang S, Chen Z, Zhang K, Al-Deyab SS, Lai Y (2017) One-dimensional $\mathrm{TiO} 2$ nanotube photocatalysts for solar water splitting. Adv Sci 4:1600152
[7] Gong S, Cheng W (2017) One-dimensional nanomaterials for soft electronics. Adv Electron Mater 3:1600314

[8] Karnati P, Akbar S, Morris PA (2019) Conduction mechanisms in one dimensional core-shell nanostructures for gas sensing: a review. Sens Actuat B: Chem 295:127-143

[9] Sayin S, Ozdemir E, Acar E, Ince GO (2019) Multifunctional one-dimensional polymeric nanostructures for drug delivery and biosensor applications. Nanotechnology, 30, 412001

[10] Lu H, Wang J, Wang T, Zhong J, Bao Y, Hao H (2016) Recent progress on nanostructures for drug delivery applications. J Nanomat. https://doi.org/10.1155/2016/ 5762431

[11] Wu T, Ding M, Shi C, Qiao Y, Wang P, Qiao R, Wang X, Zhong J (2020) Resorbable polymer electrospun nanofibers: History, shapes and application for tissue engineering. Chin Chem Lett 31:617-625

[12] Rajgarhia S, Jana SC (2017) Influence of secondary stretching on diameter and morphology of bicomponent polymer nanofibers produced by gas jet fiber process. Polymer 123:219-231

[13] Ellison CJ, Phatak A, Giles DW, Macosko CW, Bates FS (2007) Melt blown nanofibers: fiber diameter distributions and onset of fiber breakup. Polymer 48:3306-3316

[14] Wang P, Wang Y, Tong L (2013) Functionalized polymer nanofibers: a versatile platform for manipulating light at the nanoscale. Light Sci Appl. https://doi.org/10.1038/1sa.2013. 58

[15] Ma B, Qin A, Li X, He C (2013) High tenacity regenerated chitosan fibers prepared by using the binary ionic liquid solvent (Gly. $\mathrm{HCl}$ )-[Bmim] $\mathrm{Cl}$. Carbohyd Polym 97:300-305

[16] Li G, Li P, Zhang C, Yu Y, Liu H, Zhang S, Jia X, Yang X, Xue Z, Ryu S (2008) Inhomogeneous toughening of carbon fiber/epoxy composite using electrospun polysulfone nanofibrous membranes by in situ phase separation. Comp Sci Technol 68:987-994

[17] Yin H, Strunz F, Yan Z, Lu J, Brochhausen C, Kiderlen S, Clausen-Schaumann H, Wang X, Gomes ME, Alt V (2020) Three-dimensional self-assembling nanofiber matrix rejuvenates aged/degenerative human tendon stem/progenitor cells. Biomaterials, 236, 119802

[18] Li Z, Mei S, Dong Y, She F, Kong L (2019) High efficiency fabrication of chitosan composite nanofibers with uniform morphology via centrifugal spinning. Polymers 11:1550

[19] Zhang N, Qiao R, Su J, Yan J, Xie Z, Qiao Y, Wang X, Zhong J (2017) Recent advances of electrospun nanofibrous membranes in the development of chemosensors for heavy metal detection. Small 13:1604293 
[20] Xu M, Wang M, Xu H, Xue H, Pang H (2016) Electrospuntechnology-derived high-performance electrochemical energy storage devices. Chem Asian J, 11, 2967-2995

[21] Cavaliere S (2015) Electrospinning for advanced energy and environmental applications. CRC Press, USA

[22] Cavaliere S, Subianto S, Savych I, Jones DJ, Rozière J (2011) Electrospinning: designed architectures for energy conversion and storage devices. Energy Environ Sci 4:4761-4785

[23] Teo WE, Ramakrishna S (2006) A review on electrospinning design and nanofibre assemblies. Nanotechnology 17:R89

[24] Ramakrishna S (2005) An introduction to electrospinning and nanofibers; World Scientific

[25] Sharma J, Lizu M, Stewart M, Zygula K, Lu Y, Chauhan R, Yan X, Guo Z, Wujcik EK, Wei S (2015) Multifunctional nanofibers towards active biomedical therapeutics. Polymers 7:186-219

[26] Strutt JW, Rayleigh L (1878) On the instability of jets. Proc London Math Soc. https://doi.org/10.1112/plms/s1-10.1.4

[27] Rayleigh L (1879) On the capillary phenomena of jets. Proceed Royal Soc 29:71-97

[28] Rayleigh LXX (1882) On the equilibrium of liquid conducting masses charged with electricity. Philosophic Mag Ser 14:184-186

[29] Strutt JWI (1879) The influence of electricity on colliding water drops. Proc R Soc Lond 28:405-409

[30] Cooley JF (1900) Improved methods of and apparatus for electrically separating the relatively volatile liquid component from the component of relatively fixed substances of composite fluids. United Kingdom Patent 6385:19

[31] Morton W (1902) Method of dispersing fluids US Patent Specification 705691

[32] Zeleny J (1920) Electrical discharges from pointed conductors. Phys Rev 16:102

[33] Zeleny J (1907) The discharge of electricity from pointed conductors differing in size. Phys Rev 25:305

[34] Zeleny J (1908) The influence of humidity upon the electrical discharge from points in air. Phys Rev 26:448

[35] Zeleny J (1908) The discharge of electricity from pointed conductors. Phys Rev 26:129

[36] Zeleny J (1914) The electrical discharge from liquid points, and a hydrostatic method of measuring the electric intensity at their surfaces. Phys Rev 3:69

[37] Zeleny J (1915) On the condition of instability of electrified drops, with applications to electrical discharge from liquid points. In Proceedings of the Proc. Camb. Phil. Soc., pp. $71-83$

[38] Anton F (1934) Process and apparatus for preparing artificial threads
[39] Anton F (1937) Production of artificial fibers

[40] Anton F (1938) Artificial fiber construction

[41] Anton F (1938) Method and Apparatus for the Production of Fibers

[42] Anton F (1939) Method of producing artificial fibers

[43] Anton F (1939) Method and apparatus for the production of artificial fibers

[44] Anton F (1943) Production of artificial fibers from fiber forming liquids

[45] Norton CL (1936) Method of and apparatus for producing fibrous or filamentary material

[46] Filatov Y, Budyka A, Kirichenko V (2007) Electrospinning of micro-and nanofibers: fundamentals in separation and filtration processes. J Eng Fibers Fabrics 3:488

[47] Taylor GI (1964) Disintegration of water drops in an electric field. Proc R Soc Lond 280:383-397

[48] Taylor, G.I.J.P.o.t.R.S.o.L.S.A.M. (1966) Sciences, P. The force exerted by an electric field on a long cylindrical conductor. Proceedings of the Royal Society of London, 291, 145-158

[49] Taylor GI (1969) Electrically driven jets. Proc R Soc Lond 313:453-475

[50] Simons HL (1966) Process and apparatus for producing patterned non-woven fabrics

[51] Baumgarten PKJJOC (1971) Electrostatic spinning of acrylic microfibers. J Coll Int Sci 36:71-79

[52] Annis D, Bornat A, Edwards R, Higham A, Loveday B, Wilson J (1978) An elastomeric vascular prosthesis. ASAIO J 24:209-214

[53] Larrondo L, John Manley R (1981) Electrostatic fiber spinning from polymer melts. I. experimental observations on fiber formation and properties. J Polym Sci Polym Phys Ed. https://doi.org/10.1002/pol.1981.180190601

[54] Larrondo L, John Manley R (1981) Electrostatic fiber spinning from polymer melts II Examination of the flow field in an electrically driven jet. J Polym Sci Polym Phys Ed. https://doi.org/10.1002/pol.1981.180190602

[55] Larrondo L, John Manley R (1981) Electrostatic fiber spinning from polymer melts Electrostatic deformation of a pendant drop of polymer melt. J Poly Sci Poly Phys Ed. h ttps://doi.org/10.1002/pol.1981.180190603

[56] Fisher A, De Cossart L, How T, Annis D (1985) Long term in-vivo performance of an electrostatically-spun small bore arterial prosthesis: the contribution of mechanical compliance and anti-platelet therapy. Life Supp Syst J Eur Soc Artif Org 3:462

[57] Reneker DH, Chun I (1996) Nanometre diameter fibres of polymer, produced by electrospinning. Nanotechnology $7: 216$ 
[58] Jirsak O, Sanetrnik F, Lukas D, Kotek V, Martinova L, Chaloupek J (2009) Method of nanofibres production from a polymer solution using electrostatic spinning and a device for carrying out the method

[59] Selvaraj S, Thangam R, Fathima NN (2018) Electrospinning of casein nanofibers with silver nanoparticles for potential biomedical applications. Int $\mathrm{J}$ Biol Macromol 120:1674-1681

[60] Ngadiman NHA, Yusof NM, Idris A, Misran E, Kurniawan D (2017) Development of highly porous biodegradable $\gamma$ Fe2O3/polyvinyl alcohol nanofiber mats using electrospinning process for biomedical application. Mater Sci Eng C 70:520-534

[61] Hemamalini T, Dev VRG (2018) Comprehensive review on electrospinning of starch polymer for biomedical applications. Int J Biol Macromol 106:712-718

[62] Liu Q, Zhu J, Zhang L, Qiu Y (2018) Recent advances in energy materials by electrospinning. Renew Sust Energy Rev 81:1825-1858

[63] Zhang Y, Liu X, Yu J, Fan M, Ji X, Sun B, Hu P (2019) Optimizing the dielectric energy storage performance in $\mathrm{P}$ (VDF-HFP) nanocomposite by modulating the diameter of PZT nanofibers prepared via electrospinning. Comp Sci Technol, 184, 107838

[64] Chen W, Weng W (2016) Ultrafine lauric-myristic acid eutectic/poly (meta-phenylene isophthalamide) formstable phase change fibers for thermal energy storage by electrospinning. Appl Energy 173:168-176

[65] Zhang T, Li H, Yang Z, Cao F, Li L, Chen H, Liu H, Xiong $\mathrm{K}$, Wu J, Hong Z (2019) Electrospun YMn2O5 nanofibers: a highly catalytic activity for NO oxidation. Appl Catal B 247:133-141

[66] Guo Z, Ye W, Fang X, Wan J, Ye Y, Dong Y, Cao D, Yan D (2019) Amorphous cobalt-iron hydroxides as high-efficiency oxygen-evolution catalysts based on a facile electrospinning process. Inorganic Chemistry Frontiers 6:687-693

[67] Hosseini SR, Ghasemi S, Kamali-Rousta M (2017) Preparation of $\mathrm{CuO} / \mathrm{NiO}$ composite nanofibers by electrospinning and their application for electro-catalytic oxidation of hydrazine. J Power Sources 343:467-476

[68] Huang X, Wang R, Jiao T, Zou G, Zhan F, Yin J, Zhang L, Zhou J, Peng Q (2019) Facile preparation of hierarchical AgNP-loaded MXene/Fe3O4/polymer nanocomposites by electrospinning with enhanced catalytic performance for wastewater treatment. ACS Omega 4:1897-1906

[69] Ge L, Yin J, Yan D, Hong W, Jiao T (2021) Construction of nanocrystalline cellulose-based composite fiber films with excellent porosity performances via an electrospinning strategy. ACS Omega 6:4958-4967
[70] Wang C, Sun S, Zhang L, Yin J, Jiao T, Zhang L, Xu Y, Zhou J, Peng Q (2019) Facile preparation and catalytic performance characterization of AuNPs-loaded hierarchical electrospun composite fibers by solvent vapor annealing treatment. Colloids Surf A Physicochem Eng Asp 561:283-291

[71] Liu Y, Hou C, Jiao T, Song J, Zhang X, Xing R, Zhou J, Zhang L, Peng QJN (2018) Self-assembled AgNP-containing nanocomposites constructed by electrospinning as efficient dye photocatalyst materials for wastewater treatment. Nanomaterials 8:35

[72] Huang X, Jiao T, Liu Q, Zhang L, Zhou J, Li B, Peng Q (2019) Hierarchical electrospun nanofibers treated by solvent vapor annealing as air filtration mat for high-efficiency PM2. 5 capture. Sci China Mater, 62, 423-436

[73] Cleeton C, Keirouz A, Chen X, Radacsi N (2019) Electrospun nanofibers for drug delivery and biosensing. ACS Biomater Sci Eng 5:4183-4205

[74] Ding C, Fang H, Duan G, Zou Y, Chen S, Hou H (2019) Investigating the draw ratio and velocity of an electrically charged liquid jet during electrospinning. RSC Adv 9:13608-13613

[75] Thenmozhi S, Dharmaraj N, Kadirvelu K, Kim HY (2017) Electrospun nanofibers: new generation materials for advanced applications. Mater Sci Eng B 217:36-48

[76] Lagaron J, Solouk A, Castro S, Echegoyen Y (2017) Biomedical applications of electrospinning, innovations, and products. In Electrospun Materials for Tissue Engineering and Biomedical Applications; Elsevier; pp. 57-72

[77] Park JC (2011) Electric spinning apparatus for mass-production of nano-fiber

[78] Li Y, Liu J, de Bruyn JR, Wan W (2014) Optimization of the electrospinning process for core-shell fiber preparation. J Biomater Tissue Eng 4:973-980

[79] Yang C, Jia Z, Xu Z, Wang K, Guan Z, Wang L (2009) Comparisons of fibers properties between vertical and horizontal type electrospinning systems. In Proceedings of the 2009 IEEE Conference on Electrical Insulation and Dielectric Phenomena, pp. 204-207

[80] Williams GR, Raimi-Abraham BT, Luo CJ (2018) Electrospinning fundamentals. In Nanofibres in Drug Delivery; UCL Press; pp. 24-59

[81] Aliheidari N, Aliahmad N, Agarwal M, Dalir H (2019) Electrospun nanofibers for label-free sensor applications. Sensors 19:3587

[82] Bhattacharjee P, Rutledge G (2011) Electrospinning and polymer nanofibers: process fundamentals. In Comprehensive Biomaterials; Elsevier; pp. 497-512

[83] Huang Z-M, Zhang Y-Z, Kotaki M, Ramakrishna S (2003) A review on polymer nanofibers by electrospinning and 
their applications in nanocomposites. Comp Sci Technol 63:2223-2253

[84] Panda P, Ramakrishna S (2007) Electrospinning of alumina nanofibers using different precursors. $J$ Mater Sci 42:2189-2193. https://doi.org/10.1007/s10853-007-1581-2

[85] Feng Y, Xiong T, Jiang S, Liu S, Hou H (2016) Mechanical properties and chemical resistance of electrospun polyterafluoroethylene fibres. RSC Adv 6:24250-24256

[86] Zhu M, Hua D, Pan H, Wang F, Manshian B, Soenen SJ, Xiong R, Huang C (2018) Green electrospun and crosslinked poly (vinyl alcohol)/poly (acrylic acid) composite membranes for antibacterial effective air filtration. J Coll Interf Sci 511:411-423

[87] Duan G, Fang H, Huang C, Jiang S, Hou H (2018) Microstructures and mechanical properties of aligned electrospun carbon nanofibers from binary composites of polyacrylonitrile and polyamic acid. J Mater Sci 53:15096-15106. https://doi.org/10.1007/s10853-018-270 $0-\mathrm{y}$

[88] Zhou S, Zhou G, Jiang S, Fan P, Hou H (2017) Flexible and refractory tantalum carbide-carbon electrospun nanofibers with high modulus and electric conductivity. Mater Lett 200:97-100

[89] Zhang P, Zhao X, Zhang X, Lai Y, Wang X, Li J, Wei G, Su Z (2014) Electrospun doping of carbon nanotubes and platinum nanoparticles into the $\beta$-phase polyvinylidene difluoride nanofibrous membrane for biosensor and catalysis applications. ACS appl Mater Interf 6:7563-7571

[90] Bortolassi ACC, Nagarajan S, de Araújo Lima B, Guerra VG, Aguiar ML, Huon V, Soussan L, Cornu D, Miele P, Bechelany M (2019) Efficient nanoparticles removal and bactericidal action of electrospun nanofibers membranes for air filtration. Mater Sci Eng C, 102, 718-729

[91] Lin Q, Li Y, Yang M (2012) Polyaniline nanofiber humidity sensor prepared by electrospinning. Sens Actuat B Chem 161:967-972

[92] Li Y, Lim CT, Kotaki M (2015) Study on structural and mechanical properties of porous PLA nanofibers electrospun by channel-based electrospinning system. Polymer 56:572-580

[93] Wang X, Wu T, Wang W, Huang C, Jin X (2016) Regenerated collagen fibers with grooved surface texture: physicochemical characterization and cytocompatibility. Mater Sci Eng C 58:750-756

[94] Katoch A, Sun G-J, Choi S-W, Byun J-H, Kim SS (2013) Competitive influence of grain size and crystallinity on gas sensing performances of $\mathrm{ZnO}$ nanofibers. Sens Actuat B Chem 185:411-416

[95] Fan H, Zhang T, Xu X, Lv N (2011) Fabrication of N-type $\mathrm{Fe} 2 \mathrm{O} 3$ and P-type $\mathrm{LaFeO} 3$ nanobelts by electrospinning and determination of gas-sensing properties. Sens Actuat B Chem 153:83-88

[96] Zhong J, Zhang H, Yan J, Gong X (2015) Effect of nanofiber orientation of electrospun nanofibrous scaffolds on cell growth and elastin expression of muscle cells. Colloids Surf B Biointerf 136:772-778

[97] Jiang S, Duan G, Zussman E, Greiner A, Agarwal S (2014) Highly flexible and tough concentric triaxial polystyrene fibers. ACS Appl Mater Interf 6:5918-5923

[98] Burger C, Hsiao BS, Chu B (2006) Nanofibrous materials and their applications. Annu Rev Mater Res 36:333-368

[99] Teo W-E, Ramakrishna S (2009) Electrospun nanofibers as a platform for multifunctional, hierarchically organized nanocomposite. Compos Sci Technol 69:1804-1817

[100] Thompson C, Chase GG, Yarin A, Reneker D (2007) Effects of parameters on nanofiber diameter determined from electrospinning model. Polymer 48:6913-6922

[101] Bhat G (2016) Advances in polymeric nanofiber manufacturing technologies. J Nanomater Mol Nanotechnol $5: 2324$

[102] Pillay V, Dott C, Choonara YE, Tyagi C, Tomar L, Kumar P, du Toit LC, Ndesendo VM (2013) A review of the effect of processing variables on the fabrication of electrospun nanofibers for drug delivery applications. J Nanomater. $\mathrm{h}$ ttps://doi.org/10.1155/2013/789289

[103] Haider S, Al-Zeghayer Y, Ali FAA, Haider A, Mahmood A, Al-Masry WA, Imran M, Aijaz MO (2013) Highly aligned narrow diameter chitosan electrospun nanofibers. J Polym Res 20:105

[104] Fong H, Chun I, Reneker DH (1999) Beaded nanofibers formed during electrospinning. Polymer 40:4585-4592

[105] Kohse S, Grabow N, Schmitz K-P, Eickner T (2017) Electrospinning of polyimide nanofibres-effects of working parameters on morphology. Current Direct Biomed Eng 3:687-690

[106] Topuz F, Satilmis B, Uyar T (2019) Electrospinning of uniform nanofibers of polymers of intrinsic microporosity (PIM-1): The influence of solution conductivity and relative humidity. Polymer, 178, 121610

[107] Kriegel C, Arrechi A, Kit K, McClements D, Weiss J (2008) Fabrication, functionalization, and application of electrospun biopolymer nanofibers. Crit Rev Food Sci Nutrit 48:775-797

[108] Topuz F, Uyar T (2017) Electrospinning of gelatin with tunable fiber morphology from round to flat/ribbon. Mater Sci Eng C 80:371-378

[109] Biber E, Gündüz G, Mavis B, Colak U (2010) Effects of electrospinning process parameters on nanofibers obtained from Nylon 6 and poly (ethylene-n-butyl acrylate-maleic 
anhydride) elastomer blends using Johnson S B statistical distribution function. Appl Phys A 99:477-487

[110] Tam N, Oguz S, Aydogdu A, Sumnu G, Sahin S (2017) Influence of solution properties and $\mathrm{pH}$ on the fabrication of electrospun lentil flour/HPMC blend nanofibers. Food Res Int 102:616-624

[111] Wei L, Qiu Q, Wang R, Qin X (2018) Influence of the processing parameters on needleless electrospinning from double ring slits spinneret using response surface methodology. J Appl Polym Sci 135:46407

[112] Nie H, He A, Zheng J, Xu S, Li J, Han CC (2008) Effects of chain conformation and entanglement on the electrospinning of pure alginate. Biomacromol 9:1362-1365

[113] Mirtič J, Balažic H, Zupančič Š, Kristl J (2019) Effect of solution composition variables on electrospun alginate nanofibers: response surface analysis. Polymers 11:692

[114] Hiep NT, Hai ND, Toi VV (2017) Fabrication of core-shell PLGA-chitosan microparticles using electrospinning: effects of polymer concentration. Int J Polym Sci. https://d oi.org/10.1155/2017/9580209

[115] Luzio A, Canesi EV, Bertarelli C, Caironi M (2014) Electrospun polymer fibers for electronic applications. Materials 7:906-947

[116] Doshi J, Reneker DH (1995) Electrospinning process and applications of electrospun fibers. J Electrostat 35:151-160

[117] Aydogdu A, Sumnu G, Sahin S (2018) A novel electrospun hydroxypropyl methylcellulose/polyethylene oxide blend nanofibers: Morphology and physicochemical properties. Carbohyd Polym 181:234-246

[118] Liu G, Gu Z, Hong Y, Cheng L, Li C (2017) Electrospun starch nanofibers: Recent advances, challenges, and strategies for potential pharmaceutical applications. J Control Release 252:95-107

[119] Amariei N, Manea L, Bertea A, Bertea A, Popa A (2017) The influence of polymer solution on the properties of electrospun 3D nanostructures. In Proceedings of the IOP Conference Series: Materials Science and Engineering; p. 012092.

[120] Wan Y-Q, He J-H, Wu Y, Yu J-Y (2006) Vibrorheological effect on electrospun polyacrylonitrile (PAN) nanofibers. Mater Lett 60:3296-3300

[121] Li X, Qiang J, Wan Y, Wang H, Gao W (2019) The effect of sonic vibration on electrospun fiber mats. J Low Freq Noise Vib 38:1246-1251

[122] Yu G, Li TS, Xu M, Andersson M, Li B, Tang H, Parbey J, Shao J (2017) Fabrication of nickel-YSZ cermet nanofibers via electrospinning. J Alloys Comp 693:1214-1219

[123] Zander NE (2013) Hierarchically structured electrospun fibers. Polym 5:19-44
[124] Haghi A, Akbari M (2007) Trends in electrospinning of natural nanofibers. Phys Status Solidi 204:1830-1834

[125] Koski A, Yim K, Shivkumar S (2004) Effect of molecular weight on fibrous PVA produced by electrospinning. Mater Lett 58:493-497

[126] Nonato RC, Morales AR, Vieira AF, Nista SV, Mei LH, Bonse BC (2016) Solution parameters in the manufacture of ceramic $\mathrm{ZnO}$ nanofibers made by electrospinning. Appl Phys A 122:244

[127] Pearson DS, Pincus PA, Heffner GW, Dahman SJ (1993) Effect of molecular weight and orientation on the conductivity of conjugated polymers. Macromolecules 26:1570-1575

[128] Van Vooren A, Kim JS, Cornil J (2008) Intrachain versus interchain electron transport in Poly (fluorene-alt-benzothiadiazole): a Quantum-Chemical Insight. ChemPhysChem 9:989-993

[129] Choi S, Lee HM, Kim HS (2019) Effect of molecular weight on humidity-sensitive characteristics of electrospun polyethylene oxide. Sens Actuat A Phys 294:194-202

[130] Bordi F, Cametti C, Di Biasio A (1988) Electrical conductivity behavior of poly (ethylene oxide) in aqueous electrolyte solutions. J Phys Chem 92:4772-4777

[131] Choi S, Kim HR, Jeong YK, Bang JY, Kim HS (2018) Mechanism of electrospinning for poly (amic acid)/polyacrylonitrile fiber fabrication. J Macromol Sci Part B 57:222-230

[132] Abdullah NA, Ahmad Sekak K, Ahmad MR (2016) Effect of molecular weight on morphological structure of electrospun PVA nanofibre. In proceedings of the advanced materials research; pp. 203-208

[133] Kuzelova Kostakova E, Meszaros L, Maskova G, Blazkova L, Turcsan T, Lukas D (2017) Crystallinity of electrospun and centrifugal spun polycaprolactone fibers: a comparative study. J Nanomater. https://doi.org/10.1155/2017/8952390

[134] Hayati I, Bailey A, Tadros TF (1987) Investigations into the mechanisms of electrohydrodynamic spraying of liquids: I. effect of electric field and the environment on pendant drops and factors affecting the formation of stable jets and atomization. J Colloid Interf Sci 117:205-221

[135] Lasprilla-Botero J, Álvarez-Láinez M, Lagaron J (2018) The influence of electrospinning parameters and solvent selection on the morphology and diameter of polyimide nanofibers. Mater Today Commun 14:1-9

[136] Zong X, Kim K, Fang D, Ran S, Hsiao BS, Chu B (2002) Structure and process relationship of electrospun bioabsorbable nanofiber membranes. Polymer 43:4403-4412

[137] Mit-uppatham C, Nithitanakul M, Supaphol P (2004) Ultrafine electrospun polyamide- 6 fibers: effect of solution 
conditions on morphology and average fiber diameter. Macromol Chem Phys 205:2327-2338

[138] Neamnark A, Rujiravanit R, Supaphol P (2006) Electrospinning of hexanoyl chitosan. Carbohyd Polym 66:298-305

[139] Choi JS, Lee SW, Jeong L, Bae S-H, Min BC, Youk JH, Park WH (2004) Effect of organosoluble salts on the nanofibrous structure of electrospun poly (3-hydroxybutyrate-co-3-hydroxyvalerate). Int $\mathrm{J}$ Biol Macromol 34:249-256

[140] Lin T, Wang H, Wang H, Wang X (2004) The charge effect of cationic surfactants on the elimination of fibre beads in the electrospinning of polystyrene. Nanotechnology 15:1375

[141] Seo JM, Arumugam GK, Khan S, Heiden PA (2009) Comparison of the effects of an ionic liquid and triethylbenzylammonium chloride on the properties of electrospun fibers, 1-poly (lactic acid). Macromol Mater Eng 294:35-44

[142] Jarusuwannapoom T, Hongrojjanawiwat W, Jitjaicham S, Wannatong L, Nithitanakul M, Pattamaprom C, Koombhongse P, Rangkupan R, Supaphol P (2005) Effect of solvents on electro-spinnability of polystyrene solutions and morphological appearance of resulting electrospun polystyrene fibers. Eur Polymer J 41:409-421

[143] Ray SS, Chen S-S, Nguyen NC, Hsu H-T, Nguyen HT, Chang C-T (2017) Poly (vinyl alcohol) incorporated with surfactant based electrospun nanofibrous layer onto polypropylene mat for improved desalination by using membrane distillation. Desalination 414:18-27

[144] Rodrigues BV, Silva AS, Melo GF, Vasconscellos LM, Marciano FR, Lobo AO (2016) Influence of low contents of superhydrophilic MWCNT on the properties and cell viability of electrospun poly (butylene adipate-co-terephthalate) fibers. Mater Sci Eng C 59:782-791

[145] Bhardwaj N, Kundu SC (2010) Electrospinning: a fascinating fiber fabrication technique. Biotechnol Adv 28:325-347

[146] Cadafalch Gazquez G, Smulders V, Veldhuis SA, Wieringa P, Moroni L, Boukamp BA, Ten Elshof JE (2017) Influence of solution properties and process parameters on the formation and morphology of YSZ and $\mathrm{NiO}$ ceramic nanofibers by electrospinning. Nanomaterials. https://doi.org/10. 3390/nano7010016

[147] De Vrieze S, Van Camp T, Nelvig A, Hagström B, Westbroek P, De Clerck K (2009) The effect of temperature and humidity on electrospinning. J Mater Sci 44:1357-1362. h ttps://doi.org/10.1007/s10853-008-3010-6
[148] Yao T, Chen H, Samal P, Giselbrecht S, Baker MB, Moroni, L (2019) Self-assembly of electrospun nanofibers into gradient honeycomb structures. Mater Des, 168, 107614.

[149] Zhao J, Sun Z, Shao Z, Xu L (2016) Effect of surface-active agent on morphology and properties of electrospun PVA nanofibres. Fibers Polymers 17:896-901

[150] Arbeiter D, Kohse S, Eickner T, Grabow N, Schmitz K-P (2018) Influence of additives on physico-chemical properties of electrospun poly (L-lactide). Current Direct Biomed Eng 4:493-496

[151] Son WK, Youk JH, Lee TS, Park WH (2004) The effects of solution properties and polyelectrolyte on electrospinning of ultrafine poly (ethylene oxide) fibers. Polymer, 45, 2959-2966

[152] Vega-Lugo AC, Lim LT (2012) Effects of poly (ethylene oxide) and $\mathrm{pH}$ on the electrospinning of whey protein isolate. J Polym Sci, Part B: Polym Phys 50:1188-1197

[153] Xu D, Sanchez-Romaguera V, Barbosa S, Travis W, de Wit J, Swan P, Yeates SG (2007) Inkjet printing of polymer solutions and the role of chain entanglement. J Mater Chem 17:4902-4907

[154] Shenoy SL, Bates WD, Frisch HL, Wnek GE (2005) Role of chain entanglements on fiber formation during electrospinning of polymer solutions: good solvent, non-specific polymer-polymer interaction limit. Polymer 46:3372-3384

[155] Lu C, Chen P, Li J, Zhang Y (2006) Computer simulation of electrospinning. Part I. Effect of solvent in electrospinning. Polymer, 47, 915-921

[156] Hansen CM (1967) The three dimensional solubility parameter. Danish Technical, Copenhagen, p 14

[157] Hansen CM (1969) The universality of the solubility parameter. Ind Eng Chem Prod Res Develop 8:2-11

[158] Reneker D, Yarin A, Zussman E, Xu H (2007) Electrospinning of nanofibers from polymer solutions and melts. Adv Appl Mech 41:43-346

[159] Luo C, Nangrejo M, Edirisinghe M (2010) A novel method of selecting solvents for polymer electrospinning. Polymer 51:1654-1662

[160] Stanescu I, Achenie LE (2006) A theoretical study of solvent effects on Kolbe-Schmitt reaction kinetics. Chem Eng Sci 61:6199-6212

[161] Luo C, Stride E, Edirisinghe M (2012) Mapping the influence of solubility and dielectric constant on electrospinning polycaprolactone solutions. Macromolecules 45:4669-4680

[162] Mahalingam S, Raimi-Abraham BT, Craig DQ, Edirisinghe M (2015) Solubility-spinnability map and model for the preparation of fibres of polyethylene (terephthalate) using gyration and pressure. Chem Eng J 280:344-353 
[163] Sill TJ, Von Recum HA (2008) Electrospinning: applications in drug delivery and tissue engineering. Biomaterials 29:1989-2006

[164] Larrondo, L.; St. John Manley, R.J.J.o.P.S.P.P.E. Electrostatic fiber spinning from polymer melts. I. Experimental observations on fiber formation and properties. 1981, 19, 909-920.

[165] Manandhar S, Vidhate S, D’Souza N (2009) Water soluble levan polysaccharide biopolymer electrospun fibers. Carbohyd Polym 78:794-798

[166] Sencadas V, Correia DM, Areias A, Botelho G, Fonseca A, Neves I, Ribelles JG, Mendez SL (2012) Determination of the parameters affecting electrospun chitosan fiber size distribution and morphology. Carbohyd Polym 87:1295-1301

[167] Zhou H, Shi Z, Wan X, Fang H, Yu D-G, Chen X, Liu P (2019) The relationships between process parameters and polymeric nanofibers fabricated using a modified coaxial electrospinning. Nanomaterials 9:843

[168] Pezeshki-Modaress M, Mirzadeh H, Zandi M (2015) Gelatin-GAG electrospun nanofibrous scaffold for skin tissue engineering: fabrication and modeling of process parameters. Mater Sci Eng C 48:704-712

[169] Shao P, Niu B, Chen H, Sun P (2018) Fabrication and characterization of tea polyphenols loaded pullulan-CMC electrospun nanofiber for fruit preservation. Int $\mathrm{J}$ Biol Macromol 107:1908-1914

[170] Zhang C, Yuan X, Wu L, Han Y, Sheng J (2005) Study on morphology of electrospun poly (vinyl alcohol) mats. Eur Polymer J 41:423-432

[171] Righi TM, Almeida RS, d'Ávila MA (2012) Electrospinning of gelatin/PEO blends: Influence of process parameters in the nanofiber properties. In Proceedings of the Macromolecular Symposia; pp. 230-234

[172] Katsogiannis KAG, Vladisavljević GT, Georgiadou S (2016) Porous electrospun polycaprolactone fibers: effect of process parameters. J Polym Sci, Part B: Polym Phys 54:1878-1888

[173] Kim J-H, Lee J-H, Kim J-Y, Kim SS (2018) Synthesis of aligned $\mathrm{TiO} 2$ nanofibers using electrospinning. Appl Sci 8:309

[174] Yördem O, Papila M, Menceloğlu YZ (2008) Effects of electrospinning parameters on polyacrylonitrile nanofiber diameter: An investigation by response surface methodology. Materials design 29:34-44

[175] Tan S-H, Inai R, Kotaki M, Ramakrishna S (2005) Systematic parameter study for ultra-fine fiber fabrication via electrospinning process. Polymer 46:6128-6134

[176] Drosou C, Krokida M, Biliaderis CG (2018) Composite pullulan-whey protein nanofibers made by electrospinning:
Impact of process parameters on fiber morphology and physical properties. Food Hydrocolloids 77:726-735

[177] Megelski S, Stephens JS, Chase DB, Rabolt JF (2002) Micro-and nanostructured surface morphology on electrospun polymer fibers. Macromolecules 35:8456-8466

[178] Yuan X, Zhang Y, Dong C, Sheng J (2004) Morphology of ultrafine polysulfone fibers prepared by electrospinning. Polym Int 53:1704-1710

[179] Xue J, Wu T, Dai Y, Xia Y (2019) Electrospinning and electrospun nanofibers: Methods, materials, and applications. Chem Rev 119:5298-5415

[180] Hossain MF, Gong RH, Rigout M (2016) Optimization of the process variables for electrospinning of poly (ethylene oxide)-loaded hydroxypropyl- $\beta$-cyclodextrin nanofibres. J Text Inst 107:1-11

[181] Ki CS, Baek DH, Gang KD, Lee KH, Um IC, Park YH (2005) Characterization of gelatin nanofiber prepared from gelatin-formic acid solution. Polymer 46:5094-5102

[182] Cruz KFN, Botelho EC, Cristovan FH, Guerrini LM (2017) Electrospinning TPU/poly o-phenetidine (POEA) fibers: influence of POEA on fiber morphology. Polym Bull 74:2905-2919

[183] Matabola K, Moutloali R (2013) The influence of electrospinning parameters on the morphology and diameter of poly (vinyledene fluoride) nanofibers-effect of sodium chloride. J Mater Sci 48:5475-5482. https://doi.org/10.10 07/s10853-013-7341-6

[184] Pham QP, Sharma U, Mikos AG (2006) Electrospun poly (E-caprolactone) microfiber and multilayer nanofiber/microfiber scaffolds: characterization of scaffolds and measurement of cellular infiltration. Biomacromol 7:2796-2805

[185] Jaeger R, Bergshoef MM, Batlle CMI, Schönherr H, Julius Vancso G (1998) Electrospinning of ultra-thin polymer fibers. In Proceedings of the Macromolecular symposia, pp. $141-150$

[186] Parajuli D, Koomsap P, Parkhi AA, Supaphol P (2016) Experimental investigation on process parameters of nearfield deposition of electrospinning-based rapid prototyping. Virtual Phys Prototyp 11:193-207

[187] Vinogradov G, Malkin AY (1964) Temperature-independent viscosity characteristics of polymer systems. J Polym Sci Part A Gen Pap 2:2357-2372

[188] Yu D-G, Gao L-D, White K, Branford-White C, Lu W-Y, Zhu L-M (2010) Multicomponent amorphous nanofibers electrospun from hot aqueous solutions of a poorly soluble drug. Pharm Res 27:2466-2477

[189] Yang G-Z, Li H-P, Yang J-H, Wan J, Yu D-G (2017) Influence of working temperature on the formation of electrospun polymer nanofibers. Nanoscale Res Lett 12:55 
[190] Cai Y, Gevelber M (2013) The effect of relative humidity and evaporation rate on electrospinning: fiber diameter and measurement for control implications. J Mater Sci 48:7812-7826. https://doi.org/10.1007/s10853-013-7544-X

[191] Pelipenko J, Kristl J, Janković B, Baumgartner S, Kocbek P (2013) The impact of relative humidity during electrospinning on the morphology and mechanical properties of nanofibers. Int J Pharm 456:125-134

[192] De Vrieze S, De Schoenmaker B, Ceylan Ö, Depuydt J, Van Landuyt L, Rahier H, Van Assche G, De Clerck K (2011) Morphologic study of steady state electrospun polyamide 6 nanofibres. J Appl Polym Sci 119:2984-2990

[193] Bak SY, Yoon GJ, Lee SW, Kim HW (2016) Effect of humidity and benign solvent composition on electrospinning of collagen nanofibrous sheets. Mater Lett 181:136-139

[194] Alnaqbi MA, Greish Y, Mohsin M, Elumalai E, Al Blooshi A (2016) Morphological variations of micro-nanofibrous sorbents prepared by electrospinning and their effects on the sorption of crude oil. J Environ Chem Eng 4:1850-1861

[195] Nezarati RM, Eifert MB, Cosgriff-Hernandez E (2013) Effects of humidity and solution viscosity on electrospun fiber morphology. Tissue Eng Part C Methods 19:810-819

[196] Putti M, Simonet M, Solberg R, Peters GW (2015) Electrospinning poly ( $\varepsilon$-caprolactone) under controlled environmental conditions: influence on fiber morphology and orientation. Polymer 63:189-195

[197] Chen H, Huang X, Zhang M, Damanik F, Baker MB, Leferink A, Yuan H, Truckenmüller R, van Blitterswijk C, Moroni L (2017) Tailoring surface nanoroughness of electrospun scaffolds for skeletal tissue engineering. Acta Biomater 59:82-93

[198] Huang C, Thomas NL (2018) Fabricating porous poly (lactic acid) fibres via electrospinning. Eur Polymer J 99:464-476

[199] Ding B, Li C, Miyauchi Y, Kuwaki O, Shiratori S (2006) Formation of novel 2D polymer nanowebs via electrospinning. Nanotechnology 17:3685

[200] Wang C, Hsu C-H, Lin J-H (2006) Scaling laws in electrospinning of polystyrene solutions. Macromolecules 39:7662-7672

[201] Wang C, Hsu C-H, Hwang I-H (2008) Scaling laws and internal structure for characterizing electrospun poly [(R)-3hydroxybutyrate] fibers. Polymer 49:4188-4195

[202] Yousefi S, Tang C, Tafreshi HV, Pourdeyhimi B (2019) Empirical model to simulate morphology of electrospun polycaprolactone mats. J Appl Polym Sci 136:48242

[203] Ziabari M, Mottaghitalab V, Haghi AK (2010) A new approach for optimization of electrospun nanofiber formation process. Korean J Chem Eng 27:340-354
[204] Hendricks JR CD, Carson RS, Hogan JJ, Schneider JM (1964) Photomicrography of electrically sprayed heavy particles. Aiaa J, 2, 733-737

[205] Yarin AL, Koombhongse S, Reneker DH (2001) Taylor cone and jetting from liquid droplets in electrospinning of nanofibers. J Appl Phys 90:4836-4846

[206] Spivak A, Dzenis Y, Reneker D (2000) Model of steady state jet in the electrospinning process. Mech Res Commun 27:37-42

[207] Spivak A, Dzenis YA (1998) Asymptotic decay of radius of a weakly conductive viscous jet in an external electric field. Appl Phys Lett 73:3067-3069

[208] Hohman MM, Shin M, Rutledge G, Brenner MP (2001) Electrospinning and electrically forced jets II applications. Phys Fluids 13:2221-2236

[209] Hohman MM, Shin M, Rutledge G, Brenner MP (2001) Electrospinning and electrically forced jets I Stability theory. Phys Fluids 13:2201-2220

[210] Feng J (2002) The stretching of an electrified non-Newtonian jet: a model for electrospinning. Phys Fluids 14:3912-3926

[211] Shin Y, Hohman M, Brenner M, Rutledge G (2001) Experimental characterization of electrospinning: the electrically forced jet and instabilities. Polymer 42:09955-09967

[212] Baji A, Mai YW, Wong SC, Abtahi M, Chen PJCS (2010) Electrospinning of polymer nanofibers: effects on oriented morphology, structures and tensile properties. Compos Sci Technol 70:703-718

[213] Huebner A, Chu H (1971) Instability and breakup of charged liquid jets. J Fluid Mech 49:361-372

[214] Reneker DH, Yarin AL, Fong H, Koombhongse S (2000) Bending instability of electrically charged liquid jets of polymer solutions in electrospinning. J Appl Phys 87:4531-4547

[215] Yarin AL, Koombhongse S, Reneker DH (2001) Bending instability in electrospinning of nanofibers. J Appl Phys 89:3018-3026

[216] Shin Y, Hohman M, Brenner MP, Rutledge G (2001) Electrospinning: a whipping fluid jet generates submicron polymer fibers. Appl Phys Lett 78:1149-1151

[217] Fridrikh, S.V.; Jian, H.Y.; Brenner, M.P.; Rutledge, G.C. Controlling the fiber diameter during electrospinning. Physical review letters 2003, 90, 144502.

[218] Theron S, Zussman E, Yarin A (2004) Experimental investigation of the governing parameters in the electrospinning of polymer solutions. Polymer 45:2017-2030

[219] Carroll CP, Joo YL (2009) Axisymmetric instabilities in electrospinning of highly conducting, viscoelastic polymer solutions. Phys Fluids, 21, 103101 
[220] Yousefi S, Tafreshi HV (2020) Modeling electrospun fibrous structures with embedded spacer particles: application to aerosol filtration. Sep Purif Technol, 235, 116184

[221] Allen MP, Tildesley DJ (2017) Computer simulation of liquids; Oxford university press

[222] Jirsak J, Moucka F, Nezbeda I (2014) Insight into electrospinning via molecular simulations. Indus Eng Chem Res 53:8257-8264

[223] Danwanichakul P, Danwanichakul D (2014) Two-dimensional simulation of electrospun nanofibrous structures connection of experimental and simulated results. J Chem. https://doi.org/10.1155/2014/479139

[224] Sarmadi M, Shamloo A, Mohseni M (2017) Utilization of molecular dynamics simulation coupled with experimental assays to optimize biocompatibility of an electrospun PCL/ PVA scaffold. PloS one, 12, e0169451

[225] Vao-soongnern V (2019) Monte Carlo simulation of molecular and structural properties of mono-and bi-dispersed poly (ethylene oxide) nanofibers. J Polym Res 26:147

[226] Steffens L, Morás AM, Arantes PR, Masterson K, Cao Z, Nugent M, Moura DJ (2020) Electrospun PVA-Dacarbazine nanofibers as a novel nano brain-implant for treatment of glioblastoma: in silico and in vitro characterization. Europ J Pharmaceut Sci, 143, 105183

[227] Karra S (2010) Modeling electrospinning process and a numerical scheme using Lattice Boltzmann method to simulate viscoelastic fluid flows. Texas A \& M University

[228] Yin Y, Pan Z, Xiong J (2018) A tensile constitutive relationship and a finite element model of electrospun nanofibrous mats. Nanomaterials 8:29

[229] Sarkar K, Ghalia MB, Wu Z, Bose SC (2009) A neural network model for the numerical prediction of the diameter of electro-spun polyethylene oxide nanofibers. J Mater Process Technol 209:3156-3165

[230] Cui W, Zhou Y, Chang J (2010) Electrospun nanofibrous materials for tissue engineering and drug delivery. Sci Technol Adv Mater, 11, 014108

[231] Walmsley GG, McArdle A, Tevlin R, Momeni A, Atashroo D, Hu MS, Feroze AH, Wong VW, Lorenz PH, Longaker MT (2015) Nanotechnology in bone tissue engineering. Nanomed Nanotechnol Biol Med. https://doi.org/10.1016/j. nano.2015.02.013

[232] Khademhosseini A, Langer R (2016) A decade of progress in tissue engineering. Nat Protoc 11:1775-1781

[233] Wang Y, Wang X, Shi J, Zhu R, Zhang J, Zhang Z, Ma D, Hou Y, Lin F, Yang J (2016) A biomimetic silk fibroin/sodium alginate composite scaffold for soft tissue engineering. Sci Rep 6:39477
[234] Agarwal S, Wendorff JH, Greiner A (2008) Use of electrospinning technique for biomedical applications. Polymer 49:5603-5621

[235] Unnithan AR, Barakat NA, Pichiah PT, Gnanasekaran G, Nirmala R, Cha Y-S, Jung C-H, El-Newehy M, Kim HY (2012) Wound-dressing materials with antibacterial activity from electrospun polyurethane-dextran nanofiber mats containing ciprofloxacin $\mathrm{HCl}$. Carbohyd Polym 90:1786-1793

[236] Zou B, Liu Y, Luo X, Chen F, Guo X, Li X (2012) Electrospun fibrous scaffolds with continuous gradations in mineral contents and biological cues for manipulating cellular behaviors. Acta Biomater 8:1576-1585

[237] Supaphol P, Suwantong O, Sangsanoh P, Srinivasan S, Jayakumar R, Nair SV (2011) Electrospinning of biocompatible polymers and their potentials in biomedical applications. Springer, In Biomedical applications of polymeric nanofibers, pp 213-239

[238] Gunn J, Zhang M (2010) Polyblend nanofibers for biomedical applications: perspectives and challenges. Trends Biotechnol 28:189-197

[239] Du C, Cui F, Zhang W, Feng Q, Zhu X, De Groot K (2000) Formation of calcium phosphate/collagen composites through mineralization of collagen matrix. J Biomed Mater Res 50:518-527

[240] Chiara G, Letizia F, Lorenzo F, Edoardo S, Diego S, Stefano S, Eriberto B, Barbara Z (2012) Nanostructured biomaterials for tissue engineered bone tissue reconstruction. Int J Mol Sci 13:737-757

[241] Pham QP, Sharma U, Mikos AG (2006) Electrospinning of polymeric nanofibers for tissue engineering applications: a review. Tissue Eng 12:1197-1211

[242] Shin M, Yoshimoto H, Vacanti JP (2004) In vivo bone tissue engineering using mesenchymal stem cells on a novel electrospun nanofibrous scaffold. Tissue Eng 10:33-41

[243] Ratner BD, Hoffman AS, Schoen FJ, Lemons JE (2004) Biomaterials science: an introduction to materials in medicine; Elsevier

[244] Pan Y, Xiong D (2009) Friction properties of nano-hydroxyapatite reinforced poly (vinyl alcohol) gel composites as an articular cartilage. Wear 266:699-703

[245] Pandi K, Viswanathan N (2015) In situ precipitation of nano-hydroxyapatite in gelatin polymatrix towards specific fluoride sorption. Int J Biol Macromol 74:351-359

[246] LeGeros RZ (2002) Properties of osteoconductive biomaterials: calcium phosphates. Clin Orthop Relat Res 395:81-98

[247] Salifu AA, Lekakou C, Labeed FH (2017) Electrospun oriented gelatin-hydroxyapatite fiber scaffolds for bone 
tissue engineering. J Biomed Mater Res Part A 105:1911-1926

[248] Yang X, Li Y, He W, Huang Q, Zhang R, Feng Q (2018) Hydroxyapatite/collagen coating on PLGA electrospun fibers for osteogenic differentiation of bone marrow mesenchymal stem cells. J Biomed Mater Res Part A 106:2863-2870

[249] Niu B, Li B, Gu Y, Shen X, Liu Y, Chen L (2017) In vitro evaluation of electrospun silk fibroin/nano-hydroxyapatite/ BMP-2 scaffolds for bone regeneration. J Biomater Sci Polym Ed 28:257-270

[250] Surmenev RA, Shkarina S, Syromotina DS, Melnik EV, Shkarin R, Selezneva II, Ermakov AM, Ivlev SI, Cecilia A, Weinhardt V (2019) Characterization of biomimetic silicate-and strontium-containing hydroxyapatite microparticles embedded in biodegradable electrospun polycaprolactone scaffolds for bone regeneration. Eur Polymer J 113:67-77

[251] Nezafati N, Faridi-Majidi R, Pazouki M, Hesaraki S (2019) Synthesis and characterization of a novel freeze-dried silanated chitosan bone tissue engineering scaffold reinforced with electrospun hydroxyapatite nanofiber. Polym Int 68:1420-1429

[252] Chen P, Liu L, Pan J, Mei J, Li C, Zheng Y (2019) Biomimetic composite scaffold of hydroxyapatite/gelatin-chitosan core-shell nanofibers for bone tissue engineering. Mater Sci Eng C 97:325-335

[253] Ko E, Lee JS, Kim H, Yang SY, Yang D, Yang K, Lee J, Shin J, Yang HS, Ryu W (2017) Electrospun silk fibroin nanofibrous scaffolds with two-stage hydroxyapatite functionalization for enhancing the osteogenic differentiation of human adipose-derived mesenchymal stem cells. ACS Appl Mater Interf 10:7614-7625

[254] Shao W, He J, Sang F, Ding B, Chen L, Cui S, Li K, Han Q, Tan W (2016) Coaxial electrospun aligned tussah silk fibroin nanostructured fiber scaffolds embedded with hydroxyapatite-tussah silk fibroin nanoparticles for bone tissue engineering. Mater Sci Eng C 58:342-351

[255] Govindasamy K, Dahlan NA, Janarthanan P, Goh KL, Chai SP, Pasbakhsh P (2020) Electrospun chitosan/polyethyleneoxide (PEO)/halloysites (HAL) membranes for bone regeneration applications. Appl Clay Sci, 190, 105601

[256] Naderi P, Zarei M, Karbasi S, Salehi H (2020) Evaluation of the effects of keratin on physical, mechanical and biological properties of poly (3-hydroxybutyrate) electrospun scaffold: Potential application in bone tissue engineering. Europ Polym J, 124, 109502

[257] Castro VO, Fredel MC, Aragones Á, de Oliveira Barra GM, Cesca K, Merlini C (2020) Electrospun fibrous membranes of poly (lactic-co-glycolic acid) with $\beta$-tricalcium phosphate for guided bone regeneration application. Polym Test, 106489

[258] Toloue EB, Karbasi S, Salehi H, Rafienia M (2019) Potential of an electrospun composite scaffold of poly (3hydroxybutyrate)-chitosan/alumina nanowires in bone tissue engineering applications. Mater Sci Eng C 99:1075-1091

[259] Perumal G, Sivakumar PM, Nandkumar AM, Doble M (2020) Synthesis of magnesium phosphate nanoflakes and its PCL composite electrospun nanofiber scaffolds for bone tissue regeneration. Mater Sci Eng C, 109, 110527

[260] Chakraborty PK, Adhikari J, Saha P (2019) Facile fabrication of electrospun regenerated cellulose nanofiber scaffold for potential bone-tissue engineering application. Int $\mathrm{J}$ Biol Macromol 122:644-652

[261] Cardenas Turner J, Collins G, Blaber EA, Almeida EA, Arinzeh TL (2020) Evaluating the cytocompatibility and differentiation of bone progenitors on electrospun zein scaffolds. J Tissue Eng Regener Med 14:173-185

[262] Yin L, Zhu Y, He M, Chang Y, Xu F, Lai HC (2020) Preparation and characteristics of electrospinning PTH-Fc/ PLCL/SF membranes for bioengineering applications. J Biomed Mater Res Part A 108:157-165

[263] Tohidlou H, Shafiei SS, Abbasi S, Asadi-Eydivand M, Fathi-Roudsari M (2019) Amine-functionalized singlewalled carbon nanotube/polycaprolactone electrospun scaffold for bone tissue engineering: in vitro study. Fibers Polym 20:1869-1882

[264] Ding Y, Li W, Correia A, Yang Y, Zheng K, Liu D, Schubert D, Boccaccini A, Santos H, Roether J (2018) Electrospun $\mathrm{phb} / \mathrm{pcl} / \mathrm{sol}$-gel derived silica hybrid scaffolds with drug releasing function for bone tissue engineering applications. ACS Appl Mater Interf 10:14540-14548

[265] Sharifi F, Atyabi SM, Norouzian D, Zandi M, Irani S, Bakhshi H (2018) Polycaprolactone/carboxymethyl chitosan nanofibrous scaffolds for bone tissue engineering application. Int J Biol Macromol 115:243-248

[266] Hidalgo Pitaluga L, Trevelin Souza M, Dutra Zanotto E, Santocildes Romero ME, Hatton PV (2018) Electrospun F18 bioactive Glass/PCL-Poly ( $\varepsilon$-caprolactone)-Membrane for guided tissue regeneration. Materials. https://doi. org/10.3390/ma11030400

[267] Santos D, Silva DM, Gomes PS, Fernandes MH, Santos JD, Sencadas V (2017) Multifunctional PLLA-ceramic fiber membranes for bone regeneration applications. J Colloid Interf Sci 504:101-110

[268] Santos D, Correia CO, Silva DM, Gomes PS, Fernandes MH, Santos JD, Sencadas V (2017) Incorporation of glassreinforced hydroxyapatite microparticles into poly (lactic 
acid) electrospun fibre mats for biomedical applications. Mater Sci Eng C 75:1184-1190

[269] Ren K, Wang Y, Sun T, Yue W, Zhang H (2017) Electrospun PCL/gelatin composite nanofiber structures for effective guided bone regeneration membranes. Mater Sci Eng C 78:324-332

[270] Ao C, Niu Y, Zhang X, He X, Zhang W, Lu C (2017) Fabrication and characterization of electrospun cellulose/nano-hydroxyapatite nanofibers for bone tissue engineering. Int J Biol Macromol 97:568-573

[271] Gorodzha SN, Muslimov AR, Syromotina DS, Timin AS, Tcvetkov NY, Lepik KV, Petrova AV, Surmeneva MA, Gorin DA, Sukhorukov GB (2017) A comparison study between electrospun polycaprolactone and piezoelectric poly (3-hydroxybutyrate-co-3-hydroxyvalerate) scaffolds for bone tissue engineering. Colloids Surf B Biointerfaces 160:48-59

[272] Shrestha BK, Mousa HM, Tiwari AP, Ko SW, Park CH, Kim CS (2016) Development of polyamide-6, 6/chitosan electrospun hybrid nanofibrous scaffolds for tissue engineering application. Carbohyd Polym 148:107-114

[273] Chen Z, Song Y, Zhang J, Liu W, Cui J, Li H, Chen F (2017) Laminated electrospun nHA/PHB-composite scaffolds mimicking bone extracellular matrix for bone tissue engineering. Mater Sci Eng C 72:341-351

[274] Liao N, Joshi MK, Tiwari AP, Park C-H, Kim CS (2016) Fabrication, characterization and biomedical application of two-nozzle electrospun polycaprolactone/zein-calcium lactate composite nonwoven mat. J Mech Behav Biomed Mater 60:312-323

[275] Hay R, Augustin M, Griffiths C, Sterry W (2015) The global challenge for skin health. $\mathrm{Br} \mathrm{J}$ Dermatol 6:1469-1472

[276] Vatankhah E, Prabhakaran MP, Jin G, Mobarakeh LG, Ramakrishna S (2014) Development of nanofibrous cellulose acetate/gelatin skin substitutes for variety wound treatment applications. J Biomater Appl 28:909-921

[277] Metcalfe AD, Ferguson MW (2007) Tissue engineering of replacement skin: the crossroads of biomaterials, wound healing, embryonic development, stem cells and regeneration. J R Soc Interf 4:413-437

[278] Zahedi P, Rezaeian I, Ranaei-Siadat SO, Jafari SH, Supaphol P (2010) A review on wound dressings with an emphasis on electrospun nanofibrous polymeric bandages. Polym Adv Technol 21:77-95

[279] Jun I, Han H-S, Edwards JR, Jeon H (2018) Electrospun fibrous scaffolds for tissue engineering: viewpoints on architecture and fabrication. Int J Mol Sci 19:745

[280] Smith L, Ma P (2004) Nano-fibrous scaffolds for tissue engineering. Colloids Surf B Biointerf 39:125-131
[281] Dias J, Granja P, Bártolo P (2016) Advances in electrospun skin substitutes. Prog Mater Sci 84:314-334

[282] Ma Z, He W, Yong T, Ramakrishna S (2005) Grafting of gelatin on electrospun poly (caprolactone) nanofibers to improve endothelial cell spreading and proliferation and to control cell orientation. Tissue Eng 11:1149-1158

[283] Panzavolta S, Gioffrè M, Focarete ML, Gualandi C, Foroni L, Bigi A (2011) Electrospun gelatin nanofibers: optimization of genipin cross-linking to preserve fiber morphology after exposure to water. Acta Biomater 7:1702-1709

[284] Yao C-H, Lee C-Y, Huang C-H, Chen Y-S, Chen K-Y (2017) Novel bilayer wound dressing based on electrospun gelatin/keratin nanofibrous mats for skin wound repair. Mater Sci Eng C 79:533-540

[285] Adeli-Sardou M, Yaghoobi MM, Torkzadeh-Mahani M, Dodel M (2019) Controlled release of lawsone from polycaprolactone/gelatin electrospun nano fibers for skin tissue regeneration. Int J Biol Macromol 124:478-491

[286] Ramanathan G, Singaravelu S, Raja M, Nagiah N, Padmapriya P, Ruban K, Kaveri K, Natarajan TS, Sivagnanam UT, Perumal PT (2016) Fabrication and characterization of a collagen coated electrospun poly (3-hydroxybutyric acid)-gelatin nanofibrous scaffold as a soft bio-mimetic material for skin tissue engineering applications. RSC Adv 6:7914-7922

[287] Sheikholeslam M, Wright ME, Cheng N, Oh HH, Wang Y, Datu AK, Santerre JP, Amini-Nik S, Jeschke MG (2019) Electrospun Polyurethane-Gelatin composite: a new tissueengineered scaffold for application in skin regeneration and repair of complex wounds. ACS Biomater Sci Eng 6:505-516

[288] Baghersad S, Bahrami SH, Mohammadi MR, Mojtahedi MRM, Milan PB (2018) Development of biodegradable electrospun gelatin/aloe-vera/poly ( $\varepsilon$-caprolactone) hybrid nanofibrous scaffold for application as skin substitutes. Mater Sci Eng C 93:367-379

[289] Shi R, Geng H, Gong M, Ye J, Wu C, Hu X, Zhang L (2018) Long-acting and broad-spectrum antimicrobial electrospun poly ( $\varepsilon$-caprolactone)/gelatin micro/nanofibers for wound dressing. J Colloid Interf Sci 509:275-284

[290] Miguel SP, Simões D, Moreira AF, Sequeira RS, Correia IJ (2019) Production and characterization of electrospun silk fibroin based asymmetric membranes for wound dressing applications. Int J Biol Macromol 121:524-535

[291] Zahedi E, Esmaeili A, Eslahi N, Shokrgozar MA, Simchi A (2019) Fabrication and characterization of Core-Shell electrospun fibrous Mats containing medicinal herbs for wound healing and skin tissue engineering. Mar Drugs $17: 27$ 
[292] Ababzadeh S, Farzin A, Goodarzi A, Karimi R, Sagharjoghi Farahani M, Eslami Farsani M, Gharibzad K, Zahiri M, Ai J (2020) High porous electrospun poly ( $\varepsilon$-caprolactone)/gelatin/ $\mathrm{MgO}$ scaffolds preseeded with endometrial stem cells promote tissue regeneration in full-thickness skin wounds: An in vivo study. J Biomed Mater Res Part B Appl Biomater. https://doi.org/10.1002/jbm.b.34626

[293] Koosha M, Raoufi M, Moravvej H (2019) One-pot reactive electrospinning of chitosan/PVA hydrogel nanofibers reinforced by halloysite nanotubes with enhanced fibroblast cell attachment for skin tissue regeneration. Colloids Surf B Biointerf 179:270-279

[294] Nazeer MA, Yilgor E, Yilgor I (2019) Electrospun polycaprolactone/silk fibroin nanofibrous bioactive scaffolds for tissue engineering applications. Polymer 168:86-94

[295] Ghaseminezhad K, Zare M, Lashkarara S, Yousefzadeh M, Aghazadeh Mohandesi J (2020) Fabrication of althea officinalis loaded electrospun nanofibrous scaffold for potential application of skin tissue engineering. J Appl Polym Sci 137:48587

[296] dos Santos DM, Leite IS, de Lacerda Bukzem A, de Oliveira Santos RP, Frollini E, Inada NM, Campana-Filho SP (2018) Nanostructured electrospun nonwovens of poly ( $\varepsilon$ caprolactone)/quaternized chitosan for potential biomedical applications. Carbohyd Polym 186:110-121

[297] Chanda A, Adhikari J, Ghosh A, Chowdhury SR, Thomas S, Datta P, Saha P (2018) Electrospun chitosan/polycaprolactone-hyaluronic acid bilayered scaffold for potential wound healing applications. Int $\mathrm{J}$ Biol Macromol 116:774-785

[298] Rad ZP, Mokhtari J, Abbasi M (2018) Fabrication and characterization of $\mathrm{PCL} /$ zein/gum arabic electrospun nanocomposite scaffold for skin tissue engineering. Mater Sci Eng C 93:356-366

[299] Samadian H, Salehi M, Farzamfar S, Vaez A, Ehterami A, Sahrapeyma H, Goodarzi A, Ghorbani S (2018) In vitro and in vivo evaluation of electrospun cellulose acetate/gelatin/ hydroxyapatite nanocomposite mats for wound dressing applications. Artif Cells Nanomed Biotechnol 46:964-974

[300] Simões D, Miguel SP, Correia IJ (2018) Biofunctionalization of electrospun poly (caprolactone) fibers with Maillard reaction products for wound dressing applications. React Funct Polym 131:191-202

[301] Wang X, Lv F, Li T, Han Y, Yi Z, Liu M, Chang J, Wu C (2017) Electrospun micropatterned nanocomposites incorporated with $\mathrm{Cu} 2 \mathrm{~S}$ nanoflowers for skin tumor therapy and wound healing. ACS Nano 11:11337-11349

[302] Yousefi I, Pakravan M, Rahimi H, Bahador A, Farshadzadeh Z, Haririan I (2017) An investigation of electrospun Henna leaves extract-loaded chitosan based nanofibrous mats for skin tissue engineering. Mater Sci Eng C 75:433-444

[303] Perumal G, Pappuru S, Chakraborty D, Nandkumar AM, Chand DK, Doble M (2017) Synthesis and characterization of curcumin loaded PLA-Hyperbranched polyglycerol electrospun blend for wound dressing applications. Mater Sci Eng C 76:1196-1204

[304] Bhowmick S, Rother S, Zimmermann H, Lee PS, Moeller S, Schnabelrauch M, Koul V, Jordan R, Hintze V, Scharnweber D (2017) Biomimetic electrospun scaffolds from main extracellular matrix components for skin tissue engineering application-The role of chondroitin sulfate and sulfated hyaluronan. Mater Sci Eng C 79:15-22

[305] Pal P, Srivas PK, Dadhich P, Das B, Maulik D, Dhara S (2017) Nano-/microfibrous cotton-wool-like 3D scaffold with core-shell architecture by emulsion electrospinning for skin tissue regeneration. ACS Biomater Sci Eng 3:3563-3575

[306] Trinca RB, Westin CB, da Silva JAF, Moraes ÂM (2017) Electrospun multilayer chitosan scaffolds as potential wound dressings for skin lesions. Eur Polymer $\mathrm{J}$ 88:161-170

[307] Dias J, Baptista-Silva S, De Oliveira C, Sousa A, Oliveira AL, Bártolo P, Granja P (2017) In situ crosslinked electrospun gelatin nanofibers for skin regeneration. Eur Polymer J 95:161-173

[308] Miguel SP, Ribeiro MP, Coutinho P, Correia IJ (2017) Electrospun polycaprolactone/aloe vera_chitosan nanofibrous asymmetric membranes aimed for wound healing applications. Polymers 9:183

[309] Sadeghi A, Nokhasteh S, Molavi A, Khorsand-Ghayeni M, Naderi-Meshkin H, Mahdizadeh A (2016) Surface modification of electrospun PLGA scaffold with collagen for bioengineered skin substitutes. Mater Sci Eng C 66:130-137

[310] Park YR, Ju HW, Lee JM, Kim D-K, Lee OJ, Moon BM, Park HJ, Jeong JY, Yeon YK, Park CH (2016) Three-dimensional electrospun silk-fibroin nanofiber for skin tissue engineering. Int J Biol Macromol 93:1567-1574

[311] Mahdavi M, Mahmoudi N, Rezaie Anaran F, Simchi A (2016) Electrospinning of nanodiamond-modified polysaccharide nanofibers with physico-mechanical properties close to natural skins. Mar Drugs 14:128

[312] Nosar MN, Salehi M, Ghorbani S, Beiranvand SP, Goodarzi A, Azami M (2016) Characterization of wet-electrospun cellulose acetate based 3-dimensional scaffolds for skin tissue engineering applications: influence of cellulose acetate concentration. Cellulose 23:3239-3248

[313] Yu K, Zhou X, Zhu T, Wu T, Wang J, Fang J, El-Aassar M, El-Hamshary H, El-Newehy M, Mo X (2016) Fabrication 
of poly (ester-urethane) urea elastomer/gelatin electrospun nanofibrous membranes for potential applications in skin tissue engineering. RSC Adv 6:73636-73644

[314] Akturk O, Kismet K, Yasti AC, Kuru S, Duymus ME, Kaya F, Caydere M, Hucumenoglu S, Keskin DJRA (2016) Wet electrospun silk fibroin/gold nanoparticle 3D matrices for wound healing applications. RSC Adv 6:13234-13250

[315] Sadeghi-Avalshahr AR, Khorsand-Ghayeni M, Nokhasteh S, Molavi AM, Naderi-Meshkin H (2017) Synthesis and characterization of PLGA/collagen composite scaffolds as skin substitute produced by electrospinning through two different approaches. J Mater Sci Mater Med 28:14

[316] Bentzon JF, Otsuka F, Virmani R, Falk E (2014) Mechanisms of plaque formation and rupture. Circ Res 114:1852-1866

[317] Melchiorri AJ, Hibino N, Fisher JP (2013) Strategies and techniques to enhance the in situ endothelialization of small-diameter biodegradable polymeric vascular grafts. Tissue Eng Part B Rev 19:292-307

[318] Hasan A, Memic A, Annabi N, Hossain M, Paul A, Dokmeci MR, Dehghani F, Khademhosseini A (2014) Electrospun scaffolds for tissue engineering of vascular grafts. Acta Biomater 10:11-25

[319] Catto V, Farè S, Cattaneo I, Figliuzzi M, Alessandrino A, Freddi G, Remuzzi A, Tanzi MC (2015) Small diameter electrospun silk fibroin vascular grafts: mechanical properties, in vitro biodegradability, and in vivo biocompatibility. Mater Sci Eng C 54:101-111

[320] Faries PL, LoGerfo FW, Arora S, Hook S, Pulling MC, Akbari CM, Campbell DR, Pomposelli FB Jr (2000) A comparative study of alternative conduits for lower extremity revascularization: all-autogenous conduit versus prosthetic grafts. J Vasc Surg 32:1080-1090

[321] Greisler HP (1990) Interactions at the blood/material interface. Ann Vasc Surg 4:98-103

[322] Ulbricht J, Jordan R, Luxenhofer R (2014) On the biodegradability of polyethylene glycol, polypeptoids and poly (2-oxazoline) s. Biomaterials 35:4848-4861

[323] Castillo R, Müller A (2009) Crystallization and morphology of biodegradable or biostable single and double crystalline block copolymers. Prog Polym Sci 34:516-560

[324] Shinohara S, Kihara T, Sakai S, Matsusaki M, Akashi M, Taya M, Miyake J (2013) Fabrication of in vitro threedimensional multilayered blood vessel model using human endothelial and smooth muscle cells and high-strength PEG hydrogel. J Biosci Bioeng 116:231-234

[325] Wang H, Feng Y, Fang Z, Yuan W, Khan M (2012) Coelectrospun blends of PU and PEG as potential biocompatible scaffolds for small-diameter vascular tissue engineering. Mater Sci Eng C 32:2306-2315
[326] Liu L, Guo S, Chang J, Ning C, Dong C, Yan D.J.J.o.B.M.R.P.B.A.B.A.O.J.o.T.S.f.B (2008) The Japanese Society for Biomaterials,; Biomaterials, T.A.S.f.; Biomaterials, t.K.S.f. Surface modification of polycaprolactone membrane via layer-by-layer deposition for promoting blood compatibility. J Biomed Mater Res Part B, $87,244-250$

[327] Oriňaková R, Gorejová R, Králová ZO, Haverová L, Oriňak A, Maskal'ová I, Kupková M, Džupon M, Baláž M, Hrubovčáková M (2020) Evaluation of mechanical properties and hemocompatibility of open cell iron foams with polyethylene glycol coating. Appl Surf Sci, 505, 144634

[328] Yin A, Zhuang W, Liu G, Lan X, Tang Z, Deng Y, Wang Y (2020) Performance of PEGylated chitosan and poly (Llactic acid-co- $\varepsilon$-caprolactone) bilayer vascular grafts in a canine femoral artery model. Colloids Surf B Biointerf, 188, 110806

[329] Mulholland EJ, Ali A, Robson T, Dunne NJ, McCarthy HO (2019) Delivery of RALA/siFKBPL nanoparticles via electrospun bilayer nanofibres: An innovative angiogenic therapy for wound repair. J Control Release 316:53-65

[330] Rychter M, Milanowski B, Grześkowiak BF, Jarek M, Kempiński M, Coy EL, Borysiak S, Baranowska-Korczyc A, Lulek J (2019) Cilostazol-loaded electrospun three-dimensional systems for potential cardiovascular application: Effect of fibers hydrophilization on drug release, and cytocompatibility. J Coll Interf Sci 536:310-327

[331] Tondnevis F, Keshvari H, Mohandesi JA (2020) Fabrication, characterization, and in vitro evaluation of electrospun polyurethane-gelatin-carbon nanotube scaffolds for cardiovascular tissue engineering applications. J Biomed Mater Res B Appl Biomater 108:2276-2293

[332] Mani MP, Jaganathan SK, Prabhakaran P, Nageswaran G, Krishnasamy NP (2019) Electrospun polyurethane patch in combination with cedarwood and cobalt nitrate for cardiac applications. J Appl Polym Sci 136:48226

[333] Horakova J, Mikes P, Saman A, Jencova V, Klapstova A, Svarcova T, Ackermann M, Novotny V, Suchy T, Lukas D (2018) The effect of ethylene oxide sterilization on electrospun vascular grafts made from biodegradable polyesters. Mater Sci Eng C 92:132-142

[334] Li Z, Zhou P, Zhou F, Zhao Y, Ren L, Yuan X (2018) Antimicrobial eugenol-loaded electrospun membranes of poly ( $\varepsilon$-caprolactone)/gelatin incorporated with REDV for vascular graft applications. Colloids Surf B Biointerf 162:335-344

[335] Zhu T, Yu K, Bhutto MA, Guo X, Shen W, Wang J, Chen W, El-Hamshary H, Al-Deyab SS, Mo X (2017) Synthesis of RGD-peptide modified poly (ester-urethane) urea 
electrospun nanofibers as a potential application for vascular tissue engineering. Chem Eng J 315:177-190

[336] Augustine R, Dan P, Sosnik A, Kalarikkal N, Tran N, Vincent B, Thomas S, Menu P, Rouxel D (2017) Electrospun poly (vinylidene fluoride-trifluoroethylene)/zinc oxide nanocomposite tissue engineering scaffolds with enhanced cell adhesion and blood vessel formation. Nano Res 10:3358-3376

[337] Li Q, Mu L, Zhang F, Mo Z, Jin C, Qi W (2017) Manufacture and property research of heparin grafted electrospinning PCU artificial vascular scaffolds. Mater Sci Eng C 78:854-861

[338] Abdal-hay A, Bartnikowski M, Hamlet S, Ivanovski S (2018) Electrospun biphasic tubular scaffold with enhanced mechanical properties for vascular tissue engineering. Mater Sci Eng C 82:10-18

[339] Augustine R, Nethi SK, Kalarikkal N, Thomas S, Patra CR (2017) Electrospun polycaprolactone (PCL) scaffolds embedded with europium hydroxide nanorods (EHNs) with enhanced vascularization and cell proliferation for tissue engineering applications. J Mater Chem B 5:4660-4672

[340] Pezzoli D, Cauli E, Chevallier P, Farè S, Mantovani D (2017) Biomimetic coating of cross-linked gelatin to improve mechanical and biological properties of electrospun PET: A promising approach for small caliber vascular graft applications. J Biomed Mater Res Part A 105:2405-2415

[341] Karahaliloğlu Z (2017) Electrospun PU-PEG and PU-PC hybrid scaffolds for vascular tissue engineering. Fibers Polym 18:2135-2145

[342] Jiang Y-C, Jiang L, Huang A, Wang X-F, Li Q, Turng L-S (2017) Electrospun polycaprolactone/gelatin composites with enhanced cell-matrix interactions as blood vessel endothelial layer scaffolds. Mater Sci Eng C 71:901-908

[343] Dai W-W, Guo H-F, Qian D-H, Qin Z-X, Lei Y, Hou X-Y, Wen C (2017) Improving endothelialization by the combined application of polyethylene glycol coated cerium oxide nanoparticles and VEGF in electrospun polyurethane scaffolds. J Mater Chem B 5:1053-1061

[344] Yang F, Murugan R, Ramakrishna S, Wang X, Ma Y-X, Wang S (2004) Fabrication of nano-structured porous PLLA scaffold intended for nerve tissue engineering. Biomaterials 25:1891-1900

[345] Schmidt CE, Leach JB (2003) Neural tissue engineering: strategies for repair and regeneration. Annu Rev Biomed Eng 5:293-347

[346] Bellamkonda R, Aebischer PJB (1994) Tissue engineering in the nervous system. Biotechnol Bioeng 43:543-554

[347] Yang F, Murugan R, Wang S, Ramakrishna S (2005) Electrospinning of nano/micro scale poly (L-lactic acid) aligned fibers and their potential in neural tissue engineering. Biomaterials 26:2603-2610

[348] Xie J, Liu W, MacEwan MR, Bridgman PC, Xia Y (2014) Neurite outgrowth on electrospun nanofibers with uniaxial alignment: the effects of fiber density, surface coating, and supporting substrate. ACS Nano 8:1878-1885

[349] Zuidema JM, Hyzinski-García MC, Van Vlasselaer K, Zaccor NW, Plopper GE, Mongin AA, Gilbert RJ (2014) Enhanced GLT-1 mediated glutamate uptake and migration of primary astrocytes directed by fibronectin-coated electrospun poly-l-lactic acid fibers. Biomaterials 35:1439-1449

[350] Huang C, Ouyang Y, Niu H, He N, Ke Q, Jin X, Li D, Fang J, Liu W, Fan C (2015) Nerve guidance conduits from aligned nanofibers: improvement of nerve regeneration through longitudinal nanogrooves on a fiber surface. ACS Appl Mater Interf 7:7189-7196

[351] Brigham C (2018) Biopolymers: Biodegradable alternatives to traditional plastics. Elsevier, In Green chemistry, pp 753-770

[352] Verma D, Fortunati E (2019) Biopolymer processing and its composites: An introduction. In Biomass, BiopolymerBased Materials, and Bioenergy; Elsevier; pp. 3-23

[353] Miyamoto T, Takahashi SI, Ito H, Inagaki H, Noishiki Y (1989) Tissue biocompatibility of cellulose and its derivatives. J Biomed Mater Res, 23, 125-133.

[354] Märtson M, Viljanto J, Hurme T, Saukko P (1998) Biocompatibility of cellulose sponge with bone. Eur Surg Res 30:426-432

[355] Barbié C, Chauveaux D, Barthe X, Baquey C, Poustis J (1990) Biological behaviour of cellulosic materials after bone implantation: Preliminary results. Clin Mater 5:251-258

[356] Poustis J, Baquey C, Chauveaux D (1994) Mechanical properties of cellulose in orthopaedic devices and related environments. Clin Mater 16:119-124

[357] Hou Y, Wang X, Zhang Z, Luo J, Cai Z, Wang Y, Li Y (2019) Repairing transected peripheral nerve using a biomimetic nerve guidance conduit containing intraluminal sponge fillers. Adv Healthcare Mater 8:1900913

[358] Farzamfar S, Naseri-Nosar M, Vaez A, Esmaeilpour F, Ehterami A, Sahrapeyma H, Samadian H, Hamidieh A-A, Ghorbani S, Goodarzi A (2018) Neural tissue regeneration by a gabapentin-loaded cellulose acetate/gelatin wet-electrospun scaffold. Cellulose 25:1229-1238

[359] Zech J, Leisz S, Göttel B, Syrowatka F, Greiner A, Strauss C, Knolle W, Scheller C, Mäder K (2020) Electrospun Nimodipine-loaded fibers for nerve regeneration: Development and in vitro performance. Europ J Pharmaceut Biopharmaceut 
[360] Ziemba AM, Fink TD, Crochiere MC, Puhl DL, Sapkota S, Gilbert RJ, Zha RH (2020) Coating topologically complex electrospun fibers with nanothin silk fibroin enhances neurite outgrowth in vitro. ACS Biomater Sci Eng 6:1321-1332

[361] Saudi A, Amini S, Amirpour N, Kazemi M, Kharazi AZ, Salehi H, Rafienia M (2019) Promoting neural cell proliferation and differentiation by incorporating lignin into electrospun poly (vinyl alcohol) and poly (glycerol sebacate) fibers. Mater Sci Eng C, 104, 110005

[362] Lin F, Wang X, Wang Y, Yang Y, Li Y (2017) Preparation and biocompatibility of electrospinning PDLLA $/ \beta$ $\mathrm{TCP} /$ collagen for peripheral nerve regeneration. RSC Adv 7:41593-41602

[363] Zhu L, Wang K, Ma T, Huang L, Xia B, Zhu S, Yang Y, Liu Z, Quan X, Luo K (2017) Noncovalent bonding of RGD and YIGSR to an electrospun poly ( $\varepsilon$-caprolactone) conduit through peptide self-assembly to synergistically promote sciatic nerve regeneration in rats. Adv Healthcare Mater 6:1600860

[364] Yan Y, Sencadas V, Jin T, Huang X, Chen J, Wei D, Jiang Z (2017) Tailoring the wettability and mechanical properties of electrospun poly (1-lactic acid)-poly (glycerol sebacate) core-shell membranes for biomedical applications. J Colloid Interf Sci 508:87-94

[365] Xia B, Lv Y (2018) Dual-delivery of VEGF and NGF by emulsion electrospun nanofibrous scaffold for peripheral nerve regeneration. Mater Sci Eng C 82:253-264

[366] Naseri-Nosar M, Salehi M, Hojjati-Emami S (2017) Cellulose acetate/poly lactic acid coaxial wet-electrospun scaffold containing citalopram-loaded gelatin nanocarriers for neural tissue engineering applications. Int $\mathrm{J}$ Biol Macromol 103:701-708

[367] Lee SJ, Heo M, Lee D, Heo DN, Lim H-N, Kwon IK (2017) Fabrication and design of bioactive agent coated, highly-aligned electrospun matrices for nerve tissue engineering: Preparation, characterization and application. Appl Surf Sci 424:359-367

[368] Mohamadi F, Ebrahimi-Barough S, Reza Nourani M, Ali Derakhshan M, Goodarzi V, Sadegh Nazockdast M, Farokhi M, Tajerian R, Faridi Majidi R, Ai J (2017) Electrospun nerve guide scaffold of poly ( $\varepsilon-$ caprolactone)/collagen/nanobioglass: an in vitro study in peripheral nerve tissue engineering. J Biomed Mater Res Part A 105:1960-1972

[369] Motamedi AS, Mirzadeh H, Hajiesmaeilbaigi F, BagheriKhoulenjani S, Shokrgozar MA (2017) Piezoelectric electrospun nanocomposite comprising $\mathrm{Au}$ NPs/PVDF for nerve tissue engineering. J Biomed Mater Res Part A 105:1984-1993
[370] Rajabi M, Firouzi M, Hassannejad Z, Haririan I, Zahedi P (2018) Fabrication and characterization of electrospun laminin-functionalized silk fibroin/poly (ethylene oxide) nanofibrous scaffolds for peripheral nerve regeneration. J Biomed Mater Res B Appl Biomater 106:1595-1604

[371] Ranjbar-Mohammadi M, Prabhakaran MP, Bahrami SH, Ramakrishna S (2016) Gum tragacanth/poly (1-lactic acid) nanofibrous scaffolds for application in regeneration of peripheral nerve damage. Carbohyd Polym 140:104-112

[372] Hu J, Kai D, Ye H, Tian L, Ding X, Ramakrishna S, Loh XJ (2017) Electrospinning of poly (glycerol sebacate)-based nanofibers for nerve tissue engineering. Mater Sci Eng C 70:1089-1094

[373] Vimal SK, Ahamad N, Katti DS (2016) A simple method for fabrication of electrospun fibers with controlled degree of alignment having potential for nerve regeneration applications. Mater Sci Eng C 63:616-627

[374] Zhou Z-F, Zhang F, Wang J-G, Chen Q-C, Yang W-Z, He N, Jiang Y-Y, Chen F, Liu J-J (2016) Electrospinning of PELA/PPY fibrous conduits: promoting peripheral nerve regeneration in rats by self-originated electrical stimulation. ACS Biomater Sci Eng 2:1572-1581

[375] Jiang H, Hu Y, Zhao P, Li Y, Zhu K (2006) Modulation of protein release from biodegradable core-shell structured fibers prepared by coaxial electrospinning. J Biomed Mater Res B Appl Biomater 79:50-57

[376] Rujitanaroj P-O, Wang Y-C, Wang J, Chew SY (2011) Nanofiber-mediated controlled release of siRNA complexes for long term gene-silencing applications. Biomaterials 32:5915-5923

[377] Sahoo S, Ang LT, Goh JCH, Toh SL (2010) Growth factor delivery through electrospun nanofibers in scaffolds for tissue engineering applications. J Biomed Mater Res, Part A 93:1539-1550

[378] Kamble P, Sadarani B, Majumdar A, Bhullar S (2017) Nanofiber based drug delivery systems for skin: a promising therapeutic approach. J Drug Del Sci Technol 41:124-133

[379] Agrahari V, Agrahari V, Meng J, Mitra AK (2017) Electrospun nanofibers in drug delivery: fabrication, advances, and biomedical applications. In Emerging Nanotechnologies for Diagnostics, Drug Delivery and Medical Devices; Elsevier; pp. 189-215

[380] Khoshnevisan K, Maleki H, Samadian H, Shahsavari S, Sarrafzadeh MH, Larijani B, Dorkoosh FA, Haghpanah V, Khorramizadeh MR (2018) Cellulose acetate electrospun nanofibers for drug delivery systems: applications and recent advances. Carbohyd Polym 198:131-141

[381] Kuang G, Zhang Z, Liu S, Zhou D, Lu X, Jing X, Huang Y (2018) Biphasic drug release from electrospun polyblend 
nanofibers for optimized local cancer treatment. Biomaterials Sci 6:324-331

[382] Yu H, Jia Y, Yao C, Lu Y (2014) PCL/PEG core/sheath fibers with controlled drug release rate fabricated on the basis of a novel combined technique. Int $\mathrm{J}$ Pharm 469:17-22

[383] Nguyen TTT, Ghosh C, Hwang S-G, Chanunpanich N, Park JS (2012) Porous core/sheath composite nanofibers fabricated by coaxial electrospinning as a potential mat for drug release system. Int J Pharm 439:296-306

[384] Chew S, Wen Y, Dzenis Y, Leong KW (2006) The role of electrospinning in the emerging field of nanomedicine. Curr Pharm Des 12:4751-4770

[385] Repanas A, Andriopoulou S, Glasmacher B (2016) The significance of electrospinning as a method to create fibrous scaffolds for biomedical engineering and drug delivery applications. J Drug Deliv Sci Technol 31:137-146

[386] Vidyalakshmi K, Rashmi K, Pramod Kumar T, Siddaramaiah (2004) Studies on formulation and in vitro evaluation of PVA/chitosan blend films for drug delivery. J Macromol Sci Part A, 41, 1115-1122

[387] Constantin M, Bucatariu SM, Doroftei F, Fundueanu G (2017) Smart composite materials based on chitosan microspheres embedded in thermosensitive hydrogel for controlled delivery of drugs. Carbohyd Polym, 157, 493-502

[388] Xu J, Strandman S, Zhu JX, Barralet J, Cerruti M (2015) Genipin-crosslinked catechol-chitosan mucoadhesive hydrogels for buccal drug delivery. Biomaterials 37:395-404

[389] Fathollahipour S, Abouei Mehrizi A, Ghaee A, Koosha M (2015) Electrospinning of PVA/chitosan nanocomposite nanofibers containing gelatin nanoparticles as a dual drug delivery system. J Biomed Mater Res Part A 103:3852-3862

[390] Cui Z, Zheng Z, Lin L, Si J, Wang Q, Peng X, Chen W (2018) Electrospinning and crosslinking of polyvinyl alcohol/chitosan composite nanofiber for transdermal drug delivery. Adv Polym Technol 37:1917-1928

[391] Qin Z-Y, Jia X-W, Liu Q, Kong B-H, Wang H (2019) Fast dissolving oral films for drug delivery prepared from chitosan/pullulan electrospinning nanofibers. Int $\mathrm{J}$ Biol Macromol 137:224-231

[392] Shekarforoush E, Ajalloueian F, Zeng G, Mendes AC, Chronakis IS (2018) Electrospun xanthan gum-chitosan nanofibers as delivery carrier of hydrophobic bioactives. Mater Lett 228:322-326

[393] Alavarse AC, de Oliveira Silva, FW, Colque JT, da Silva VM, Prieto T, Venancio EC, Bonvent JJJMS (2017) Tetracycline hydrochloride-loaded electrospun nanofibers mats based on PVA and chitosan for wound dressing. Mater Sci Eng C, 77, 271-281

[394] Balagangadharan K, Trivedi R, Vairamani M, Selvamurugan N (2019) Sinapic acid-loaded chitosan nanoparticles in polycaprolactone electrospun fibers for bone regeneration in vitro and in vivo. Carbohyd Polym 216:1-16

[395] Fazli Y, Shariatinia Z (2017) Controlled release of cefazolin sodium antibiotic drug from electrospun chitosan-polyethylene oxide nanofibrous Mats. Mater Sci Eng C 71:641-652

[396] Liu X, Yang Y, Yu D-G, Zhu M-J, Zhao M, Williams GR (2019) Tunable zero-order drug delivery systems created by modified triaxial electrospinning. Chem Eng J 356:886-894

[397] Celebioglu A, Uyar T (2019) Fast dissolving oral drug delivery system based on electrospun nanofibrous webs of cyclodextrin/ibuprofen inclusion complex nanofibers. Mol Pharm 16:4387-4398

[398] Bulbul YE, Eskitoros-Togay ŞM, Demirtas-Korkmaz F, Dilsiz N (2019) Multi-walled carbon nanotube-incorporating electrospun composite fibrous mats for controlled drug release profile. Int J Pharmaceut, 568, 118513

[399] Eskitoros-Togay ŞM, Bulbul YE, Tort S, Korkmaz FD, Acartürk F, Dilsiz N (2019) Fabrication of doxycyclineloaded electrospun PCL/PEO membranes for a potential drug delivery system. Int J Pharm 565:83-94

[400] Jaworska J, Włodarczyk J, Karpeta-Jarząbek P, Janeczek H, Stojko M, Kasperczyk J (2019) Electrospun, drug-enriched bioresorbable nonwovens based on poly (glycolide- $\varepsilon$ caprolactone) and poly (d, 1-lactide-glycolide) for urological applications. Polym Degrad Stab 167:94-101

[401] Li H, Sang Q, Wu J, Williams GR, Wang H, Niu S, Wu J, Zhu L-M (2018) Dual-responsive drug delivery systems prepared by blend electrospinning. Int J Pharm 543:1-7

[402] Hu S, Qin Z, Cheng M, Chen Y, Liu J, Zhang Y (2018) Improved properties and drug delivery behaviors of electrospun cellulose acetate nanofibrous membranes by introducing carboxylated cellulose nanocrystals. Cellulose 25:1883-1898

[403] Herrero-Herrero M, Gómez-Tejedor J-A, Vallés-Lluch A (2018) PLA/PCL electrospun membranes of tailored fibres diameter as drug delivery systems. Eur Polymer J 99:445-455

[404] Rychter M, Baranowska-Korczyc A, Milanowski B, Jarek M, Maciejewska BM, Coy EL, Lulek J (2018) Cilostazolloaded poly ( $\varepsilon$-Caprolactone) electrospun drug delivery system for cardiovascular applications. Pharm Res 35:32

[405] Dadras Chomachayi M, Solouk A, Akbari S, Sadeghi D, Mirahmadi F, Mirzadeh H (2018) Electrospun nanofibers comprising of silk fibroin/gelatin for drug delivery 
applications: thyme essential oil and doxycycline monohydrate release study. J Biomed Mater Res Part A 106:1092-1103

[406] Esmaeili A, Haseli M (2017) Optimization, synthesis, and characterization of coaxial electrospun sodium carboxymethyl cellulose-graft-methyl acrylate/poly (ethylene oxide) nanofibers for potential drug-delivery applications. Carbohyd Polym 173:645-653

[407] Sedghi R, Shaabani A, Mohammadi Z, Samadi FY, Isaei E (2017) Biocompatible electrospinning chitosan nanofibers: a novel delivery system with superior local cancer therapy. Carbohyd Polym 159:1-10

[408] Wali A, Zhang Y, Sengupta P, Higaki Y, Takahara A, Badiger MV (2018) Electrospinning of non-ionic cellulose ethers/polyvinyl alcohol nanofibers: characterization and applications. Carbohyd Polym 181:175-182

[409] Bhattarai RS, Das A, Alzhrani RM, Kang D, Bhaduri SB, Boddu SH (2017) Comparison of electrospun and solvent cast polylactic acid (PLA)/poly (vinyl alcohol)(PVA) inserts as potential ocular drug delivery vehicles. Mater Sci Eng C 77:895-903

[410] Zhang H, Xia J, Pang X, Zhao M, Wang B, Yang L, Wan H, Wu J, Fu S (2017) Magnetic nanoparticle-loaded electrospun polymeric nanofibers for tissue engineering. Mater Sci Eng C 73:537-543

[411] Cheng M, Qin Z, Hu S, Dong S, Ren Z, Yu H (2017) Achieving long-term sustained drug delivery for electrospun biopolyester nanofibrous membranes by introducing cellulose nanocrystals. ACS Biomater Sci Eng 3:1666-1676

[412] Ferrández-Rives M, Beltrán-Osuna ÁA, Gómez-Tejedor JA, Gomez Ribelles JL (2017) Electrospun PVA/bentonite nanocomposites mats for drug delivery. Materials 10(12): 1448

[413] Karuppannan C, Sivaraj M, Kumar JG, Seerangan R, Balasubramanian S, Gopal DR (2017) Fabrication of progesterone-loaded nanofibers for the drug delivery applications in bovine. Nanoscale Res Lett 12:116

[414] Jaiturong P, Sirithunyalug B, Eitsayeam S, Asawahame C, Tipduangta P, Sirithunyalug J (2018) Preparation of glutinous rice starch/polyvinyl alcohol copolymer electrospun fibers for using as a drug delivery carrier. Asian J Pharm Sci 13:239-247

[415] Spadaro S, Santoro M, Barreca F, Scala A, Grimato S, Neri F, Fazio E (2018) PEG-PLGA electrospun nanofibrous membranes loaded with Au@ Fe 2 O 3 nanoparticles for drug delivery applications. Front Phys, 13, 136201

[416] Zhu Y, Pyda M, Cebe P (2017) Electrospun fibers of poly (1-lactic acid) containing lovastatin with potential applications in drug delivery. J Appl Polym Sci 134:45287
[417] Akduman C, Özgüney I, Kumbasar EPAJMS (2016) Preparation and characterization of naproxen-loaded electrospun thermoplastic polyurethane nanofibers as a drug delivery system. Mater Sci Eng C, 64, 383-390

[418] Ranjbar-Mohammadi M, Bahrami SH (2016) Electrospun curcumin loaded poly ( $\varepsilon$-caprolactone)/gum tragacanth nanofibers for biomedical application. Int J Biol Macromol 84:448-456

[419] Mendes AC, Gorzelanny C, Halter N, Schneider SW, Chronakis IS (2016) Hybrid electrospun chitosan-phospholipids nanofibers for transdermal drug delivery. Int $\mathbf{J}$ Pharm 510:48-56

[420] Sultanova Z, Kaleli G, Kabay G, Mutlu M (2016) Controlled release of a hydrophilic drug from coaxially electrospun polycaprolactone nanofibers. Int $\mathrm{J}$ Pharm 505:133-138

[421] Gencturk A, Kahraman E, Güngör S, Özhan G, Özsoy Y, Sarac A (2017) Polyurethane/hydroxypropyl cellulose electrospun nanofiber mats as potential transdermal drug delivery system: characterization studies and in vitro assays. Artif Cells Nanomed Biotechnol 45:655-664

[422] Zhang X, Tang K, Zheng X (2016) Electrospinning and crosslinking of COL/PVA nanofiber-microsphere containing salicylic acid for drug delivery. $J$ Bionic Eng 13:143-149

[423] Fu R, Li C, Yu C, Xie H, Shi S, Li Z, Wang Q, Lu L (2016) A novel electrospun membrane based on moxifloxacin hydrochloride/poly (vinyl alcohol)/sodium alginate for antibacterial wound dressings in practical application. Drug Delivery 23:818-829

[424] Laha A, Yadav S, Majumdar S, Sharma CS (2016) In-vitro release study of hydrophobic drug using electrospun crosslinked gelatin nanofibers. Biochem Eng J 105:481-488

[425] Ding Y, Wang Y, Su L, Bellagamba M, Zhang H, Lei Y (2010) Electrospun $\mathrm{Co} 3 \mathrm{O} 4$ nanofibers for sensitive and selective glucose detection. Biosensors Bioelectronics 26:542-548

[426] Vellayappan M, Venugopal J, Ramakrishna S, Ray S, Ismail A, Mandal M, Manikandan A, Seal S, Jaganathan S (2016) Electrospinning applications from diagnosis to treatment of diabetes. RSC Adv 6:83638-83655

[427] Unal B, Yalcinkaya EE, Demirkol DO, Timur S (2018) An electrospun nanofiber matrix based on organo-clay for biosensors: PVA/PAMAM-Montmorillonite. Appl Surf Sci 444:542-551

[428] Kim J, Hu J, Bezerra AB, Holtan MD, Brooks JC, Easley CJ (2015) Protein quantification using controlled DNA melting transitions in bivalent probe assemblies. Anal Chem 87:9576-9579 
[429] Davis BW, Niamnont N, Hare CD, Sukwattanasinitt M, Cheng Q (2010) Nanofibers doped with dendritic fluorophores for protein detection. ACS Appl Mater Interf 2:1798-1803

[430] Hu J, Yu Y, Brooks JC, Godwin LA, Somasundaram S, Torabinejad F, Kim J, Shannon C, Easley CJ (2014) A reusable electrochemical proximity assay for highly selective, real-time protein quantitation in biological matrices. J Am Chem Soc 136:8467-8474

[431] Wang X, Wang X, Wang X, Chen F, Zhu K, Xu Q, Tang M (2013) Novel electrochemical biosensor based on functional composite nanofibers for sensitive detection of p53 tumor suppressor gene. Anal Chim Acta 765:63-69

[432] Rezaei Z, Mahmoudifard M (2019) Pivotal role of electrospun nanofibers in microfluidic diagnostic systems-a review. J Mater Chem B 7:4602-4619

[433] Kosaki Y, Izawa H, Ishihara S, Kawakami K, Sumita M, Tateyama Y, Ji Q, Krishnan V, Hishita S, Yamauchi Y (2013) Nanoporous carbon sensor with cage-in-fiber structure: Highly selective aniline adsorbent toward cancer risk management. ACS Appl Mater Interf 5:2930-2934

[434] Peng G, Tisch U, Adams O, Hakim M, Shehada N, Broza YY, Billan S, Abdah-Bortnyak R, Kuten A, Haick H (2009) Diagnosing lung cancer in exhaled breath using gold nanoparticles. Nat Nanotechnol 4:669-673

[435] Röck F, Barsan N, Weimar U (2008) Electronic nose: current status and future trends. Chem Rev 108:705-725

[436] Güntner AT, Abegg S, Königstein K, Gerber PA, SchmidtTrucksäss A, Pratsinis SE (2019) Breath sensors for health monitoring. ACS Sens, 4, 268-280

[437] Semenza GL (2000) Hypoxia, clonal selection, and the role of HIF-1 in tumor progression. Crit Rev Biochem Mol Biol 35:71-103

[438] Thomlinson R, Gray L (1955) The histological structure of some human lung cancers and the possible implications for radiotherapy. Br J Cancer 9:539

[439] Mehrabi P, Hui J, Janfaza S, O’Brien A, Tasnim N, Najjaran H, Hoorfar M (2020) Fabrication of $\mathrm{SnO} 2$ composite nanofiber-based gas sensor using the electrospinning method for tetrahydrocannabinol (THC) detection. Micromachines 11:190

[440] Chen Z, Chen Z, Zhang A, Hu J, Wang X, Yang Z (2016) Electrospun nanofibers for cancer diagnosis and therapy. Biomater Sci 4:922-932

[441] Zhao G, Huang B, Zhang J, Wang A, Ren K, Wang ZL (2017) Electrospun Poly (1-Lactic Acid) nanofibers for nanogenerator and diagnostic sensor applications. Macromol Mater Eng 302:1600476

[442] Hou S, Zhao L, Shen Q, Yu J, Ng C, Kong X, Wu D, Song M, Shi X, Xu X (2013) Polymer nanofiber-embedded microchips for detection, isolation, and molecular analysis of single circulating melanoma cells. Angew Chem 125:3463-3467

[443] Sun N, Liu M, Wang J, Wang Z, Li X, Jiang B, Pei R (2016) Chitosan nanofibers for specific capture and nondestructive release of CTCs assisted by pCBMA brushes. Small 12:5090-5097

[444] Ma K, Chan CK, Liao S, Hwang WY, Feng Q, Ramakrishna S (2008) Electrospun nanofiber scaffolds for rapid and rich capture of bone marrow-derived hematopoietic stem cells. Biomaterials 29:2096-2103

[445] Zhao Y, Fan Z, Shen M, Shi X (2015) Hyaluronic acidfunctionalized electrospun polyvinyl alcohol/polyethyleneimine nanofibers for cancer cell capture applications. Adv Mater Interfaces 2:1500256

[446] Xiao Y, Shen M, Shi X (2018) Design of functional electrospun nanofibers for cancer cell capture applications. J Mater Chem B 6:1420-1432

[447] Pimentel ES, Brito-Pereira R, Marques-Almeida T, Ribeiro C, Vaz F, Lanceros-Mendez S, Cardoso VF (2019) Tailoring electrospun poly (L-lactic acid) nanofibers as substrates for microfluidic applications. ACS Appl Mater Interf $12: 60-69$

[448] Xu G, Tan Y, Xu T, Yin D, Wang M, Shen M, Chen X, Shi X, Zhu X (2017) Hyaluronic acid-functionalized electrospun PLGA nanofibers embedded in a microfluidic chip for cancer cell capture and culture. Biomater Sci 5:752-761

[449] Kalluri S, Seng KH, Guo Z, Liu HK, Dou SX (2013) Electrospun lithium metal oxide cathode materials for lithium-ion batteries. RSC Adv 3:25576-25601

[450] Wang H-G, Yuan S, Ma D-L, Zhang X-B, Yan J-M (2015) Electrospun materials for lithium and sodium rechargeable batteries: from structure evolution to electrochemical performance. Energy Environ Sci 8:1660-1681

[451] Srinivasu P, Islam A, Singh SP, Han L, Kantam ML, Bhargava SK (2012) Highly efficient nanoporous graphitic carbon with tunable textural properties for dye-sensitized solar cells. J Mater Chem 22:20866-20869

[452] Zhang B, Kang F, Tarascon J-M, Kim J-K (2016) Recent advances in electrospun carbon nanofibers and their application in electrochemical energy storage. Prog Mater Sci 76:319-380

[453] Li X, Chen Y, Huang H, Mai Y-W, Zhou L (2016) Electrospun carbon-based nanostructured electrodes for advanced energy storage-a review. Energy Storage Mater 5:58-92

[454] Jung J-W, Lee C-L, Yu S, Kim I-D (2016) Electrospun nanofibers as a platform for advanced secondary batteries: a comprehensive review. J Mater Chem A 4:703-750 
[455] Li Z, Zhang J-W, Yu L-G, Zhang J-W (2017) Electrospun porous nanofibers for electrochemical energy storage. J Mater Sci 52:6173-6195. https://doi.org/10.1007/s10853017-0794-2

[456] Sun G, Sun L, Xie H, Liu J (2016) Electrospinning of nanofibers for energy applications. Nanomaterials 6:129

[457] Wu J, Qin X, Miao C, He Y-B, Liang G, Zhou D, Liu M, Han C, Li B, Kang F (2016) A honeycomb-cobweb inspired hierarchical core-shell structure design for electrospun silicon/carbon fibers as lithium-ion battery anodes. Carbon 98:582-591

[458] Darbar D, Reddy M, Sundarrajan S, Pattabiraman R, Ramakrishna S, Chowdari B (2016) Anodic electrochemical performances of $\mathrm{MgCo} 2 \mathrm{O} 4$ synthesized by oxalate decomposition method and electrospinning technique for Li-ion battery application. Mater Res Bull 73:369-376

[459] Park JW, Wycisk R, Pintauro PN, Yarlagadda V, Van Nguyen T (2016) Electrospun Nafion ${ } /$ Polyphenylsulfone composite membranes for regenerative Hydrogen bromine fuel cells. Materials 9:143

[460] Wang G, Zhang L, Zhang J (2012) A review of electrode materials for electrochemical supercapacitors. Chem Soc Rev 41:797-828

[461] Kabir S, Medina S, Wang G, Bender G, Pylypenko S, Neyerlin K (2020) Improving the bulk gas transport of Fe-NC platinum group metal-free nanofiber electrodes via electrospinning for fuel cell applications. Nano Energy, 104791

[462] Pant B, Park M, Park S-J (2019) TiO2 NPs assembled into a carbon nanofiber composite electrode by a one-step electrospinning process for supercapacitor applications. Polymers 11:899

[463] Li P, Ma X, Liu F, Zhao YL, Ding Y, Yang J (2020) Synthesis of highly ordered mesoporous carbons nanofiber web based on electrospinning strategy for supercapacitor. Microporous Mesoporous Mater, 110283

[464] Ma W, Zhang Q, Hua D, Xiong R, Zhao J, Rao W, Huang S, Zhan X, Chen F, Huang C (2016) Electrospun fibers for oil-water separation. RSC Adv 6:12868-12884

[465] Obaid M, Barakat NA, Fadali O, Motlak M, Almajid AA, Khalil KA (2015) Effective and reusable oil/water separation membranes based on modified polysulfone electrospun nanofiber mats. Chem Eng J 259:449-456

[466] Li J-J, Zhu L-T, Luo Z-H (2016) Electrospun fibrous membrane with enhanced swithchable oil/water wettability for oily water separation. Chem Eng J 287:474-481

[467] Lu P, Murray S, Zhu M (2019) Electrospun nanofibers for catalysts. In Electrospinning: Nanofabrication and Applications; Elsevier; pp. 695-717

[468] Shao L, Xing G, He L, Chen J, Xie H, Liang X, Qi C (2012) Sulfonic groups functionalized preoxidated polyacrylonitrile nanofibers and its catalytic applications. Appl Catal A 443:133-137

[469] Kim J, Kang J, Jeong U, Kim H, Lee H (2013) Catalytic, conductive, and transparent platinum nanofiber webs for FTO-Free dye-sensitized solar cells. ACS Appl Mater Interf 5:3176-3181

[470] Ma W, Xu Y, Ma K, Zhang H (2016) Electrospinning synthesis of H3PW12O40/TiO2 nanofiber catalytic materials and their application in ultra-deep desulfurization. Appl Catal A 526:147-154

[471] Pei CC, Leung WW-F (2015) Photocatalytic oxidation of nitrogen monoxide and o-xylene by $\mathrm{TiO} 2 / \mathrm{ZnO} / \mathrm{Bi} 2 \mathrm{O} 3$ nanofibers: Optimization, kinetic modeling and mechanisms. Appl Catal B 174:515-525

[472] Ternero-Hidalgo J, Torres-Liñán J, Guerrero-Pérez M, Rodríguez-Mirasol J, Cordero T (2019) Electrospun vanadium oxide based submicron diameter fiber catalysts. Part I: Preparation procedure and propane ODH application. Catal Today, 325, 131-143

[473] Lu Y, Liu Z, You SW, McLoughlin L, Bridgers B, Hayes S, Wang X, Wang R, Guo Z, Wujcik EK (2020) Electrospun carbon/iron nanofibers: the catalytic effects of iron and application in Cr (VI) removal. Carbon. https://doi.org/10. 1016/j.carbon.2020.05.031

[474] Xu P, Cen C, Chen N, Lin H, Wang Q, Xu N, Tang J, Teng Z (2018) Facile fabrication of silver nanoparticles deposited cellulose microfiber nanocomposites for catalytic application. J Colloid Interf Sci 526:194-200

[475] Hu D, Xiao Y, Liu H, Wang H, Li J, Zhou B, Liu P, Shen M, Shi X (2018) Loading of $\mathrm{Au} / \mathrm{Ag}$ bimetallic nanoparticles within electrospun PVA/PEI nanofibers for catalytic applications. Colloids Surf A Physicochem Eng Aspects 552:9-15

[476] Hosseini SR, Ghasemi S, Kamali-Rousta M, Nabavi SR (2017) Preparation of NiO nanofibers by electrospinning and their application for electro-catalytic oxidation of ethylene glycol. Int J Hydrogen Energy 42:906-913

[477] Chen S, Chi M, Zhu Y, Gao M, Wang C, Lu X (2018) A Facile synthesis of superparamagnetic $\mathrm{Fe} 3 \mathrm{O} 4$ nanofibers with superior peroxidase-like catalytic activity for sensitive colorimetric detection of L-cysteine. Appl Surf Sci 440:237-244

[478] Tebyetekerwa M, Xu Z, Yang S, Ramakrishna S (2020) Electrospun nanofibers-based face masks. Adv Fiber Mater 2:161-166

[479] Zhang Z, Ji D, He H, Ramakrishna S (2021) Electrospun ultrafine fibers for advanced face masks. Mater Sci Eng $R$ Rep, 143, 100594

Publisher's Note Springer Nature remains neutral with regard to jurisdictional claims in published maps and institutional affiliations. 